\title{
Uma Ferramenta de Sonificação para Visualização Distribuída na Internet
}

\author{
Bruno Sousa Freitas
}

Orientadora: Profa. Dra. Rosane Minghim

Dissertação apresentada ao Instituto de Ciências Matemáticas e de Computação - ICMC-USP, como parte dos requisitos para obtenção do título de Mestre em Ciências de Computação e Matemática Computacional.

USP - São Carlos

Abril/2001 
A Comissão Julgadora:

Profa. Dra. Rosane Minghim

Prof. Dr. Luis Gustavo Nonato

Prof. Dr. Antonio Cesar Germano Martins

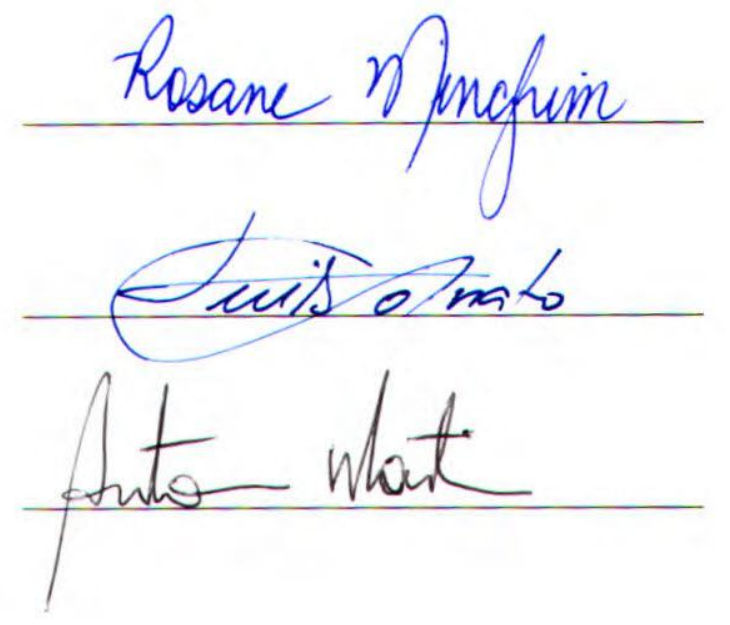


Aos meus pais:

Sérgio Roberto de Freitas e Elisabete Sousa Freitas 


\section{Agradecimentos}

A Prof. Rosane, pela orientação, ensinamentos, apoio e amizade no transcorrer deste trabalho.

Aos meus pais, Sérgio e Elisabete, pelo apoio, carinho, confiança, compreensão, paciência e tudo mais o que possa ter surgido durante toda minha vida. A minha irmã Mariana por todo carinho, amizade, e por ela ser como ela é.

Aos "piores", amigos para toda vida, Fellow, Funny, Cinho, Ted e Zé por toda amizade.

À Rebecca por toda amizade e carinho.

Ao meu amigo Miguel, pelo apoio quando cheguei em São Carlos, pelas conversas, desabafos, conselhos, bagunças, mini-teras, teras mesmo, arrumações, problemas, madrugadas de estudo e, principalmente, por todo respeito e amizade.

Aos pilantras Kenji, Gioyani, Drake, Alessandre, Zé Roberto, Benê, Omar, Mané, André, Régis pelas festas, churrascos, tardes de tereré, "RDT X RCV"s, pela acolhida em São Carlos e pela amizade.

Aos amigos do grupo de Computação Gráfica Dani, Marcelo, Rogério, Igor, Veri, Alex, Helton, Teddy, Billy e Luís Fernando pela amizade e apoio.

Aos professores do grupo de Computação Gráfica Castelo, Cristina, Gustavo, pela amizade e apoio.

Aos funcionários do ICMC em especial à Adriana, Sandra, Beth, Laura e Marília pela atenção dedicada.

À FAPESP pelo apoio fipanceiro. 


\section{Conteúdo}

1 Conccitos de Visualização 1

1.1 Visualização Científica - Visão Geral . . . . . . . . . . . . . . . 2

1.2 Tipos o Organização dos Dados . . . . . . . . . . . . . . 3

1.3 Classificação dos Dados . . . . . . . . . . . . . . . . 5

1.4 Técnicas de Visualização . . . . . . . . . . . . . . . . 6

1.4 .1 Técricas para Entidades Escalares $\left(E_{n}^{S}\right) \ldots \ldots \ldots 6$

Dominio Bidimensional $\left(E_{2}^{S}\right) \ldots \ldots \ldots \ldots 7$

Donunio Tridimensional $\left(E_{3}^{S}\right) \ldots \ldots \ldots . \ldots 7$

1.4 .2 Técnicas para Entidades Vetoriais $\left(E_{n}^{V}\right) \ldots \ldots \ldots 10$

Hedgehogs e Glyphs Orientados . . . . . . . . . . . . . . . 10

1.5 Visualization Toolkit (VTK) . . . . . . . . . . . . . 10

2 Conceitos de Sonificação 13

2.1 o Uso do Som . . . . . . . . . . . . . . . . . . . . 13

2.2 Propricdades do Sorn . . . . . . . . . . . . . . . . 14

2.2 .1 Acústica . . . . . . . . . . . . . . . 15

Volunde do Som (Loudness) . . . . . . . . . . . . 16

Entoação $($ pitch $) \ldots \ldots \ldots \ldots \ldots \ldots \ldots$

Timbre....................... 17

2.3 Síntese de Sons por Software . . . . . . . . . . . . . 18

2.3.1 Síntese Digital de Sons . . . . . . . . . . . . . . . . 19

2.3 .2 CSound . . . . . . . . . . . . . . . . 20

2.4 Motivação para a Sonificação en Visualização . . . . . . . . . . 21

2.5 Estudos eln Sonificação . . . . . . . . . . . . . . . . . . . . . . . . . . . . . . . . . . . . .

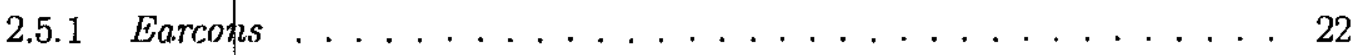

2.5 .2 Auditory Icons . . . . . . . . . . . . . . . . 23

2.5.3 Mapcanmento de Parâmetros . . . . . . . . . . . . . . 24 
2.6 Revisão de Trabalhos em Sonificação . . . . . . . . . . . . . . . 24

2.6 .1 Listen . . . . . . . . . . . . . . . . . . . 28

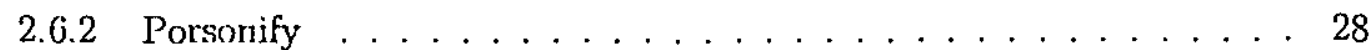

2.6 .3 SSound . . . . . . . . . . . . . . . . . 29

2.6 .4 MUSE . . . . . . . . . . . . . . . . . . 29

2.6 .5 Sonificação de Imagens Texturizadas . . . . . . . . . . . . 30

3 Visualizaçāo Distribuída e'na Internet 33

3.1 Arquiteturas Distribuídas . . . . . . . . . . . . . . . . . 34

3.1 .1 Thin Client . . . . . . . . . . . . . . . 34

3.1 .2 Fat Client . . . . . . . . . . . . . . . 35

3.2 Un modclo de Referência para Visualização Cliente/Servidor . . . . . . . . 35

3.2 .1 Conário $1 \ldots \ldots \ldots \ldots \ldots$

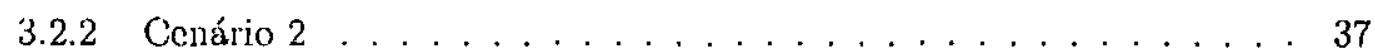

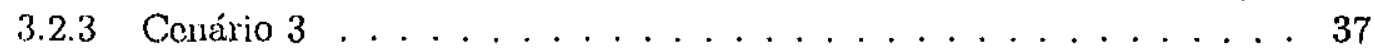

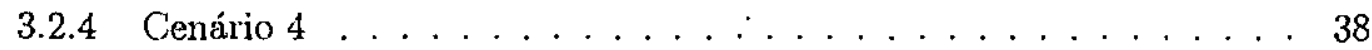

3.3 Visualização na $W e b \ldots \ldots \ldots \ldots$

3.3.1 Primórdios da Visualização na Internet . . . . . . . . . . . . . 40

3.3 .2 VRML . . . . . . . . . . . . . . . . . 41

3.3 .3 Visualização com Java . . . . . . . . . . . . . . . . . 41

3.3 .4 Java3D . . . . . . . . . . . . . . . . . . . 42

3.3 .5 Novas Tendências . . . . . . . . . . . . . . . . 43

3.4 Recursos de Distriluuição na Área de Visualização . . . . . . . . . . . . . 43

3.4 .1 COM/DCOM . . . . . . . . . . . . . . 44

$3.4 .2 \mathrm{J \Lambda V \Lambda /RMI} \ldots \ldots \ldots \ldots \ldots \ldots$

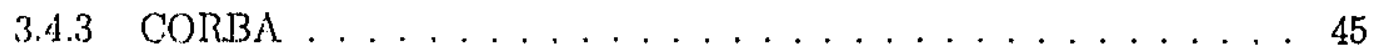

3.5 Sistemas de Visualização Distribuída c na Internet . . . . . . . . . . . . 46

4 DSVol - Implementaçāo 51

4.1 Inrplennentaçĩo do DSVol - Visão Geral . . . . . . . . . . . . . . . . . 52

4.2 Módulo de Interface Indireta . . . . . . . . . . . . . . . . . . 54

4.3 Módılo de Visualização . . . . . . . . . . . . . . . . . . 57

4.3 .1 Extração de Isosuperfícies . . . . . . . . . . . . . . . . 58

4.3.2 R.cndering Volumćtrico Direto . . . . . . . . . . . . . . 60

4.4 Módulo de Sonificação . . . . . . . . . . . . . . . . 64

4.4 Síntese de Som enr DSVol . . . . . . . . . . . . 65 
MIDIKernel . . . . . . . . . . . . . . . 65

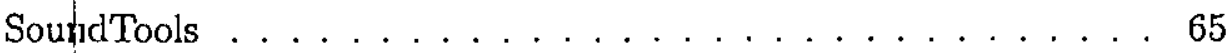

4.4 .2 Display Progressivo . . . . . . . . . . . . . . . 66

4.4 .3 Sondla Sonora $\ldots \ldots \ldots \ldots \ldots \ldots$

4.4 .4 . Display de Malha . . . . . . . . . . . . . . 73

4.5 Módulo de Intcração $\ldots \ldots \ldots \ldots \ldots \ldots \ldots \ldots \ldots$

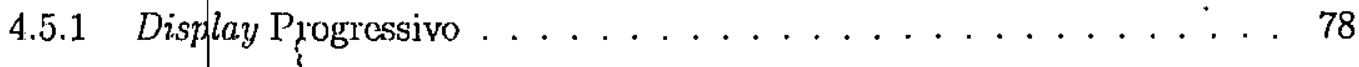

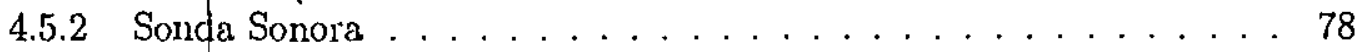

4.5 .3 Display de Malha . . . . . . . . . . . . . 81

4.6 DSVol na Internet . . . . . . . . . . . . . . . . . . . . . . 81

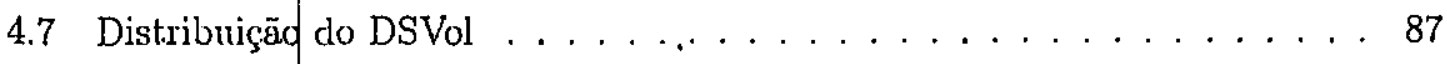

4.7.1 Definição da Interface IDL . . . . . . . . . . . . . . . . 87

Servịdor de Sonificação . . . . . . . . . . . . . . . . . . 87

Scrvidor de Visualização de Isosuperfícies . . . . . . . . . . . . 88

4.7.2 Definição dos Arquivos Stub e Skeleton . . . . . . . . . . 88

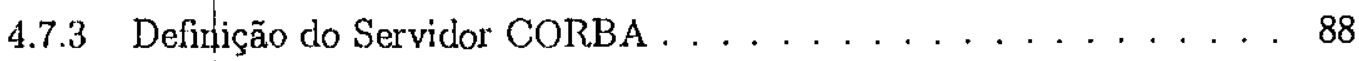

Servildor de Sonificação . . . . . . . . . . . . . . . . . 89

Scrvidor de Visualização de Isosuperfícies . . . . . . . . . . . . . 90

4.7.4 Definição do Cliente CORBA . . . . . . . . . . . 91

4.8 Resumo dos Resultados Obtidos . . . . . . . . . . . 93

5 Conclusões

A Arquivos .h de DSVol 105

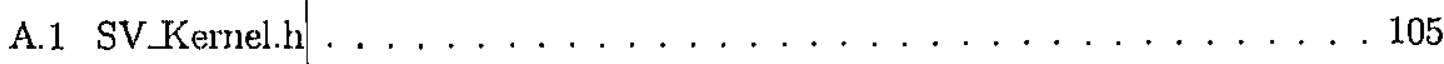

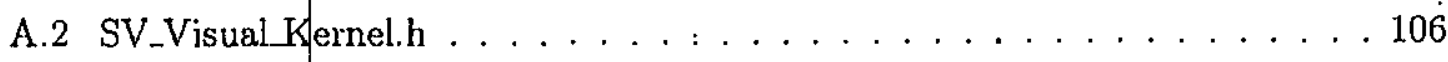

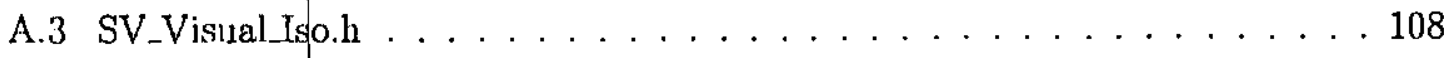

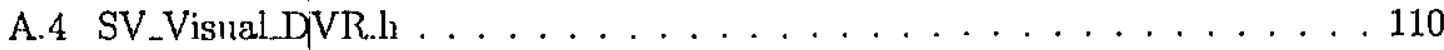

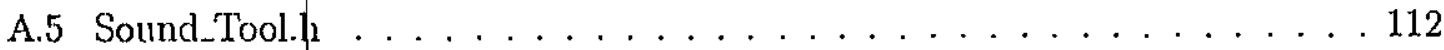

A.6 SV.Sound_kiernel.h . . . . . . . . . . . . . . . . . . . 120

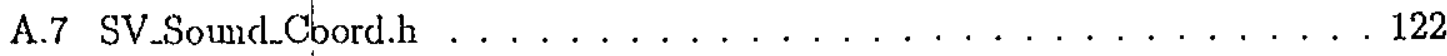

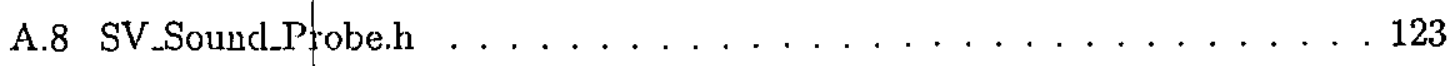

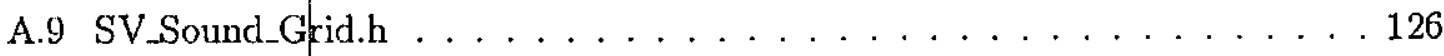

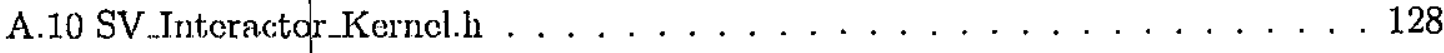

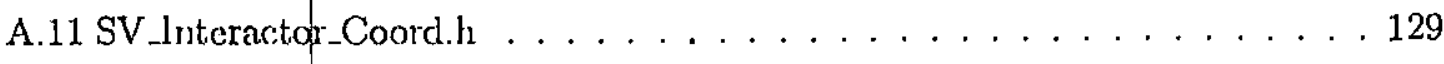

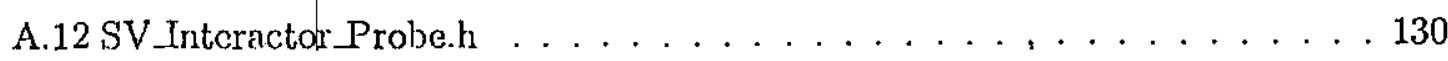


A.13 SV_Interactor_Grid.h . . . . . . . . . . . . . . . 130

A.14 VkThread.h . . . . . . . . . . . . . . . . . . . . . . . 131

A.15 Vizualization idl . . . . . . . . . . . . . . 136

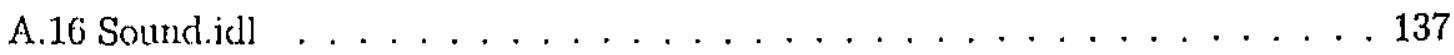

А.17 ViznalizationInpl.h . . . . . . . . . . . . . . . . . 138

A.18 Soundlmpl.h . . . . . . . . . . . . . . . . . . . . 139

A.19 ClientVizualizationObj.h . . . . . . . . . . . . . . 141

A.20 ClientSoundObj.lı . . . . . . . . . . . . . . . . . . 142 


\section{Lista de $\mid$ Figuras}

1.1 Estrutura de Conexão de Módulos no VTK - Adaptada de [6] . . . . . . 11

2.1 Exemplo onda sonora . . . . . . . . . . . . . . 15

2.2 Duas onclas sonoras com amplitudes diferentes . . . . . . . . . . 16

2.3 Exemplo de como os sons são gerados pelo CSound - Adaptacla de [31] . . 21

3.1 Esquema dạ Área de Visualização . . . . . . . . . . . . . . . . . . . . 36

3.2 Conário 1 - Exibindo irnagcus atravćs da Web ........... 36

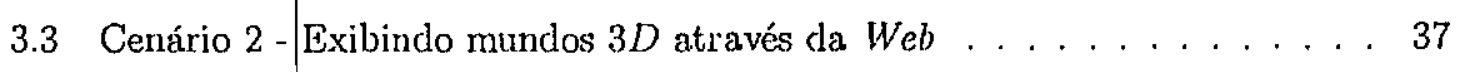

3.4 Cenário 3 - Exibindo visualizações atravćs da Web . . . . . . . . . 38

3.5 Cenário 4 - Criando visualizações através da Web . . . . . . . . . . 39

3.6 Comunicação entre objetos RMI - Adaptada de [45] . . . . . . . . 45

3.7 Comunicação entre objetos CORBA - Adaptada cle [45] . . . . . . . . 46

4.1 Esquena Geral de Classes de DSVol . . . . . . . . . . . . . . 55

4.2 Interface de Entrada de Parâmetros de DSVol . . . . . . . . . . . . 56

4.3 Interface de Definição de Parâmetros de Sorn . . . . . . . . . . . . . 56

4.4 Interface do Método Visualização de Isosuperfícics . . . . . . . . . . . . 59

4.5 Visualização de Isosuperfícics . . . . . . . . . . . . . . . . 60

4.6 Interface de Visualização através do Método de Rendering Volumétrico Direto 62

4.7 Definição de Parâmetros para o Rendering Volumétrico Direto . . . . . . . 63

4.8 Rendering Volumétrico Direto . . . . . . . . . . . . . 63

4.9 Sonificação de Coordenadas . . . . . . . . . . . . . . . 67

4.10 Intcrface do método de Sonificação de Coordenadas . . . . . . . . . . 69

4.11 Interface de definição de incremento para o Display Progressivo . . . . . . 69

4.12 Sonda Sonota . . . . . . . . . . . . . . . . . 70

4.13 Interfnce do método de Sonda Sonora . . . . . . . . . . . . . . 72

4.14 Interface de definição do tamanho inicial da Sonrla Sonora . . . . . . . . 72

4.15 Orichtação yo Display de Malha - Adaptada de [9] . . . . . . . . . . . 74 
4.16 Sonificação de Malha . . . . . . . . . . . . . . . . . . . . 75

4.17 Interface do método de Sonificação de Malha . . . . . . . . . . . . . . 76

4.18 Exploração através la Sonda Sonora . . . . . . . . . . . . . . . 79

4.19 Escuema Simplificado da $\Lambda$ rquitetura Distribuída de DSVo] . . . . . . . . 87

4.20 Esquema de Organização das Classes no Programa Cliente . . . . . . . . . 92 


\section{Lista de Tabelas}

4.1 Psendo-Códlgo - Visualização com Sonificação em DSVol . . . . . . . . . 57

4.2 Pseudo-Códígo - Isosuperfícies . . . . . . . . . . . . . . 58

4.3 Principais Mćtodos de SV_Visual_Iso . . . . . . . . . . . . . 60

4.4 Pseudo-Códiggo - Rendering Volunétrico Dircto . . . . . . . . . . . . 61

4.5 Principais Métodos de SV_Visual_DVR . . . . . . . . . . . . . 64

4.6 Principais Métodos de SV_Sound_Coord . . . . . . . . . . . . 68

4.7 Principais Métodos de SV_Sound_Probe . . . . . . . . . . . . 73

4.8 Principais Métodos de SV_Sound_Grid . . . . . . . . . . . . . 75

4.9 Tabela DSVol . . . . . . . . . . . . . . . . . . . 76

4.10 Percepşão de mapeamentos para freqiiência en DSVol . . . . . . . . . . 77

4.11 Teclas de acesso à intcração através do proccsso da Sonda Sonora . . . . . 80

4.12 Pseuclo-Código - Chamada a una função nativa $\mathrm{C}++$ a partir do Código Java ... . . . . . . . . . . . . . . . . 84

4.13 Pseudo-Códligo - Exemplo de coino rcalizar chamadas ern DSVol a partir cla classe VTKThread . . . . . . . . . . . . . . . . . . . 84

1.1. Funções Nativas Acessadas a partir do código Java . . . . . . . . . . 85

4.15 Fuuçõos Nativas Accssadas a partir do código Java . . . . . . . . . . . 86

4.16 Servidor de Sonificação - Principais Métodos . . . . . . . . . . . . . . 90

4.17 Servidor de Visualização - Principais Métodos . . . . . . . . . . . . 91 


\section{Resumo}

O presente trabalho de mestrado é parte de um projeto em andamento ICMC-USP denominaclo PowerVis que desenvolve pesquisa nøs áreas de visualização científica, sonificação de dados e em aplicą̧õos reais das técnicas desenvolvidas.

A visualização científica é urna área da computação gráfica que abrange um conjunto de técnicas para a geração de representações gráficas a partir de um conjunto de dados.

Algumas vezes esses conjuntos de dados formam imagens complexas e de difícil entendimento, o cue tonna diff́cil sua apresentação em um arnbiente bi-dinnensional como a tela do computador. Uma alternativa para amenizar tais problemas é o uso de som como apoio às técnicas visuais. A área da computação responsável pelo estudo de mapeamentos sonoros de conjuntos de dados com o objetivo de exibir algum tipo de informação é conhecida como sonificação.

Este trabalho apresenta uma evolução de um trabalho em sonificação desenvolvido anteriormente (SVol) para apoio à visualização de dados científicos volumétricos. Os processos visuais apojados pela sonificação neste trabalho são a geração de isosuperfícies e o rendering volumétrico direto.

A versão aqui implementada, além de reorganizar o código e aumentar sua funcionalidade, implementa duas estratégias para a evolução do sistema: o acesso à suas funções pela internet usando Java, e a distribuição de algumas funções de geração de sons e imagens usando CORBA. 


\section{Abstrăct}

Scientific Visualization comprehends a series of techniques and methods to support data analysis, mainly through graphical mappings.

Some limitations imposed by the bidimensional nature of software and hardware for graphical displays inake the interpretation of highly complex images difficult. An alternative to handle some of these problems is the use of sound as support for visual techniques. The computational field of sound mappings from data sets with the intent of displaying information is called sonification.

This work presents an evolution of a sonification system previously developed (SVol) to support visualization of volumetric data. The graphical processes supported by the sonifications are Isosurface Extraction and Direct Volume Rendering.

Besides providing reorganization of the former code and increasing its functionality, the version implemented here adds two strategies for the development of the system: internet access to its functions using Java, and distribution of aural and visual components of the system using CORB|A. 


\section{Introdução}

A visualização cièntífica é a área da computação que estuda a geração de representações gráficas a partir de um conjunto de dados, geralmente obtidos através de simulações e de dispositivos de medição. A idéia de se criar representações gráficas aparece como uma tentativa de oferecer ao usuário uma interação com tais conjuntos de dados, possibilitando assim sua interpretação, bem como a dos processos e fenômenos que os geraram. Apesar de algumas limitações, as técnicas de visualização são de grande ajuda a cientistas e outros profissionais que de putra forma ficariam impossibilitados de analisar e entender conjuntos de.dados estritamente numéricos.

Um dos problemas em visualização é a dificuldade de se conseguir representações eficientes de informação que possuem dimensões mais altas. A própria natureza dos dispositivos de display gráfico impõe uma apresentação bi-dimensional, o que pode causar ambigüidade e perda ou ocultação de informações. Para solucionar tais problemas, novos mecanismos de mapeamento dos dados são estudados, tendo como principal objetivo encontrar representações que são, ao mesmo tempo, precisas em seu conteúdo, e de fácil interpretação. Pesquisas nessa área têm se voltado para o estudo dos aspectos perceptivos dos seres humanos e também para o uso de técnicas alternativas à visual para representação dos dados. Uma delas é a utilização de sons de uma maneira estruturada para auxílio à interpretação da informação contida nos dados.

Existem diversas maneiras através das quais o uso do som pode ser útil em interfaces computacionais e sistemas de computação gráfica. Uma das vantagens do som é o fato de que os seres humanos estarem acostumados a utilizar e interagir com estímulos sonoros em muitas de suas atividades cotidianas (como responder ao telefone ou detectar a aproximação de pessoas). Outro fator.importante é a riqueza e o poder do senso auditivo humano. Seres humanos são capazes de reconhecer fontes sonoras e suas propriedades físicas a partir dos sons que produzem, e também são capazes de separar algumas propriedades particulares como freqüência, intensidade, timbre, e assim por diante, a partir de um determinado estimulo sonoro [8]. Assim, sinais sonoros carregam quantidades signifi- 
cativas de informação e podem ser usados de maneira eficiente para aumentar o nível de interação entre o ser humano e o computador. Juntamente com displays gráficos, streams sonoros ' podem ser utilizados tanto de uma forma suplementar (onde o som apresenta informações que não são vistas, mas apenas associadas ao display visual) quanto complementar, onde se utiliza de redundância para confirmar detalhes visuais nas figuras formadas [8].

O mapeamento de algum conjunto de dados numéricos para som com a intenção de transmitir informação é conhecido como sonificação.

A idéia por trás de sonificação é a de que sons não falados sintéticos podem representar clados numéricos e oferecer suporte a diversas atividades de exploração de algum tipo de informação [11].

Este trabalho apresenta conceitos e sistemas para a sonificação de dados com o objetivo de ajudar o usuário a reconhecer e interpretar algum tipo de informação em algum contexto. Isso inclui números, cálculos, objetos e eventos.

Uma outra área que tem evoluído muito nesse campo de exploração de dados é a de visualização distribuída. Através de técnicas e conceitos de distribuição de informação, pode-se criar bancos de dados remotos e permitir que vários usuários, localizados em diversos lugares possam acessar e traballar com esses dados. Adicionalmente, através de arquiteturas de distribuição é possível aproveitar recursos computacionais para processamento em máquinas remotas. Isso contribui não apenas com o nível e a capacidade de interação dos usuários com os dados, mas também com a capacidade de armazenar conjuntos de dados muito grandes em diferentes máquinas.

A área de visualização distribuída tende a se integrar ao avanço da Internet por todo mundo. $O$ objetivo principal da visualização na Internet é o de que usuários de qualquer parte do mundo possam ter acesso a técnicas de visualização e dados antes não disponíveis. Assim, conjuntos de pesquisadores e usuários podem, mesmo sem estar localizados em um mesmo lugar físico, estudar em conjunto e chegar a conclusões mais precisas e melhor discutidas sobre a informação na qual estão interessados.

Este trabalho é parte de um projeto em andamento ICMC-USP denominado PowerVis [5] [7]. O PowerVis surgiu com base nos resultados obtidos da tese de doutorado da orientadora deste projeto [3] e nos últimos avanços na área de visualização. Seus principais objetivos são: estender os resultados obtidos com som, desenvolver funções gráficas de visualização baseadas na sua usabilidade, utilizar técnicas de visualização para analisar

\footnotetext{
${ }^{1}$ Um "stream" sonoro é unn estímulo audivel apresentado com o objetivo de provocar uma reaçào no usuńrio
} 
dados específicos e promover a visualização e exploração de dados através da Internet.

Vários trabalhos'já foram desenvolvidos dentro do projeto PowerVis e entre esses pode-se citar o SVol [9] [8]. O SVol é um protótipo de um sistema de sonificação para técnicas volumétricas de visualização com o objetivo de disponibilizar ferramentas sonoras que auxiliem o entendimento e estudo de dados.

Também dentro desse projeto, foi desenvolvido um trabalho de mestrado, com o objetivo de disponibilizar e possibilitar a interação do usuário com ferramentas de visualização e dados pela Internet [40].

Ainda na área de sonificação e visualização distribuída, está sendo desenvolvido um trabalho de doutorado intitulado "Desenvolvimento de um Modelo para Exploração em Visualização Científica Distribuída usando Sorn", em cujo contexto o presente traballıo se insere (proc. FAPESP no. 98/13879-9).

Nesse contexto, este trabalho de mestrado mescla os conceitos dos trabalhos já desenvolvidos no projeto PowerVis para a obtenção, em uma primeira instância, de uma versão do sistema SYol em um ambiente distribuído e mais especificamente na Internet. Um segundo passo fọi o uso de conceitos e técnicas que possibilitassem a implementação de um esquema de distribuição de visualização, incluindo também sons. Em terceira instância, esse projeto buscou aumentar a funcionalidade de SVol através da inclusão de novas funções no mapeamento e apresentação dos dados através de sons. Ao sistema resultante deste trabalho foi dado o nome DSVol (Distributed Sound for Volumes).

Para atingir esses objetivos, vários conceitos importantes foram estudados, e são apresentados nesta monografia, juntamente com o levantamento bibliográfico referente às áreas afins e as implementações realizadas.

O capítulo 1 apresenta conceitos e conhecimentos na área de visualização científica. O capítulo 2 deste trabalho apresenta alguns conhecimentos essenciais para sonificação, e algumas propriedades do som. O capítulo 3 apresenta um estudo sobre visualização distribuída, incluindo conceitos de visualização na Internet. O capítulo 4 apresenta o sistema de sonificação para apoio à tarefas de visualização DSVol desenvolvido como extensão ao SVol [9] no contexto de um sistema de visualização de propósito geral, o VTK [1]. O capítulo 5 apresenta as conclusões deste trabalho e sugestões para trabalhos futuros incentivados por este projeto. 
xvi 


\section{Conceitos de Visualização}

Durante a última década, a quantidade de informações produzidas no chamado mundo dos computadores tem sido tão grande que a tarefa de processá-las em tempo hábil é realmente complexa. Verificada a necessidade de se interpretar informações (principalmente em grandes fontes de dados) de forma mais rápida e eficiente, foi adicionada à área de computação gráfica, a visualização de dados, também chamada visualização computacional [1][6]. Essa área usa técnicas de computação gráfica para representar informação, de forma a facilitar o entendimento de conjuntos de dados numéricos de alta complexidade. Exemplos de áreas de aplicação são: visualização de imagens médicas, meteorologia, dados financeiros, visualização de programas, dinâmica dos fluidos, e muitas outras. A visualização científica é a área da computação, iıserida na área de visualização de dados, que estuda a geração de representações gráficas para conjuntos de dados geralmente obtidos através de simulações e de dispositivos de medição. A idéia de se criar representações gráficas aparece como uma tentativa de oferecer ao usuário uma interação com tais conjuntos de dados, possibilitando assim sua interpretação, bem como a dos processos e fenômenos que os geraram.

A seção 1.1 deste capítulo apresenta uma visão geral sobre a área de visualização científica e conceitos e técnicas básicas nessa área. As seções 1.2 e 1.3, apresentam um estudo sobre tipos, organização e classificação de conjunto de dados. As principais técnicas de visualização são apresentadas na seção 1.4. A seção 1.5 é destinada à apresentação do VTK [1], a biblioteqa utilizada neste trabalho para a geração de visualizações. 


\subsection{Visualização Científica - Visão Geral}

Um dos principais objetivos da visualização é o de oferecer meios para que o usuário possa extrair a informação importante "escondida" nos dados e apresentá-la de forma a ser compreendida mais facilmente. Isso é possível porque a visualização tira vantagem da habilidade natural do sistema visual humano, que é capaz de reconhecer e processar imagens mais rapidamente. Dessa forma, pode-se representar dados de forma gráfica, mais natural ao ser-humano, gerando assim um aumento na capacidade de interpretação desses dados.

A visualização nño procura entender somente os dados em si mas também o fenômeno (1ue os geron e, para isso, utiliza uma série de técnicas dentro de um contexto de investigação científica [6]. Os passos envolvidos nessa investigação são apresentados a seguir.

O primeiro passo dentro do processo de visualização é a criação de um modelo empírico que reflita a realidade do fenômeno observado e a coleta dos dados (que podem ser obtidos por medições experimentais ou por simulações computacionais). Os dados obtidos servem para verificar e refinar o modelo criado, chegando-se a um modelo matemático e a um computacional. O próximo passo é aplicar alguma técnica que possa mapear o. modelo para uma representação gráfica, como uma imagem, poclendo-se acrescentar funções de interação para a exploração do modelo gráfico. A representação gráfica pode então ser analisada e fornecer dados (feedback) para os passos de modelagem e visualização. Esse processo de investigação pode ser continuado pelo usuário do sistema de visualização que, através de interfaces, interage com o sistema fornecendo novos dados. Como resultado, o usuário aumenta seu conlecimento sobre a validade da hipótese originalmente formulada e sobre o fenômeno estudado.

Dentro do processo cle visualização existem várias etapas onde os dados originais podem ser modificados e alterados, gerando erros. O processo de aquisição dos dados pode introduzir erros aleatórios, fazendo com que os dados necessitem ser "filtrados". A filtragem pode distorcer os dados, retirando características interessantes ou acrescentando informações espúrias. Outros tipos de erros que podem ser introduzidos são os de interpolação. Muitas vezes ć necessńrio que valores para esses dados sejam obtidos em regiões onde seu valor não é conhecido. Para resolver esse problema, são utilizadas técnicas de interpolação, que infercrn o valor do dado em um certo ponto baseando-se em informações sobre os clados "próximos" is ele. O processo de interpolação é também uma fonte bastante comum de erros em visualização. 


\subsection{Tipos e Organização dos Dados}

Para visualizar daclos é importante conhecer suas características para que modelos do dados úteis e sistemas de visualização eficientes possam ser criados.

Os conjuntos de dados em visualização são definidos por uma estrutura de organização e atributos associados a essa estrutura, composta por uma topologia e uma geometria. A topologia é o conjunto de propriedades que não variam quando sofrem transformações geométricas (rotação, translação e escala não uniforme). A geometria é a instanciação da topologia, pela especificação de posições no espaço $3 D$. Atributos associados a uma estrutura para conjuntos de dados, compreendem informações associadas à geometria e à topologia.

Modelos de conjunto de dados, como por exemplo o adotaclo por Schroeder et al [1], podem assumir que a estrutura de organização para os dados consiste de células e pontos. Dessa forma, as células especificam a topologia e os pontos a geometria. Células são a uniclade básica em sistemas de visualização. Elas são definidas especificando-se um tipo em conjunto com uma lista ordenada de pontos (também chamada de lista de conectividade). A fista de pontos e o tipo da célula definem a topologia da célula e as coordenadas $x-y-z$ dos pontos definem sua geometria. Os tipos mais comuns de célula são:

- Vértice: é definido como um único ponto.

- Poli-vértice: é uma lista de pontos arbitrariamente ordenada.

- Linha: é definida por dois pontos, sendo que a direção vai do primeiro para o segundo ponto.

- Poli-linha: é um conjunto de $n+1$ pontos onde $n$ é o número de linhas na poli-linha. Cada par de pontos $(i, i+1)$ define uma linha.

- Triângulo: é definido por uma lista de três pontos ordenados em sentido antihorário. A ordem dos pontos especifica a direção da superfície normal pela regra da mão direita.

- Tira de triângulos (triangle strip): é uma célula bi-dimensional consistindo de um ou mais triângulos. Os pontos definindo uma tira não necessitam estar em um mesmo plano. A tira de triângulos é definida por uma lista ordenada de $n+2$ pontos, onde $n$ é o número de triângulos. A ordem dos pontos em cada conjunto de três pontos $(i, i+\mid 1, i+2)$ com $i$ entre 0 e 1 define um triângulo. 
- Quadrilátero: é definido como uma lista ordenada de quatro pontos que se encontram em um plano. O quadrilátero é convexo e as arestas não se interceptam. Os pontos são ordenados em sentido anti-horário, definindo a normal à superfície pela regra da mão direita.

- Pixel: un pixel é uma célula topologicamente jdêntica ao quadrilátero, corn a adição de restrições geométricas. Toda aresta é perpendicular às aresta adjacentes e paralela a um do eixos principais.

- Polígono: é definido com uma lista ordenada de três ou mais pontos em um plano. O polígono pode ser côncavo mas não pode ter loops internos a não pode autointerceptar-se. Uin polígono tem $n$ aresta ollde $n$ é o número de pontos no polígono.

- Tetraedro: é definido com uma lista de quatro pontos não planares. Um tetraedro tem seis aresta e quatro faces triangulares.

- Hexaedro: é uma célula cujas seis faces são quadriláteros e possui doze arestas e oito vértices. As faces e arestas não deve se interceptar com quaisquer outras faces ou arcstas e o hexaedro deve ser convexo.

- Voxel: um voxel é topologicamente equivalente a um hexaedro com algumas restrições geométricas. Cada face do voxel é perpendicular a um dos eixos $x, y$ ou $z$.

Os atributos para um conjunto de dados são categorizados de acordo com os tipos de dados que representam. Tais dados podem ser escalares, vetoriais, normais, coordenadas de textura, tensoriais e, definidos pelo usuário. Esta divisão tem influência na organização dos algoritmos de visualização, que são categorizados de acordo com os dados sobre os quais operam. A seguir são apresentados exemplos dos tipos de dados mais comuns em visualização. Uma descrição mais detalhada sobre conjunto de dados, células e aṭibutos pode ser encontrada em [1].

- Escalares: Dados escalares são dados que possuem um único valor em cada posição do conjunto de dados. É a forma mais simples e mais comum da dados de visualização. Exemplos desse tipo de dados são: temperatura, pressão e densidade.

- Vetores: são dados que possuem magnitude e direção. Exemplos são fluxo, trajetória de partículas, movimento do vento e função gradiente. 
- Tensorẹs: são generalizações matemáticas de vetores e matrizes. Um tensor de rank $k$ pode sфłr considerado uma tabela $k$-dimensional. Um tensor de rank 0 é um escalar, um tensor de rank 1 é um vetor, um tensor de rank 2 é uma matriz e um tensor de ranl 3 é um array retangular tridimensional. Tensores com rank maior que 3 são arrays retangulares $k$-dimensionais.

Um conjunto de dados normalmente segue alguma organização, geralmente consistindo de uma malha de células. Os dados são posicionados nos vértices de cada célula e os valores no interior clas células podem ser obtidos por interpolação. Assim, a estrutura de um conjunto de dadps está implicitamente definida por pontos (que associam informação geométrica aos ítens de dados) e células (que associam propriedades topológicas). Os dados propriamente ditos são atributos associados aos elementos (pontos e células) dessa estrutura. Dependendo da organização definida pela estrutura, pode-se ter vários tipos de malhas.

A principal distinção para conjuntos de dados é que eles podem ser regulares (estruturados) ou irregulares (desestruturados). Conjuntos regulares possuem algum relacionamento entre os pontos. Em malhas totalmente regulares (cartesianas), por exemplo, não é necessário armazenar explicitamente as posições de todos os pontos, bastando manter a posição inicial, o espaçamento entre os pontos e o número total de pontos horizontal e verticalmente. Isso torna sua representação computacional compacta. Conjuntos irregularcs, por outro lado, precisam armazenar explicitamente as posições de todos os pontos e células, porém, são mais flexíveis e permitem representações adaptativas [6].

\subsection{Classificação dos Dados}

En visualização, como a variedade de conjuntos de dados possíveis é grande, nem sempre a técnica utilizada para uma situação é adequada para outra. Dessa forma, se faz necessário obter uma classificação que mostre quais técnicas são mais adequadas para cada situação. $\mathrm{Na}$ área de visualização, ainda não existe uma forma suficientemente abrangente de classificação dos dados. A classificação apresentada a seguir foi elaborada a partir de uma notação concisa introduzida por Brodlie et al [2]. Essa classificação será utilizada para situar as técnicas de visualização.

Um conjunto de dados pode ser considerado como uma entidade com algumas proprieclades, com a seguinte notação:

$$
E_{n}^{S}
$$


Onde a entidade $E$ é uma entidade escảlar $(S)$ definida sobre um domínio de dimensão $n$. Da mesma forma, os sobrescritos $V, T$ e $P$ indicam entidades vetoriais, tensoriais e pontos esparsos, respectivamente.

Assim, a notação

$E_{2}^{V}$

indica uma entidade vetorial definida sobre um domínio $2 D$. Acrescentado sufixos pode-se determinar a dimensão das entidades vetoriais, por exemplo, se na notação anterior for utilizado o sobrescrito $V_{2}$ em lugar de $V$, tem-se uma entidade vetorial de dimensão 2 definida sobre um domínio $2 D$.

A dimensão do domínio é usada como sub-classificação e permite estabelecer distinções adicionais de acordo com a natureza do domínio. Por exemplo, a entidade pode ser definida ponto a ponto ou sobre regiões em um domínio contínuo, ou pode ser definida sobre um conjunto enumerado. Dessa forma, a notação $E_{[n]}$ indica um domínio n-dimensional com a entidade definida sobre regiōes, e $E_{\{n\}}$ indica um domínio $n$-dimensional consistindo de um conjunto de valores enumerados.

A situação onde uma entidade contém mais de um conjunto de valores é muito comum e pode ser expressa em uma mesma representação gráfica.

Nesse caso, a notação $E_{n}^{m S}$

indica um conjunto de $m$ campos escalares definidos sobre um domínio $n$-dimensional.

\subsection{Técnicas de Visualização}

Até agora, foi vista uma forma de definição e algumas maneiras de representação dos divcrsos tipos de dados de visualização. Este capítulo fornece uma noção das técnicas que trausformam esses clados e criam representações que permitam sua visualização. São apresentadas algumas das técnicas de visualização mais utilizadas e difundidas no campo de visualização científica. Os dados aos quais essas técnicas de visualização se aplicam estão classificados nesse capítulo segundo o modelo definido nos capítulos anteriores.

\subsubsection{Técnicas para Entidades Escalares $\left(E_{n}^{S}\right)$}

Escalares são valores de dados associados a cada ponto e célula de uma conjunto de dados [1]. A seguir, são apresentadas algumas técnicas de visualização de dados escalares, tanto para dados definidos em um domínio $2 D$ quanto $3 D$. 
Domínio Bidimensional $\left(E_{2}^{S}\right)$

Mapeamento de Cores (Color Mapping)

O mapeamento de cores é uma técnica de visualização de escalares muito comum e que tem como idéia principal fazer o mapeamento de escalares em cores. Esse mapeamento dos daclos é feito através de uma indexação a uma tabela cle cores conhecicla como color lookup table, onde os valores associados a cada escalar definido no domínio serve como índice para essa tabeia.

\section{Imagens}

A idéir básica clessa técnica é a de fazer uma associação entre os escalares definidos sobre o plano $2 D$ que representa o domínio e os pixeis da tela. Essa associação é feita através da clivisão do domínio em uma grade de células (oncle geralmente cada célula corresponcle a um pixel cla tela) e uma posterior escollia do valor de cor de cada célula de acordo com o valor da função de definição dos escalares no ponto correspondente. Como exemplo de utilização dessa técniç, podemos citar a visualização de dados obtidos por scanners e por satélites.

\section{Isolinhas (Mapas de Contornos)}

A partir de um conjunto de valores escalares definidos sobre um plano $2 D$, pode-se traçar isolinhas de valores constantes (valores de interesse) sobre esse plano.

Um exemplo de utilização dessa técnica é o traçado de isotermas (linhas de temperatura constante) em mapas de previsão do tempo.

\section{Mapeamento Sobre Superfícies}

Essa técnica gera uma superfície que representa os dados escalares definidos sobre um plano $2 D$. Essa superfície é gerada através da atribuição de valores de altura associados ao conjunto de dados e pode ser apresentada na forma fio-de-arame ou até mesmo tonalizada. Uma variação dessa técnica são os height-fields que possibilitam a exibição de dois campos escalares definidos sфbre um domínio 2D. A idéia de height-fields é exibir um campo escalar como uma mallia que descreva uma superfície e o outro na forma de contornos posicionados sobre a superfície.

\section{Domínio Tridimensional $\left(E_{3}^{S}\right)$}

As próximas tćcnicas a serem representadas operam sobre daclos escalares definidos sobre I11n clomínio 3D. Enn muitas aplicações estudadas estão definiclos, sobre os vértices de uma malha $3 D$ regular e as técnicas de visualização associadas são conhecidas como técnicas 
de visualização de volume (VV)[6].

As técnicas de visualização de escalares definidos no espaço, podem ser subdivididas basicamente em duas classes: a primeira procura gerar superfícies dentro do volume de dados, e a segunda que inclui técnicas de rendering volumétrico direto, cujo princípio é observar diretamente o conjunto de dados sem a necessidade da criação de uma representação intermediária.

\section{Extração de Isosuperfícies de Interesse}

As técnicas para traçado de isosuperfícies são compostas basicamente de três passos: numa primeira etapa, é aplicado um detector de superfícies ao volume de pontos anostrados;

- Euı seguida, é feito o ajuste de primitivas geométricas sobre as superfícies detectadas qure são posteriormente renderizadas por técnicas tradicionais.

Os métodos para o ajuste das primitivas geométricas incluenn métodos de conexão de contornos e inćtodos de interseç̧ão de células.

Métodos de conexão de contorno envolvem a identificação de contornos por um valor de interesse em fatias do volune de dados (planos que cortam o volume). Em seguida, as curvas em fatias adjacentcs são conectadas em urna abordagem denominada tecelagem (patching) ou triangulação.

Técuicas de interseç̧ão de células operam em cada célula do volume de dados procurando fazer umı aproximação da superfície de interesse naquela célula. Essas aproximações são posteriormente conectadas para formar a superfície definida pelo usuário.

A seguir, é apresentado o algoritmo Marching Cubes utilizado na geração de isosuperfícies para um conjunto de dados através da técnica de interseç̧ão de células. Podemos citar também nessa classe de algoritmos, o Marching Thetraedra [6] e o Dividing Cubes [6] corno extensões do Marching Cubes.

\section{- Marching Cubes}

A idéia bésica clesse algoritmo é processar cada célula do volume de dados independenternente, associando a cada uma delas uma aproximação à isosuperfície de interesse. $\mathrm{O}$ método marching cubes classifica as células de um volume de dados como completamente fora da isosuperfície, completamente dentro e células que são interceptadas pela isosuperfície. Para as células que são interceptadas pela isosuperfície, o algoritmo determina (através de técnicas de interpolação) os pontos de intersecção da isosuperfície como célula (finitos) e liga esses pontos para formar aproximaçōes para isosuperfície na célula que está sendo processada.

$\mathrm{Na}$ ligação dos pontos em uma célula o algoritmo utiliza uma tabela de casos de 
interseç̧ão para evitar a ocorrência de ligações ambíguas que podem até mesmo gerar buracos na superfície visualizada.

Depois que todas as células do volume cle dados foram visitadas, a isosuperfície, definida em termos de uma malha poligonal, está pronta para ser renderizada.

A principal vantagem da técnica de geração de isosuperfícies é a possibilidade de se utilizar hardware especializado no rendering das superfícies geradas, aumentando com isso a velocidade da geração de imagens e possibilitando ao usuário uma interação em tempo real com as visualizações. Outro fator importante é que através da geração de isosıperfícies pode-se identificar estruturas nos dados cle medição e simulação [6].

Uma desvantagen dessa classe de técnicas é a perda natural do conteúdo total do conjunto de dados na visualização, visto que apenas uma parte desse conjunto estará senclo apresentado. Além disso, nem sempre os dados podem ser descritos em termos de superfícies, como é o caso de objetos amorfos (como nuvens ou fumaça).

Rendering Volumétrico Direto (DVR)

Técnicas DVR geram imagens $3 D$ dos objetos diretamente a partir dos dados, sem a utilização de uma estrutura intermediária. Essas técnicas podem ser agrupadas em duas categorias: as que operam na ordem dos objetos e as que operam na ordem das imagens. Técnicas que operam no espaço do objeto tem como principal característica a de calcular, para cada objeto do volume de dados (células de malha onde estão representados os dados) sua contribuição na formação da visualização. Como exemplo dessa técnica, podemos citar o algoritmo splashing cuja principal característica é a utilizaçãọ de um núcleo (Kernel) no cálculo de contribuição de cada voxel para formação de imagem.

Uma outra abordagem para algoritmos DVR é as classes de métodos que operam na orclem das imagens. Nessas classes de algoritmo DVR, é calculada para cada pixel, a contribuição do volume de dados em sua cor.

A seguir, é apresentado um algoritmo clássico de DVR que opera na ordem da imagem conlecido como Ray Casting.

- Ray-Casting (Disparo de Raios)

No algoritmo de ray-casting, são traçados raios partindo de cada pixel da tela em direção ao volume de dados. O raio é então amostrado no volume de dados em valores discretos, separados por uma distância com especificada. O valor associado ao interior de célula é calculado por interpфlação constante ou por interpolação linear a partir dos vórtices da célula. Ein seguida, \$ão utilizadas tabelas de mapeamento para determinar os valores de cor e opacidade que \$ão adicionados ao valor do raio. Depois disso, o raio prossegue para 
o próximo ponto de amostragem. Esse processo é encerrado quando o raio deixa o volume de dados, ou atinge um valor 1 de opacidade [6].

Como vantagens desse método pode-se citar a capacidade de visualização do volume como um todo e principalmente sua facilidade de se paralelização. Uma desvantagem é seu alto custo computacional.

\subsubsection{Técnicas para Entidades Vetoriais $\left(E_{n}^{V}\right)$}

Dados vetoriais são representações tridimensionais que possuenı uma direção e uma magnitude. Dados vetoriais geralmente são resultados de estudos na área de que envolve fluxo. Esses dados vetoriais podeın ter duas, três ou mais direções e podern estar definidas em domínio planares ou volumétricos.

A seguir são apresentadas duas técnicas para visualização de entidades vetoriais que se enquadram tanto na categoria $E_{2}^{V_{2}}$ quanto $E_{3}^{V_{3}}$

\section{Hedgehogs e Glyphs Orientados}

Una técnica natural de visualização de vetores é desenhar um segmento de reta para representação de cada valor de dados. O segmento de reta começa no ponto com o qual o vetor está associado e é orientado de acordo com a direção das componentes $\left(u_{x}, u_{y}, u_{z}\right)$ do vetor. Essa técnica é conhecida como visualização através de Hedgehogs.

Existem muitas variaçōes dessa técnica. Setas podem ser adicionadas para indicar a clireção de un segmento, as linhas podem ser coloridas de acordo com a magnitude do vetor ou alguma outra entrada escalar (por exemplo, pressão ou temperatura).

Uma icléia para o aperfeiçoamento dessa técnica é o uso de ghyphs orientados ao invés de segmentos de retas, onde um ghyph pode ser qualquer representação geométrica $2 D$ ou $3 D$ (como um triângulo ou cone).

A próxima seção apresenta uma introdução à biblioteca VTK, que tem sido utilizada como base para implementação das funções de visualização e sonificação no PowerVis.

\subsection{Visualization Toolkit (VTK)}

O VTK [1] oferece uma biblioteca de rotinas que executam funções gráficas $3 D$ e de visualização. $O$ ambiente foi projetado segundo a metodologia orientada a objetos, e escrito em $\mathrm{C}++$ (com código disponível), podendo ser programado em $\mathrm{C}++, \mathrm{Tcl} / \mathrm{Tk}$ ou Java. 
O VTK utiliza uma técnica de programação baseada na conexão de módulos para gerar as visualizações. O processo de criação de uma representação gráfica de um conjunto de dados é divido em dois conjuntos principais: a parte dos módulos que controlam o pipeline de visualização, responsável pela transformação dos dados originais para 11 ma representação visual; e a parte que controla o pipeline de rendering, responsável pela exibição da representação gráfica na tela, segundo atributos visuais selecionados pelo programador. A figura 1.1 apresenta um esquerna da estrutura de módulos do VTK.

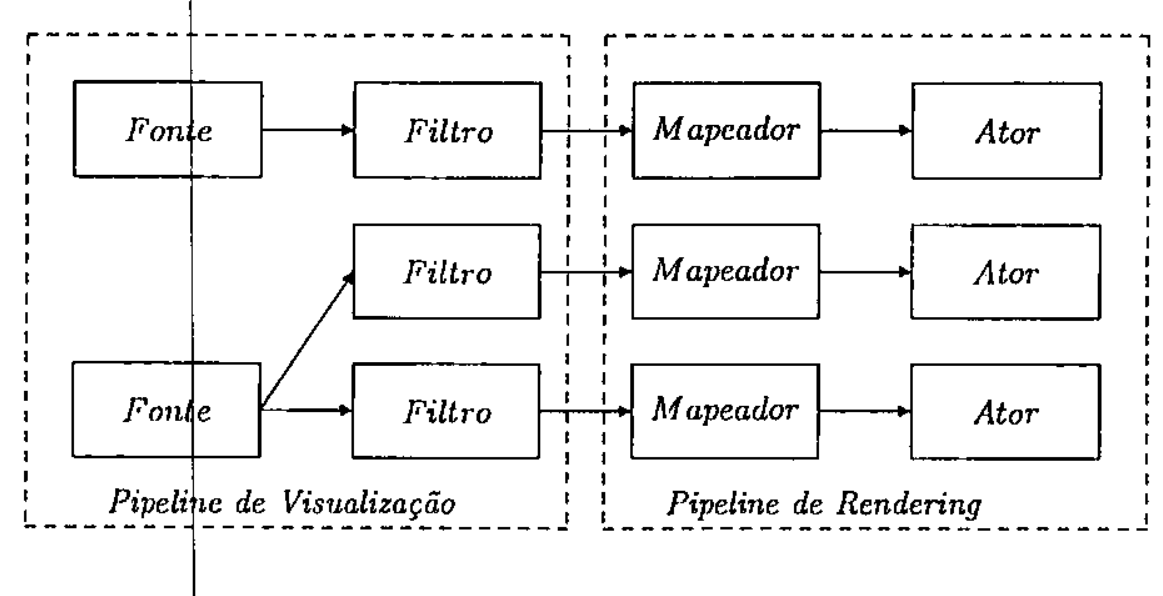

Figura 1.1: Estrutura de Conexão de Módulos no VTK - Adaptada de [6]

$\mathrm{Na}$ estrutura de módulos, os objetos são conectados de acordo com suas entradas e saídas. Assim, a saída de um objeto (ou módulo) deve ser compatível com a entrada de ontro para que a conexão entre eles seja possível.

Existem no VTK, basicamente dois tipos de objetos:

- Objetos de Dados (Data Objects): são objetos que implementam os tipos de dados: grids (malhas), valores, vetores, tensores, metardados (como fontes de luz, dimensões, transformações) e muitos outros.

- Objetos de Processo (Process Objects): são objetos que executam a criação e a transformação de dados. Esses objetos podem: gerar dados (fontes - sources), transformar e manipular esses dados (filtros - filters), ou gravar informações em arquivos (writers).

O último tipo de módulo a ser conectado ao pipeline de visualização é um mapeador (ver figura 1.1), que élo início do pipeline de rendering e é responsável pela transformação dos dados em primitivas compatíveis com a biblioteca gráfica em uso. O próximo passo é então criar atores que representam as estruturas criadas a partir do conjunto de dados. 
Umas clas principais vantagens do VTK são seus recursos para interação com os gráficos $3 D$ gerados. Tais recursos possibilitam que o usuário "navegue" através dessas imagens, e conseqüentemente, através dos dados.

A classe do VTK cliamada vtkRenderWindowInteractor é a responsável por transformar eventos do mouse e teclado em modificações aos atores e câmeras que compõem a visualização. Através dessa classe é possível realizar interações como rotação, walk-through e LOD. Outra vantagem é a capacidade dos usuários capturarem os eventos gerados por essa classe e implementarem as interações da maneira mais adequada à seus fins.

A classe vtkStructuredPoints é o objeto do VTK que representa o tipo de dados malha estruturada, e é utilizado nas implementações associadas a este trabalho de mestrado.

Este capítulo apresentou alguns conceitos e técnicas em visualização científica essenciais para o desenvolvimento deste trabalho. O próximo capítulo é destinado ao estudo da área de sonificação de dados. 


\section{Capítulo 2}

\section{Conceitos de Sonificação}

Conforme mencionado anteriormente, pode-se definir sonificação como sendo a área da computação que estuda o mapeamento de algum conjunto de dados para sons com o objetivo de fornecer ao usuário alguma informação sobre esses dados.

Estudos em sonificação são de fundamental importância e fornecern a base para o desenvolvimento deste trabalho. Os estudos realizados com esse objetivo são apresentados aqui.

A seção 2.1 deste capítulo apresenta algumas formas de apresentação de sons no diadia das pessoas. A seção 2.2 apresenta as principais características do som. A seção 2.3 clescreve o processo de criação e manipulação de sons, conlecido como síntese de sons. A seção 2.4 descreve maneiras através das quais a sonificação pode ser utilizada em conjunto com a visualízação. A seção 2.5 e 2:6 são destinadas à apresentação de trabalhos de sonificação.

\subsection{O Uso do Som}

O som é uma forma de transmissão de informações muito presente na vida das pessoas. Uma das principais yantagens dos estímulos sonoros é o fato das pessoas já estarem familiarizadas com eles e serem capazes de identificar informações transmitidas dessa forma no seu dia-dia.

A forma mais comum de se trocar informações é através da fala. Porém, o canal auditivo não está restrito somente a esse meio. Existe uma grande variedade de outras formas de interação baseadas em sons não falados que são reconhecidas e utilizadas pelas pessoas.

Os sons são fundarmentais em diversas situações da vida das pessoas, podendo ajudar 
a diagnosticar doenças e até mesmo a salvar vidas. $\mathrm{Na}$ área da medicina, por exemplo, médicos utilizam-se de aparelhos (como o estetoscópio) para ouvir nosso organismo e identificar possiveis problemas. Estudantes de medicina são ensinados a ouvir sons como os de gases no intestino e do sangue fluindo pelas veias. Algumas outras informações sobre o corpo hiımano (como temperatura) podem ser medidas e mostradas através de gráficos. Entretanto, os gráficos podem se tornar cansativos aos usuários durante longas tarefas de observação, e a solução para esse problema pode ser, algumas vezes, o uso de sons.

O campo cinematográfico é outro onde o som possui grande importância nos dias de hoje, sendo a parte de trilha e efeitos sonoros uma das partes de um filme mais estudadas e projetadas. A música, o som, os efeitos sonoros de um filme podem sugerir ao usuário sentimentos coino nedo, expcctativa, calma ou humor. Esse fato ilustra muito bem - quanto é necessária a presença de estímulos sonoros na apresentação de algum tipo de informação e o quanto os seres humanos já estão acostumados a responder a esses estímulos.

Atualınente, jogos de computador e aplicações multimídia também fazem uso de sons para facilitar a transmissão de informações aos usuários. Quando se joga um jogo de computaclor o primeiro aspecto que se observa é a qualidade dos gráficos. Hoje em dia, essa deixou de ser a única preocupação dos fabricantes desse tipo de software. A qualidade e definição dos sons tem, juntamente com os gráficos $3 D$, uma grande importầncia no mundo dos jogos e requerem de seus projetistas muitas horas de trabalho e pesquisa. Uma boa forma de se entender a importância do som nos jogos e aplicações é experimentando jogar um desses jogos cle luta ou suspense com o sistema de som do microcomputador clesligado. Ontras áreas da computação que se beneficiam e fazem muito uso do som são os sisteemas operacionais e tainbérn as aplicaçōes via Internet. $\mathrm{Na}$ área de visualização e interpretação cle dados, várias tentativas têm sido feitas de incluir som como forma de aprosentação (ver seção 1.4).

O estudo do som e suas propriedades é fundamental para $11 \mathrm{~m}$ bom mapeamento dos dados. A próxima seção apresenta as principais características dos sons.

\subsection{Propriedades do Som}

Recentemente, o uso do som como forma de representação de informação passou de uma possibilidacle quase remota em sistemas computacionais a uma área intensamente estudada e de grande desenvolvimento tecnológico.

Un dos principais motivos para que o som ainda não seja muito utilizado em sistemas 
computacionais é o fato de ainda existirem características de percepção sonoras desconhecidas pelo ser lummano. No contexto de aplicações computacionais, pode-se distinguir duas classes de som: a dos sons falados e a dos sons não falados. Um fator importante é que os sons não falados não dependem tão fortemente de uma linguagem ou cultura e por esse motivo apresentam e codificam melhor as informações a serem observadas (evitando ambigüidades lingüísticas e diferenças culturais)[9].

\subsubsection{Acústica}

O que se ouve em forma de som é uma classe da energia cinética física denominada energia acística, que resulta de ondas de pressão que se propagam em um meio físico, geralmente o ar. Essas ondas de pressão provocam movimentos do ar que são percebidos pelos nossos ouvidos na forma de sons. Portanto, para que um som seja percebido por seres humanos, um meio, como por exemplo o ar, deve ser deslocado em movimentos "para frente" e "para trás", resultando assim em ondas de movimento. Essas ondas podem ser descritas em termos da quantidade de ar que é movida, o quão freqüente é esse movimento do ar, e colno é esse movimento. A figura 2.1 apresenta um exemplo de uma onda sonora descrita através da pressão (eixo $y$ ) em função do tempo (eixo $x$ ). A onda exibida na figura é chamada de onda senoidal e raramente é resultado de algum evento natural. A maioria dos sons possuem energias e freqüências diferentes, gerando assim, ondas sonoras bem mais complexas e irregulares.

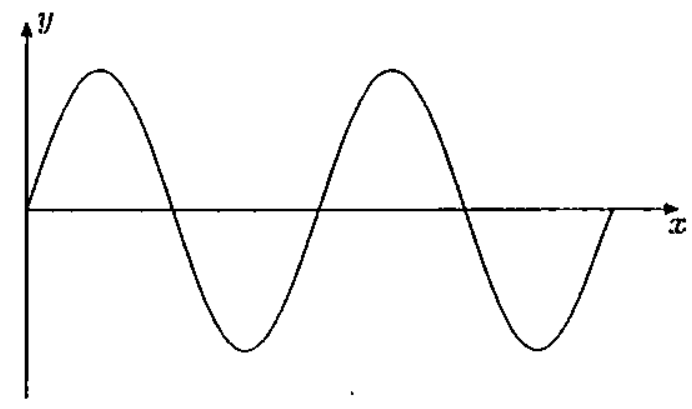

Figura 2.1: Exemplo onda sonora

Em instrumentos acústicos, o movimento do ar (onda sonora) é realizado por alguma vibração física, como a cle uma corda, ou por qualquer outra parte do instrumento. Já em instrumentos eletrônicos, onde se encaixam os sintetizadores, o movimento do ar é realizado por um auto-falante. Essas ondas chegam ao ouvido humano, onde se encontra o tímpano, e fazem com que ele vibre. Mudanças fisiológicas ocorrem e transformam o 
movimento físico do tímpano em sinais elétricos analógicos que caminham pelos nervos em ¿lireção ao cérebro. Quando esses sinais chegam ao cérebro, o som é finalmente percebido.

Apesar de existir um número linitado de características sonoras, essas podem ser manipuladas parn formar un rico conjurtto de sons.

A percepção e o reconhccimento de um som cm sua existência podem ser descrita em termos de três parâınetros:

- Entoação (pitch)

- Volume (loudness)

- Timbre

Um fator interessante é que esses não são os únicos parâmetros que identificam um determinado som; porém, pode-se interpretar as propriedades de todo som através de cada uma dessas três variáveis. A seguir, é apresentada uma descrição de cada uma dessas propriedades que identificam os sons.

\section{Volume do Som (Loudness)}

O volume de um som é uma característica diretamente ligada à sua amplitude, e representa a quantidade de ar que é movido ern um determinado momento, na formação da onda sonora. Mais especificamente, o volume representa a altura de uma onda sonora acima e abaixo de seu ponto central. A figura 2.2 apresenta um exemplo de variações de volume através de duas ondas senoidais - uma representando um som de volume alto, e outra, o rnesmo som com um volume baixo.
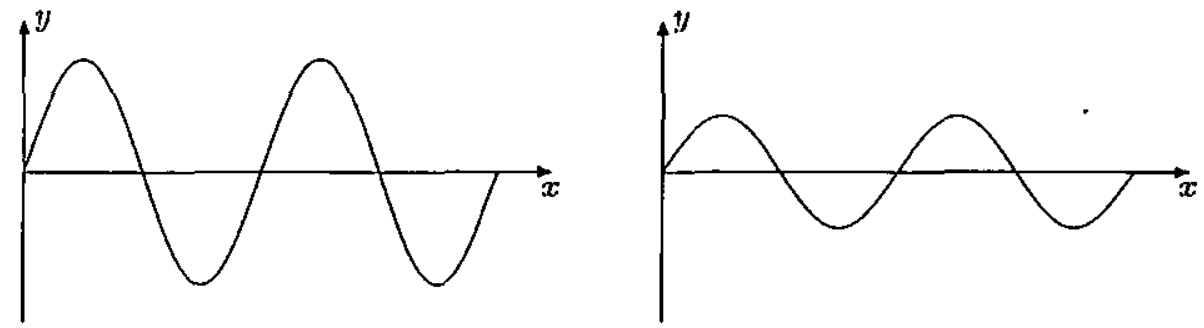

Figura 2.2: Duas ondas sonoras com amplitudes diferentes

Uma característica importante do volume é que ele sempre se altera no período de duração de um som. Assim, não se pode encontrar ondas sonoras onde a altura permaneça sempre constante. Um exemplo disso é o som gerado por um tambor, que se inicia repentinamente em um alto volume e então desaparece rapidamente. 


\section{Entoaçāo (pitch)}

A entoação é uma impressão subjetiva que corresponde bem à freqüência e indica o quão grave ou agudd é um som. A entoação representa, portanto, o quão freqüente são realizados os movimentos de ar que geram os sons, ou seja, qual a freqüência de ocorrência de uma onda sonora em um determinado período de tempo.

Pode-se perceber na figura 2.1 que cada parte superior da onda é seguida de uma porção inferior, e que a primeira é um espello da segunda, criando assim uma forma de "pico e vale". A quantidade de tempo que uma onda leva para produzir um pico seguido de um vale é denominado período de uma onda, e um ciclo de onda é gerado em cada período. O número de ciclos gerados em um segundo determina a freqiiência, ou entoação, de uma onda sonora. Nem toda onda sonora é periódica, entretanto.

A faixa de valores de freqüência capazes de serem ouvidos pelos seres humanos vai de 20 a $20.000 \mathrm{~Hz}$.

Na realidade, sons não são formados apenas por uma freqüência, mas por uma união de muitas. Normalmente, uma onda com determinada freqüência se sobressai em relação as demais de um som por ser apresentada com uma amplitude maior. A essa onda, dá-se o nome de freqüência fundamental ou básica [27]. A natureza das freqüências secundárias, oll overtones, e sua contribuição na percepção de um som será discutida na seção que estuda o timbre de uma onda sonora.

A frequiência de um som, assim como sua amplitude, sempre se altera durante sua duração, apesar de serem alterações bastante sutis.

\section{Tillbre}

Tambén conlecido como "a cor do som", pode ser definiclo como "o atributo da sensação auditiva que permite que dois sons similares com o mesmo volume e a mesma entoação possam ser julgados como sendo diferentes" [9]. O que torna possível, por excmplo, que se possa diferenciar os sons dos diversos instrumentos acústicos (como violão e flauta) é o fato de cada instrumento possuir um timbre característico.

Apesar de parecer uma característica puramente subjetiva ou um aspecto ilusório dos sons, o timbre pode ser precisamente definido em termos matemáticos. Isso se deve ao fato dele representar as relações entre ạs freqüências secundárias (overtones) de uma onda sonora e sua relação com a freqüência básica da onda.

Portanto, o que qaracteriza o timbre de um som são seus overtones, e essa alteraçāo no timbre pode ser percebida como mudanças na forma de uma onda sonora. Assim, um som suave, ou seja, um que contcnlı poucos overiones, irá produzir uma onda sonora 
suave [27].

Além das propriedades anteriores, algumas outras características do som e da audição influenciam na percep̧ão do som pelo canal auditivo humano. Entre estas, podemos citar:

- Duração: o teinpo do som

- Rituno: a "baticla" de sons longos

- Mascaramento: a influência de um som na percepção de outros

- Localização Espacial: a capacidade humana de localizar a posição da fonte de um soin

- Segregação de Sons: a capacidade humana de distinguir dois sons, quando apresentados simultaneamente

- Agrupamento de Sons: a característica humana de entender sons gerados separadamente como um único som

Os conceitos acústicos e princípios de percepção apresentados neste capítulo são fundamentais na escolha de sons e suas propriedades para sonificação. Mais ainda, o poder de representação de urn projeto sonoro depende diretamente da manipulação correta dos aspectos perceptivos e propriedades sonoras apresentadas.

A próxima seção apresenta um estudo sobre algumas formas de se e manipular esses parâmetros sonoros na criação e projeto de um determinado som. A tal tarefa dá-se o nome de síntese de sons.

\subsection{Síntese de Sons por Software}

A tarefa exercida por aparelhos que realizam a síntese de sons (sintetizadores) é a de produzir sons (tanto musicais quanto não musicais) e permitir que o usuário interaja com os parâmetros que determinam o som para obtenção dos resultados sonoros desejados [27]. Existem duas formas principais de se realizar a síntese de sons. Uma delas é através de hardware com dispositivos e instruções que permitem ao usuário criar e manipular seus sons. A outra é através de sistemas de computador que simulam o hardware de som.

Dispositivos que realizam síntese de sons por hardware manipulam um conjunto reduziclo de carnctcrísticas sonoras, o cute limita a capacidade do usuário de criar e compor sons [28]. Uma mancira de se melhorar a capacidade de interação do usuário com os sons por 
ele gerados é através do uso de elementos software que manipulem certas características sonoras e possibilitem ao usuário a síntese de sons mais detalhados.

Nesta seção são apresentados os conceitos básicos envolvidos na síntese de sons por software. Nesse contexto, é apresentado um software para síntese de sons no apoio à tarefa cle sonificação, o CSound.

\subsubsection{Síntese Digital de Sons}

Síntese digital de sons pode ser definida como a forma de gerar conjuntos de números que representam amostras (samples) de uma onda sonora. Na realização dos sons, essas amostras são enviadas a um aparelho denominado DAC (digital-to-analog-converter) cuja função é a de converter sinais digitais em analógicos. Esse conversor é responsável pela convcrsão dos números da amostra para uma voltagem variando continuamente no tempo, que pode ser amplificada e enviada às caixas de som.

O processo de síntese digital de sons pode ser visto da seguinte forma: pode-se imaginar um programa de computador que calcula as amostras de acordo com uma fórmula mateınática e envia esses valores, um após o outro, ao DAC. Todos os cálculos são feitos pelo programa, que pode ser modificado de forma arbitrária pelo usuário para sintetizar sons específicos. Dessa forma, a síntese digital de sons nada mais é do que uma síntese de sons através da utilização de programas computacionais, ou seja, via software. A principal vantagem da síntese por hardware é a existência de circuitos especiais que se encarregam dos cálculos necessários, aumentando a velocidade da síntese de sons.

Apesar de necessitar de um tempo maior de processamento, a síntese de sons por software garante ao usuário uma flexibilidade na geração de sons que não pode ser obtida através de dispositivos de hardware, o que torna essa técnica muito útil para a área de sonificação de dados [32]. Tal flexibilidade pode ser exemplificada através cle um exemplo bem simples: suponha que um desejado som para ser sintetizado necessite de nove oscilaclores e un filtro de sons. O usuário precisa, para realizar tal som, de lodo esse equipamento de hardware. Outro som, porém, pode precisar cle nove filtros de sons e apenas um osciladpr. Para esse, o usuário teria que comprar mais oito filtros para geração clo som desejado. No entanto, utilizando dispositivos de software, o usuário pode programar um computador para simular tanto os oito osciladores e um filtro, quanto os oito filtros e um oscilaclor.

Qualquer soin imaginável pode ser sintetizado a partir instruções de software - partindo-se do princípio que o usıário dispõe de tempo para esperar pelos resultados [28]. Com uma taxa de amostragem de 44.100 amostras por segundo, o tempo disponível por amostra 
é cle 20 microssegundos, que é un intervalo pequeno para síntese em tempo real de sons complexos. Por essa razão, a inaioria dos programas de síntese de sons gera arquivos de sons que são enviados ao DAC e então reproduzidos.

As principais vantagens da sintese de sons por software são, portanto, sua economia e flexibilidacle para geração de sons. Mais ainda, um computador pode simular qualquer unidade de geração de sons e implemnentar qualquer técnica de síntese de sons, tanto as tradicionnis e mais utilizadas, quanto as que ainda nem existem.

A seguir, é apresentado um sistema de software que realiza a síntese de sons, e que está sendo consiclerndo para uso no presente traballı.

\subsubsection{CSound}

CSound é um programa de síntese digital de sons criado no MIT (Massachusetts Institute of Téchnology) [32] e escrito em linguagem C. Grande parte. do sucesso desse software entre os usuários de síntese sonora se deve ao fato do CSound ser um software gratuito e de código livre. Assim, cientistas, músicos e usuários de qualquer parte do mundo podem ter acesso a esse programa e, se necessário, alterá-lo para a execução de tarefas específicas.

A funcionalidade do CSound é uma das suas principais qualidades. Com a atual versão clo softwarc, pode-se implementar qualquer tipo de técnica ou processo para a geração de sons. Mais ainda, tal flexibilidade permite que o usuário crie uma "máquina de som" virtual que seja adequada às suas necessidades. Outra característica determinante desse software é sua portabilidade. Atualmente existem versões suas para vários ambientes e sistemas, como, por exemplo, PC, Mac, PowerMac e SGI [31].

Para a geração de sons, o CSound necessita da especificação de dois arquivos texto chamados arquivos Orchesta e Score. Nesses arquivos, estão especificados tudo o que é necessário para que o usuário crie sua "máquina virtual" e controle os parâmetros adequados para a geração de seus sons.

Para a realização de uın som, o programa CSound compila e executa os arquivos Orchestra e Score especificados pelo usuário e gera, como saída, um arquivo binário representando o som gerado. Os sons gerados pelo CSound podem também ter como fonte sons reais gravados digitalmente.

A figura 2.3 exemplifica a forma de geração de sons através do CSound. 


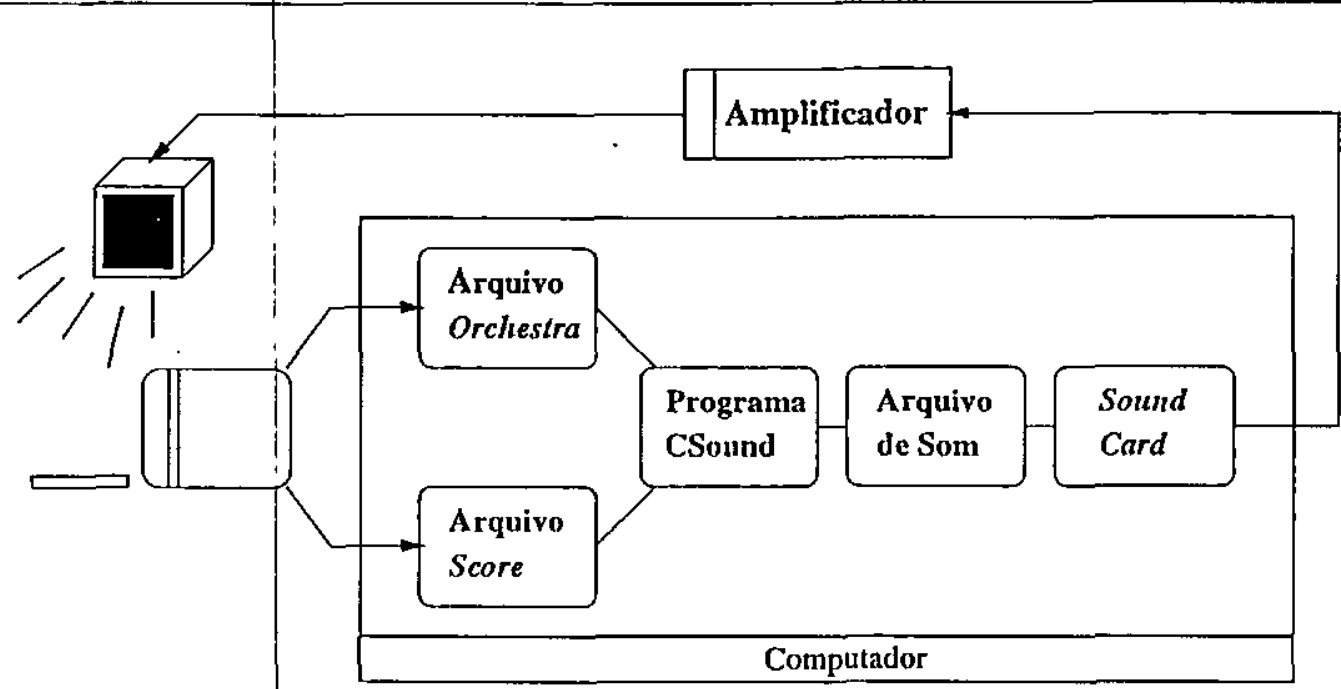

Figura 2.3: Exemplo de como os sons são gerados pelo CSound - Adaptada de [31]

Portanto, os sons gerados pelo sistema CSound podem, com base nas características apresentadas, serem classificados como "Sons Virtuais", que são sons criados "do nada", baseaclos apenas em idéias, fórmulas, expectativas e algum tipo de metodologia [31].

A atual versão do CSound permite a implementação de qualquer método de síntese de sons, tanto os já existentes (como o de síntese aditiva, substrativa e por modulação de freqüência), como a criação de novos métodos [31].

A próxima seção apresenta algumas formas através das quais pode-se fazer uso de sons e técnicas de sonificação no auxílio à tarefas de visualização de dados científicos.

\subsection{Motivação para a Sonificação em Visualização}

Conforme discuticlo anteriormente neste texto, uma forma de auxiliar e solucionar alguns problemas encontrados na visualização de dados é através do uso do canal auditivo como um outro meio de transmissão de informações. Através da utilização de técnicas de sonificação, é possível oferecer ao usuário novas formas de exploração dos dados que visam não só buscar um melhor nível de interação entre os usuários e seu conjunto de dados, unas também oferecef uma nova alternativa ao canal visual e a exploração exaustiva de gráficos $3 D$.

A principal contribuição do som em sistemas de visualização é a representação dos dados. Unna clas grandes vantagens do uso de sons está no fato de que a audição possui propriedades cliferentes da visão, podendo assim ser útil na identificação de padrões e estruturas não obseryados na imagem [4]. 
Existein certos tipos de informação científica para as quais não é natural o mapeamento em objetos gráficos [8]. Para esses tipos de informações, o mapeamento por som pode ser una boa ferramenta para que o usuário possa interagir e entender melhor os dados. Como exemplo desses tipos de dados, pode-se citar dados lineares ou quadráticos com características temporais, e também tarefas de comparação de valores escalares.

Além disso, o som também pode ser muito útil na validação de daclos gráficos. Em muitos casos é difícil saber se os dados apresentados de forma gráfica estão corretos ou se o que é visualizado provém de algum de tipo de erro (erro que pode ser introduzido de diversas formas, como por exemplo, através da interpolação de dados). O mapeamento sonoro desses dados ou das entidades gráficas formadas por eles pode confirmar ou questionar o resultado obtido na representação gráfica.

A adição da dimensão temporal é outra contribuição do som para tarefas de visttalização [9]. O tempo pode ser naturalmente representado por mapeamentos sonoros. Quando existe esse mapeamento, o usuário pode ter noção da progressão no tempo dos valores de uma determinada variável sendo observada. O que garante isso é a natureza temporal do som.

Apesar da área de sonificação aincla ser bastante nova na computação, os benefícios do uso do som em sistemas computacionais têm sido reconhecidos e pesquisados pela comunidade científica. Hoje em dia já existem foros de discussão de renome (sound.acm.org) e congressos dedicados ao estudo do display auditivo (ICAD - www.santafe.edu/ i icad).

A próxima seção é dedicada à apresentação de algumas das principais técnicas e alguns traballıos na área de sonificação de dados.

\subsection{Estudos em Sonificação}

O estudo do som e de formas através das quais esse estímulo pode contribuir na apresentação de informações sobre os dados atinge atualmente uma grande área que vai desde estudos técnicos ein áreas de engenharia a estudos em realidade virtual.

Existem diversas maneiras através das quais se pode realizar o projeto de uma sonificação, ou seja, definir de qual forma os dados podem ser mapeados para algum tipo de estímulo sonoro. Alguns dos métodos de sonificação mais conhecidos são os earcons, os auditory icons e o mapeamento de parâmetros, apresentados a seguir.

\subsubsection{Earcons}

Earcons são motifs musicais de curta duração que usam tons musicais na representação 
dos dados. Os earcons foram desenvolvidos com o objetivo principal de fornecer ao usuário respostas a atividades em uma GUI (Graphical User Interface[11].

Earcons utilizam a técnica de combinação de sons simples para criar um som mais complexo contendo a informação que deve ser transmitida ao usuário. Fsses sons básicos podem variar quantp ao ritmo, entoação, timbre, registro e dinâmica. Por exemplo, um tom A com entoaçã de $440 \mathrm{~Hz}$ pode significar "arquivo" e um tom B com entoação 600 $\mathrm{Hz}$ significar "deletado"; assim, combinando A com B em série, será produzido um tom significando "arquivo deletado".

A facilidade de se construir os earcons em qualquer computador com ferramentas existentes para manipulação de audio é uma das principais vantagens desse método de sonificação. A principal desvantagem é, entretanto, a dificuldade na aprendizagem dos sons gerados. Pessoas não acostumadas com os sons produzidos podem aprender de 4 a 6 sons simbólicos em alguns minutos. Porém, a aprendizagem de mais símbolos pode levar horas. Outro fator que contribui para a utilização desse método em sistemas de sonificação é o fato clos earcons produzirem uma representação abstrata para os dados. Isso significa que os sons dos earcons näo precisam sugerir os objetos que eles representam, o que garante que mesmo bbjetos que produzam sons desagradáveis possam ser representados.

\subsubsection{Auditory Icons}

$\mathrm{O}$ auditory icons é um método que usa sons do dia-dia, como o bater de uma porta ou o barulho de um ventilador, para transmitir informações. Assim como os earcons, eles surgiram como uma forma de oferecer resposta em uma interface gráfica [11]. Nessa técnica, objetos e eventos da interface são mapeados para sons do mundo real que melhor representem esses objetos. Por exemplo, o encerramento de um programa pode ser modelado para sons como uma porta sendo fechada.

A principal vantagem do uso dessa técnica é a familiaridade dos usuários com os sons apresentados. Unn fator negativo dos auditory icons é a dificuldade de se desenvolver um algoritrno que possa produzir sons que representem fielmente os sons do dia-dia. A solução para esse problema poderia ser a gravação e manipulação de sons reais, o que também é uma tarefa bastante complicada. Outro problema desse método é o processo de abstração ao se apresentar tarefas virtuais (como operações de software) com sons mecânicos reais. Essa abstração pode causar dificuldade na sua aprendizagem semelhante à dos earcons. 


\subsubsection{Mapeamento de Parâmetros}

O terceiro método de sonificação é o mapeamento de parâmetros. Nesse método, o que ocorre normalnente é o mapeamento de alguma dimensão dos clados em um parâmetro sonoro como entoação, duração ou volume [11]. Diferentes variáveis podem ser mapeadas para diferentes parâmetros em una sonificação, formando assiın sons complexos. Assim, por exemplo, valores altos podem ser mapeados para volumes altos; valores distantes por frequîencias altas, e ussinn por diante.

$O$ fato de existirem ferramentas que permitem e facilitam o mapeamento de dados em parâmetros sonoros é unna das principais vantagens desse método. É importante também o fato de que, através do mapeamento de parâmetros, o usuário é capaz de representar inuitas dimensões dos dados ao mesmo tempo. Um problema dessa técnica é que o mapeamento de dados para parâmetros sonoros pode muitas vezes gerar sons desagradáveis que dificultem o trabalho de pesquisa do usuário. Algumas técnicas controlam essa formação limitando a quantidade de sons possíveis.

Os princípios das três técnicas descritas até aqui guiam a criação de sonificações na maioria das abordagens publicadas até o momento.

O restante deste capítulo é destinado à apresentação de trabalhos recentes em diversas áreas de sonificação.

\subsection{Revisão de Trabalhos em Sonificação}

Pessoas com deficiência visual necessitam e confiam em sons mais do que as com visão normal ou corrigida. Assim, através da apresentação sonora de informações, sistemas de sonificação podcm ajudar essas pessoas a analisar dados e gráficos, ou mesmo navegar e ter acesso a uma interface computacional. O KnowWhere [12] foi criado por Krueger e Gilden com o intuito de apresentar informações geográficas a pessoas cegas. Nesse sistema, as H1ños do usuńrio ficam posicionadas em uma interface luminosa coberta por um grid em alto relevo que é filmado por uma câmera de vídeo. Essa imagem de vídeo é então analisada por processadores especializados e a localização dos dedos do usuário na mesa luminosa pode ser determinada. Um mapa virtual invisível é definido na superfície da mesa, e conforme o usuário move os dedos pelo mapa, sons característicos são emitidos pelo sistema. Assim, o usuário pode identificar características do mapa movendo seus dedos pelo grid que representa o mapa virtual.

$\mathrm{Na}$ interação com interfaces multimídia, o usuário tem que identificar e processar vários tipos de informação. Além de receber dados na forma visual, os usuários podem 
escutar seus computadores e em alguns casos até mesmo sentir seu ambiente de trabalho. Usualmente, esses tipos de informação atingem o usuário simultaneamente e ele tem que identificar a informação çuc está sendo transmitida, sendo que tanto as imagens quanto o soin podem carregar informações importantes. Analisando isso, Bussemakers e Haan [15] desenvolveram um estudo que busca melhores maneiras de se combinar imagens e sons para otiınizar a transmissão de informações ao usuário em interfaces multimídia. A tarefa de identificação de informações foi estudada através da apresentação da combinação de presença ou ausência de ícones(representação visual) e earcons(representação auditiva). Os resultados do estudo mostram que, quando as mensagens principais são apresentadas 11a forma visual, informações adicionais auditivas causam um atraso no reconhecimento da iıformação. Já no caso onde a informação principal é apresentada por sons, a adição de imagens aumenta a velocidade de resposta do usuário.

Conjuntos de dados multidimensionais e em grandes quantidades são um desafio às tarefas de visualização. Um exemplo desse tipo de dados são os conjuntos de dados sísmicos, que geralmente possuem bilhões de amostras de dados. É difícil que se consiga uma visualização de todos esses dados sem que pequenas, mas importantes características ou eventos sejam perdidos. Esse problema levou os profissionais em sismologia a "escutar" seus dados ao invés de apenas visualizá-los. Saue e Fjeld [19] desenvolveram um trabalho que investiga o uso de técnicas de sonificação na interpretação sísmica para exploração de petróleo. Nesse trabalho, é feita a extração de parâmetros sísmịcos para sonificação e posterior o mapeamento desses parâmetros para parâmetros MIDI de velocidade e freqüência. Resultados mostram eficiência da adição do display auditivo na interpretação desse tipo de dados, apesar do tempo necessário para a adaptação aos sons.

Hermann, Meiniqke e Ritter [22] apresentaram uma nova abordagem para a sonificação de clados inultidimensionais que permite a percepção da estrutura principal da distribuição dos dados. A forma através da qual isso foi possível foi através da sonificação da curva principal de um conjunto de dados. A curva principal pode ser definida como sendo a trajetória que passa pelo "meio" dos dados e permite a definição de uma organização temporal para eles. Experimentos mostraram que a sonificação da curva principal pode fornecer uma apresentação bastante útil, já que os agrupamentos de dados puderam ser mais facilmente percebidos e estruturas de difícil reconhecimento visual puderam ser detectadas. A idéia foi aplicada na análise de dados médicos, onde estruturas devem ser encontradas a partir de longas séries temporais.

Saue [21] apresentou um modelo geral para navegação e sonificação em grandes conjuntos de dados espaciais baseado no uso de sons do dia-dia. O modelo foi criado incluindo 
som e técnicas de interação. $O$ usuário interage com a apresentação de movimentando através das regiōes do conjunto de dados ouvindo sons locais e gerais. Os sons que constituem o modelo construído são:

1. MoveSounds: sons locais gerados pela movimentação do usuário (como por exemplo, o soin de passos).

2. ObjectSounds: Sons decorrentes de eventos e objetos.

3. AmbientSounds: Sons globais que caracterizam o ambiente (como por exemplo, o som de chuva).

4. ExamincSounds: Sons locais causados por manipulaçōes deliberadas (por exemplo: batidas).

A apresentação multi-modal aumenta significativamente a qualidade em ambientes de realidade virtual. Dcssa forma, o uso de sons juntamente com as imagens $3 D$ podem garantir una melhor qualidade de imersão e interação de usuários de mundos virtuais. O COOLVR (Complete Object Oriented Library for Virtual Reality) [18] é um toolkit enn desenvolvimento no Graphics, Visualization and Usability Center (GVU) em Geogia Tech por Jarrel e Kooper. Esse toolkit foi escrito para permitir que programadores criem ambientes virtuais que podem ser compilados em diversas plataformas. Ao contrário da inaioria dos toolkits que se direcionam totalmente à percepção visual, o COOLVR busca unir os sentidos da visão e audiçāo para atingir melhores resultados. Através da capacidade de integração de sons espaciais em um mundo virtual, o COOLVR garante a obtenção de um maior nível de imersão e presença em ambientes virtuais.

Procedimentos inédicos de longa duração causain fadiga mental e deficiências na atenção. Jovanov et al [14] estudaram o uso de sons como uma maneira de fixar a atenção durante procedimentos de análise longos. Nesse trabalho, os autores apresentam os conceitos de andio tátil e rendering acústico. $O$ audio tátil estuda o uso de respostas auditivas para facilitar o posicionamento preciso e exato de um objeto em relação a outro. Esse conceito é muito útil na área de medicina, pois ajuda o cirurgião a posicionar seus instrumentos sem a necessidade de tirar seus olhos do paciente como no caso da análise de un ultra-som ou outras ferramentas visuais. O rendering acústico é o uso de inapeamentos para parâmetros sonoros. Nesse trabalho foi implementado um ambiente para o monitoramento da atividade elétrica cerebral. Esse ambiente consiste de um sistema de visualização $3 D$ e um sistema de sonificação de dados de eletro-encefalograma (EEG), 
coun suporte ì espaçialização $3 D$ dos sons (mudanças na localização dos sons de acordo coin mudanças uos dados do EEG). Outra técnica de sonificação utilizada foi o uso de padrões sonoros com mudanças apropriadas em sua freqüência. Essas mudanças na freqüência servem como alerta a mudanças no EEG do paciente durante os longos períodos de observação.

Sturm [23] desenvolveu métodos para sonificação de sistemas de partículas utilizando a hipótese de Broglie, a qual afirma que partículas podem atuar como ondas, assim como ondas podem atuar como partículas. Utilizando essa hipótese o autor criou um sistema de sonificação com $\oint$ objetivo de facilitar a percepção e o entendimento de sistemas de partículas. A "espacialização" desses sistemas é feita da seguinte maneira: o espaço do sistema, isto é, $\oint$ plano $x y$, é dividido em quadrantes, com origem no observador; cada quadrante é percebido através de um auto-falante em um sistema quadrafônico (por exemplo, a região do plano $x y$ onde $x>0$ e $y>0$ é sonificada no auto-falante direito frontal clo sistema quadrafônico). Quando uma partícula começa a se mover entre os quadrantes, o sistema calcula a quantidade de som em cada auto-falante pela determinação da porcentagem da esfera que representa a partícula contida naquele quadrante.

O problema da ortogonalidade em sistemas sonoros, onde mudanças em uma variável sonora podem influenciar a percepção de outras variáveis, foi abordado por Neuhoff, Kramer e Wayand [25]. Nesse trabalho, eles demonstram a influência perceptiva entre mudanças na entoaçáo e altura dos sons. Os experimentos realizados mostraram que mudanças realizadas na altura podem influenciar nas mudanças de entoação e vice-versa. Foi observado que quando freqüência e intensidade mudavam na mesma direção, a percepção dessas unudanças crescia em relação a situações onde essas variáveis mudavam em direções opostas.

Uma ferramenta colaborativa para navegação na $W e b$ foi descrita por Dieberger [24]. Nesse trabalho, o sistema CoWeb foi modificado para agregar o histórico de interações nas páginas indicando os acessos recentes e quando foi realizada a última modificação realizada em uma determinada página. O som foi adicionado na apresentação dos links das páginas, apresentação de múltiplos links simultâneos com mesmo histórico, e apresentação da quantidade de acessos para os links, entre outros.

Os traballios aciłna representam algumas experiências de sucesso com o uso do sorn. A seguir, são apresentados em mais detalhe alguns trabalhos com implicação direta no desenvolvimento do projeto no qual este mestrado se insere. 


\subsubsection{Listen}

O Listen é um sistema orientado a objetos, desenvolvido por Lodha e Wilson [26], que realiza a sonificação de dados científicos. Ele foi escrito em linguagem $\mathrm{C}++$ para a plataforma Silicon Graphics (SGI) e pode trabalhar com o chip de audio interno da SGI, com un dispositivo MIDI ou mesmo com ambos. Um dos principais objetivos do Listen era o de ser urn sistema para sonificação modular, flexível, adaptável, portável, interativo e extensível. Seu uso ainda é muito limitado, mas suas idéias podem ser úteis para as extensões planejadas para o DSVol.

- A idéia principal quando se desenvolveu o Listen era a de criar um sistema que servisse - cle apoio ì tarefa de visualização cle incerteza. Incerteza pode ser definida de forma bastante ampla incluindo conceitos de erro, imprecisão, nível de confiança e qualidade dos dados. Geralmente esses problemas estão associados à aquisição (medição), transformação (interpolação) ou visualização dos dados (modelos de rendering e algoritmos inadequados).

Para realizar o mapeamento de dados para sons, o Listen utiliza variações na entoação, localização, duração e volume do som apresentado. Além disso, o sistema possui um esquema de utilização de un timbre por stream de dados na implementação MIDI.

Dois experimentos utilizando esse sistema foram realizados, ambos para a sonificação de algum tipo de incerteza. O primeiro experimento procurava identificar incertezas geométricas, enquanto o segundo tinha como objetivo sonificar incertezas em fluxo de fluidos. Resultados desses experimentos mostraram que o uso de sons foi de fundamental importância na deteç̧ão de informações difíceis de serem detectadas somente através do display visual. A sobrecarga visual também foi diminuída com o uso do som para o mapeamento de parâmetros dos dados.

\subsubsection{Porsonify}

O toolkit Porsonify para sonificação foi desenvolvido por Madhyastha e Reed [20]. A idéia principal desse sistema era a de ser facilmente integrado a sistemas de visualização já existentes.

Para oferecer portabilidade, o software é baseado em descrições de dispositivos de som abstratos. Através da manipulação desses dispositivos abstratos, o sistema permite acesso transparente a dispositivos de audio, escondendo do usuário conceitos de mais alto nível em sonificaçāo.

O Porsonify provê tambéın mecanismos para que se estenda o software, permitindo assim o desenvolvimento de diversos tipos de sonificação como: mapeamentos pa- 
ra parâmetros sonoros, streams de audio no tempo e também as audio cues. Alguns parâmetros sonoros usados pelo software para o mapeamento de dados são a freqüência, timbre, volume e a duração do som.

Duas aplicações para do software foram criadas para testar sua flexibilidade e generalidade. A primeira foi o desenvolvimento de uma ferramenta gráfica, denominada sdinterface, que fornecia e permitia uma interação gráfica com dispositivos de audio. A segunda, chamada de Pablo Performance Analysis Environment, é um toolkit de visualização com suporte para sonificação oferecida pelo Porsonify.

\subsubsection{SSound}

Minghiın e Forrest [3] projetaraın e implementaram um sistema de sonificação para dados de superfície, dénominado SSound. O SSound implementa algumas funções sonoras responsáveis por apyesentar e permitir que o usuário interaja e explore a visualização de superfícies. O capítulo 3 deste trabalho apresenta em maiores detalhes o DSVol [9], um sistema de sonificação que foi criado como extensão ao SSound.

\subsubsection{MUSE}

Lodlıa e Beahan desenvolveram o MUSE (Musical Sonification Environment) [17], um sistema de sonificaçäo com o objetivo de mapear dados científicos em sons musicais.

O fato de só traballharem com sons não musicais pode ser considerado um problema na maioria dos sistemas de sonificação. Esse tipo de som pode se tornar irritante ao usuário principalmente quando grandes conjuntos de dados estão sendo explorados durante longos períodos de tempo. Assim, O MUSE tenta introduzir um novo conceito na área de sonificação através do mapeamento dos dados em sons musicais, mais agradáveis ao usuário. $\mathrm{O}$ principal desafio dos autores foi o de garantir e preservar o significado dos dados através desse tipo de mapeamento.

O MUSE permite mapeamentos flexíveis de dados em parâmetros sonoros como entoação (melodia), ritmo, tempo, volume, timbre e harmonia. O softwore foi escrito en C++ para uma plataforma Silicon Graphics e trabalha com o software responsávcl pela especificação dos sons CSound mencionado na seção 1.3.2.

O MUSE foi utilizado para visıalizar incertezas em isosuperfícies e dados volumétricos. 


\subsubsection{Sonificação de Imagens Texturizadas}

Esse trabalho foi desenvolvido por Martins e Rangayyan [16] e teve como principal objetivo verificar o potencial do display auditivo e métodos de sonificação na análise auditiva de imagens texturizadas. Entre os diversos problemas envolvidos no mapeamento de texturas de imagens em sons, o primeiro que se nota é que o som é um fenômeno temporal, ou seja, que se altera no tempo, enquanto que uma imagem é estática.

Para mapear texturas ralıômicas, os autores convertiam as imagens $2 D$ em sinais unidimensionais através de projeções da imagem em diversos ângulos. Através da representação de diversas projeções como sons, os autores buscavam representar as características .espectrais da textura randômica.

No caso cle texturas quasi-periódicas, foi utilizado o mapeamento de atributos do elemento de textura e periodicidacle para parâmetros sonoros. Em particular, projeções clo elemento de textura são utilizados na síntese de sons "parecidos-com-fala", com a freqüência sendo uma função da periodicidade vertical. A periodicidade horizontal é utilizada para fornecer ritmo na apresentação das séries de projeções do elemento de textura.

Un total de 15 experimentos (10 para texturas randômicas e 5 para periódicas) foram realizados para comprovar a eficiência desse modelo. Os principais objetivos no caso de texturas randômicas eram: classificar a textura de acordo com a forma do ponto, ordenar os sons derivados de imagens com mesmo ponto de diferentes tamanhos e associar uma innagem texturizada com o som gerado. Já no caso de texturas periódicas, o objetivo era verificar se os mapeamentos tinham uma associação natural com as imagens e se as funções de mapeamento possibilitavam a ordenação de imagens de acordo com as variações em seus parâmetros.

Devido ao fato de que a derivada enfatiza as componentes de alta-freqüência de um sinal, foi utilizada a derivada das projeções com a intenção de se obter uma melhora na análise dos sons. Porém, os resultados mostraram que a apresentação de sons sem o uso cla derivada levarn a uma melhor performance que com o uso da derivada. Isso ocorre por que a operação de derivação resulta em sinais co muito ruído e difíceis de serem analisados.

Outros resultados mostram que ritmo, freqïência e duração são facilmente identificados con periodicidade lorizontal, vertical e tamanlıo do ponto, respectivamente.

5 na rede mundial de computadores sem tanta dependência em

Esse capítulo apresentou um estudo sobre os sons, suas propriedades e a maneira que eles podem ser utilizados como auxílio à tarefas computacionais, e em especial à visualização científica. 
Algumas dificuldades são encontradas na utilização do som èm sistemas computacionais. A principal delas é a falta de padrões que permitam que sistemas sonoros funcionem en diferentes plataformas.

Como alguns outros problemas ainda a serem resolvidos, e estudos a serem realizados na área de sonificaçăo, pode-se citar: a necessidade de se garantir que os dados sejam ouvidos corretamente e seguramente como sons; o efeito que a sonificação exerce sobre unna cleterminada tarefa (seus benefícios e desvantagens); a quantidade de treinamento de usuários antes que uma sonificação possa se tornar útil; o nível de aceitação dos usuários com a utilização do display sonoro; e a necessidacle de ferramentas mais simples de se utilizar e mais acessfveis a un maior número de usuários.

$\Lambda$ pesar de seus łlesafios, a área de sonificação tende a continuar sua tendência de clcscrivolvimcuto nos próximos anos, principalmente no contexto de visualização, interfaccs e ambicntes virtuais. Para isso, os aspectos de visualização distribuŕda e na Internet, cliscutidos no próximo capítulo, são de extrema importância. 


\section{Capítuld 3}

\section{Visualização Distribuída e na Internet}

A área da visualização de dados vem crescendo muito nos últimos anos. Porém, alguns dos fatores que ainda impedem o seu desenvolvimento são sua falta de popularização', problemas de interação dos usuários com os sistemas de visualização existentes, e o custo de armazenamento de grandes quantidades de dados e de processamento de rendering complexo en tempo-real [1]. Estudos recentes buscam soluções para esses problemas através do uso de recursos de visualização distribuída e também a visualização na WWW.

A distribuição de recursos (dados, simulação e processamento) em rede, tarefa desempenlıada pela visualização científica, aparece como uma tentativa de solucionar o probleına de sobrecarga de recursos na máquina do usuário [35]. Assim, um usuário que está trabalhando com um фonjunto de dados muito grande pode armazenar e acessar esses dados em diversas localidades diferentes. Nos casos em que os recursos computacionais de um usuário não são suficientes para processos de visualização, computadores externos mais poderosos podem oferecer os recursos necessários para que esses usuários possam utilizar seus processos de visualização.

A idéia de se poder acessar dados, e até mesmo sistemas de visualização, localizados remotamente em qualquer lugar do mundo, aparece como uma tentativa de solucionar alguns dos problemas da área de visualização de dados citados, como o acesso a sistemas de visualização [1] Através da evolução das tecnologias de visualização na WWW, os usuários e pesquisadores não ficam limitados a somente acessar informações sobre técnicas e estudos em visua|ização, mas também a interagir, tirar suas próprias conclusões e ainda discutir e compart: 1 har seus resultados com outros pesquisadores de todo mundo.

Este capítulo discute maneiras através das quais se pode utilizar recursos de distri- 
buição e programação na Web para tornar o campo de visualização mais acessível, interativo e poderoso. O objetivo é selecionar um conjunto de ferramentas para tornar esses recursos disponíveis no contexto do DSVol (capítulo 4).

A seção 3.1 apresenta um esquema de classificação para arquiteturas distribuídas. A seção 3.2 descreve um modelo que indica como as diversas etapas da visualização de dados podern ser analisadas através de um paradigma distribuído. A seção 3.3 apresenta técnicas e ferramentas para a realização de visualização na WWW, e a seção 3.4 apresenta alguns recursos disponíveis atualmente na área de distribuição.

\subsection{Arquiteturas Distribuídas}

A World Wide Web é basicamente um sistema cliente/servidor e sua tecnologia permite a execıção de visualizações combinadas no cliente e no servidor, garantindo algumas vantagens e desvantagens a ambas as abordagens.

Do ponto de vista de cliente/servidor, as aplicações e técnicas de visualização distribuida podem ser divididas em duas classes principais: a fat client e thin client [35]. Essa classificação é feita de acordo com a maneira como são implementadas as interaçōes entre o cliente e o servidor.

\subsubsection{Thin Client}

Un exemplo de clieute Internet atual é o browser, que funciona como um visualizador clas informações contidas en umn servidor. Um verdacleiro cliente de Web não é capaz de executar programas a inenos que os programas executáveis sejam "baixados" para esse cliente na forma de Plug-Ins ou Componentes de Web. A esse tipo de clientes, é dado o nome de clientes thin. Uin cliente thin, por definição, possui requerimentos mínimos de software necéssários para funcionar como uma interface para uma aplicação com suporte a $W e b[35]$.

Um cliente do tipo thin falha sobretudo na parte de interação do usuário com a visualização. Nesse tipo de cliente, os dados ficarn armazenados no servidor e a função do cliente é solicitar a execução de um programa de visualização localizado no servidor. Com isso, o cliente perde em controle e capacidade de interação corn as imagens e animações produzidas. A vantagem é que os resultados podem ser vistos por qualquer cliente sem a necessidade de hardware ou softuare especiais. 


\subsubsection{Fat Client}

Dá-se o nome de cliente fat às aplicações de visualização distribuída onde o cliente é responsável por grande parte do processamento para que sejam realizadas as visualizações. Assim, tanto o software quanto os dados devem estar localizados no cliente. O principal problema dessa técnica é a dificuldade de transmissão de grandes conjuntos de dados via Internet, já que o seryidor não sabe o que o cliente irá fazer com os dados. Adicionalmente, o cliente pode não ter memória ou mesmo poder de processamento suficientes para executar a visualizaçấ. A vantagem desse tipo de técnica é que o usuário tem um controle completo da visualizạ̧ão e pode interagir ou modificá-la da maneira que achar melhor.

As próximas seções apresentam um estudo sobre as diferentes abordagens para a execução de uma aplicação de visualização distribuída e na WWW.

\subsection{Um modelo de Referência para Visualização Cli- ente/Servidor}

Um modelo de referência para a visualização científica atual é proposto por Upson et al [33]. Este modelo vê o processo de visualização como um pipeline, no qual uma fonte de dados é alimentada, filtrada, mapeada e renderizada para criar uma imagem final. $O$ processo de filtragem seleciona os dados de interesse (por exemplo, um corte); o processo de mapeamento cria uma representação geométrica abstrata dos dados (por exemplo, um mapa de contorno); e o processo de renderização, a partir da geometria $3 D$ gerada pelo processo de inapeamento, aplica modelos de iluminação, tonalização e projeção para criar uma imagem. Esse pipeline é ilustrado na figura 3.1 e é muito útil para o entendimento do conceito de visualizaçăo distribuída e na Web. Nesse esquema, os dados são gerados pelo editor (servidor) e a magem é apresentada ao observador (cliente), porém, essa tarefa pode ser realizada de diferentes maneiras através da manipulação na forma em que são executados os processps intermediários (filtragem, mapeamento e rendering).

O restante dessa seção apresenta um modelo de referência para a visualização na $W e b$ descrito na forma de cenários de distribuição [34]. 


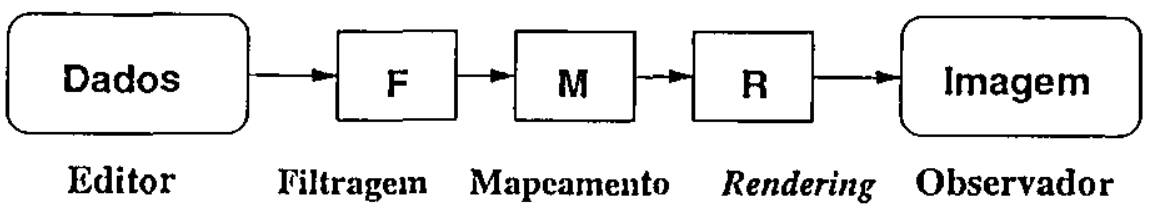

Figura 3.1: Esquema da Área de Visualização

\subsubsection{Cenário 1}

Este é o tipo de configuração mais comum em visualizações distribuídas e na $W e b$. Através dessa arquitetura, o editor executa o programa de visualização e produz como resultado uma imagem (como no cliente thin). Essas imagens são então salvas em algum formato gráfico padrão, como por exemplo GIF e JPEG, e depois transmitidas vịa rede ao cliente que solicitou a visualização. O cliente pode também solicitar algum tipo de animação, que é gerada pelo editor e também transmitida em algum formato padrão (MPEG por exemplo). Esse cenário é ilustrado na figura 3.2, interpretado em termos do modelo de referência anterior.
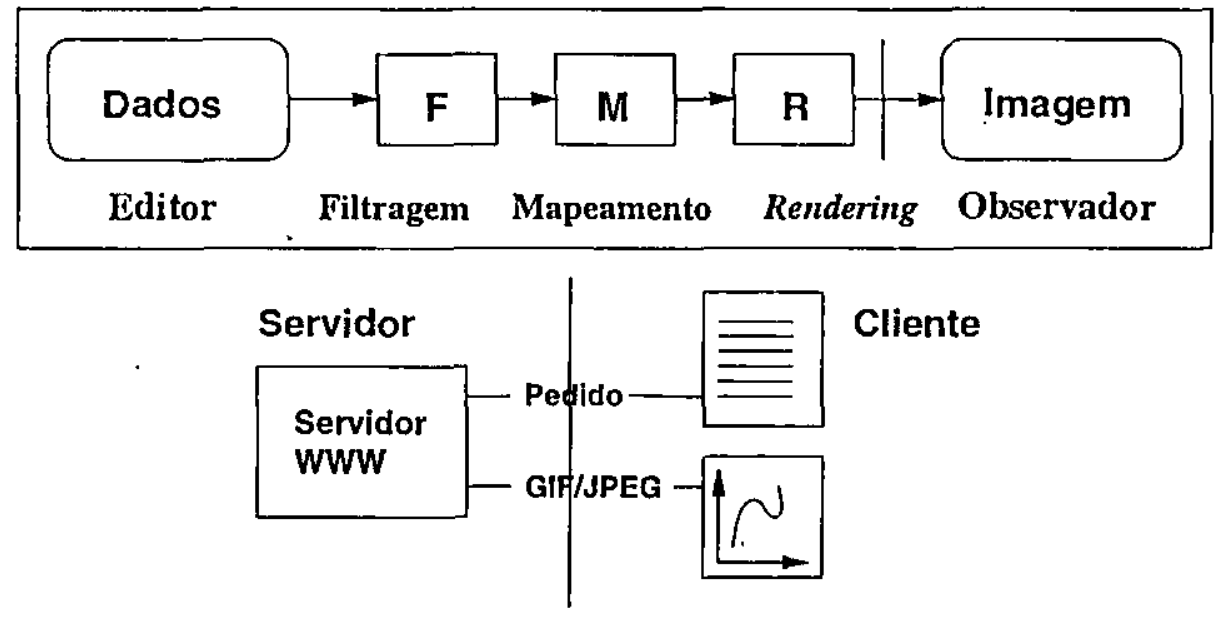

Figura 3.2: Cenário 1 - Exibindo imagens através da $W e b$

O principal problenu dessa abordagcin ć a baix interação do usuário com os resultados da visualização, já que esse fica limitado a observar as imagens e animações obtidas. Outro problema que pode ser citado é a possível demora na transmissão dos resultados obtidos na visualização atravćs da rede. 


\subsubsection{Cenário 2}

Nessa configuração o cliente ganha em capacidade de interação com a visualização gerada pelo fato do resultado obtido não mais ser transmitido como imagens estáticas, mas sim como um modelo 3D. Esse modelo pode então ser renclerizado no próprio cliente que ganha poder de navegação no modelo gerado. Esse tipo de esquema para visualização distribuída torna-se possível com a utilização de protocolo do tipo VRML, que oferece ferramentas para que o usuário renderize o modelo como desejar, além possibilitar a navegação em um espaço $3 D$. Assim, observando o modelo da figura 3.3 , o editor é responsável pela produção do modelo VRML e o observador pode interagir com o mesmo através da utilização de um browser que suporte VRML.

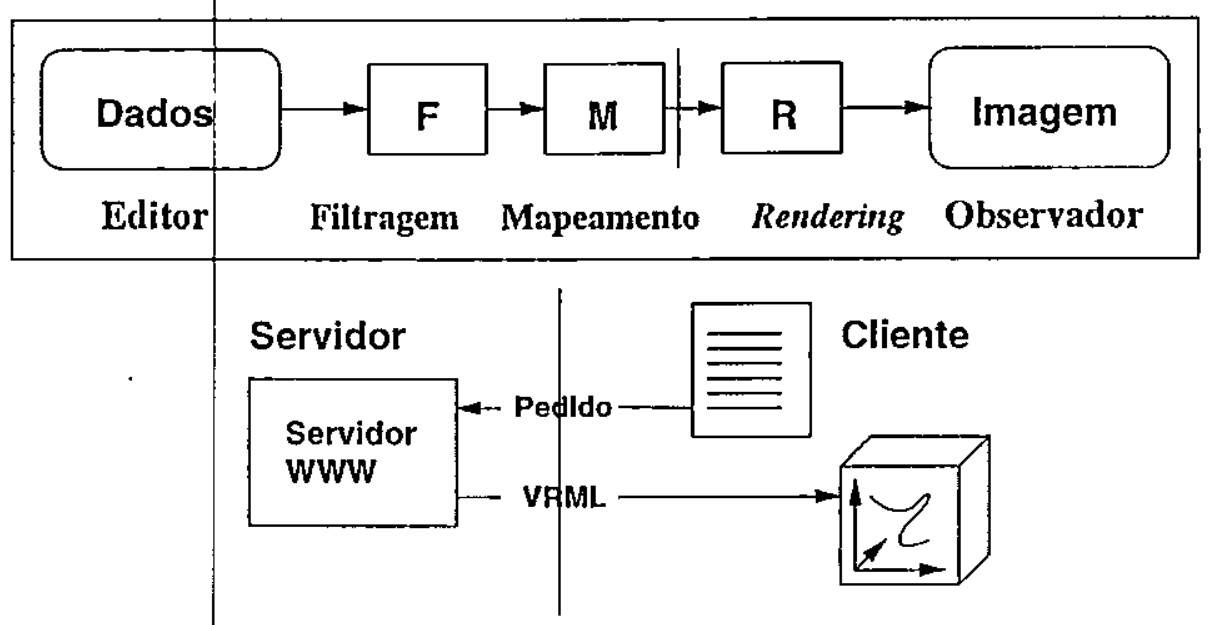

Figura 3.3: Cenário 2 - Exibindo mundos $3 D$ através da $W e b$

Apesar de garantir um maior nível de interação com o usuário, a utilização desse modelo aincla está linnitada à simples observação dos resultados na forma em que foram geraclos pelo serviclo:. Assim, o usuário ainda não é capaz de manipular os parâmetros da visualização para que um modelo adequado ao que ele necessita seja produzido.

\subsubsection{Cenário 3}

O cenário 3 corresponde basicamente a uma aplicação cliente/servidor do tipo cliente fat. Aqui, o servidor fica responsável por disponibilizar os dados sob investigação ao cliente, que executa uma aplicação de visualização e, através desta, é capaz de manipular e explorar os clados de uma forma mais eficiente e interativa. Um esquema ilustrativo é apresentado na figura 3.4 . 


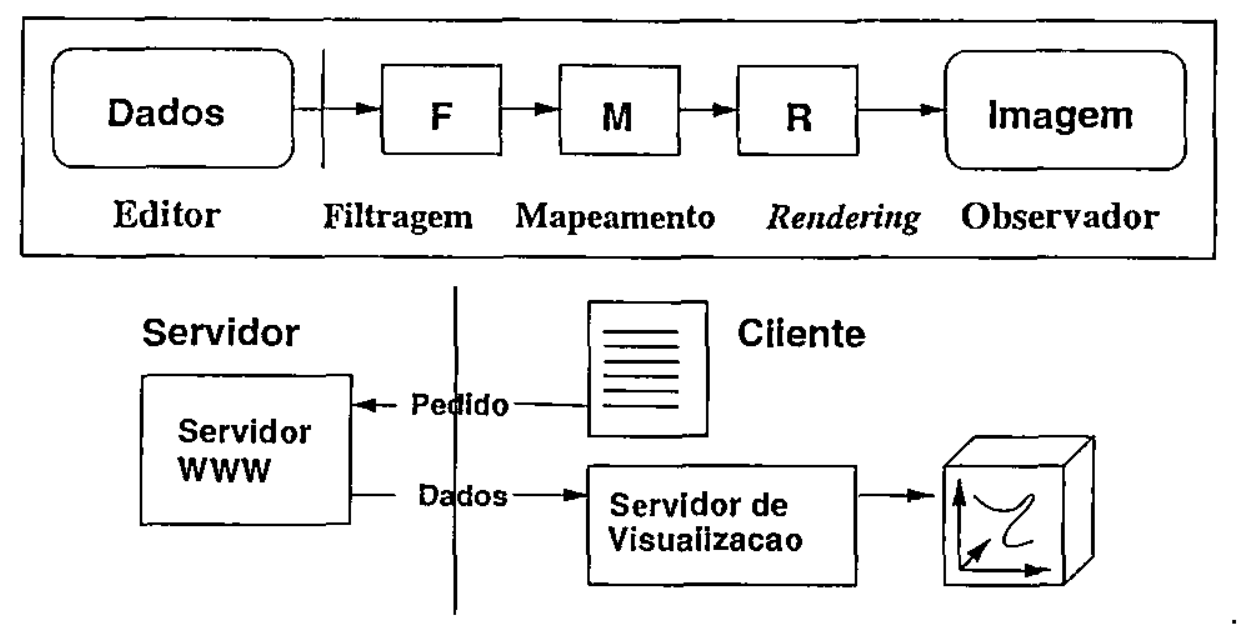

Figura 3.4: Cenário 3 - Exibindo visualizações através da $W e b$

A principal vantagem desse tipo de abordagem é a alta interação atingida entre o usuário e a visualização gerada. Uma desvantagem, porém, é o fato de que usando esse tipo de cenário, o usuário precisa executar o programa de visualização em sua máquina, que pode, em algumas ocasiōes não atender aos requisitos de memória e processamento.

\subsubsection{Cenário 4}

Os cenários anteriores atribuem a responsabilidade de criação das visualizações ao servidor (Cenários 1 e 2) e também ao cliente (Cenário 3). Porém, as desvantagens encontradas nos vários casos podem dificultar o deselıvolvimento de técnicas de visualização distribuída. Com base nisso, estudos e debates discutem se o processamento computacional deve ser centralizado e os resultados transmitidos como um serviço de rede, ou se o poder de processamento deve ser clistribuído entre os usuários finais. Isso significaria estudar um modelo que fosse intermediário entre os clientes thin e fat.

O cenćrio 4 ropresenta a alternativa de se criar esse meio termo em visualização distribuída, possibilitando a criação de um ambiente onde servidor e cliente compartilhem a responsabilidade da criação da visıalização. Esse cenário é ilustrado na figura 3.5. Aqui, o servidor é responsável por oferecer o poder de processamento e a estrutura de visualização básica apropriada para os dados relacionados, e o cliente tem um conjunto de opções (como por exemplo, um formulário HTML) para definição de alguns parâmetros da visualização. 


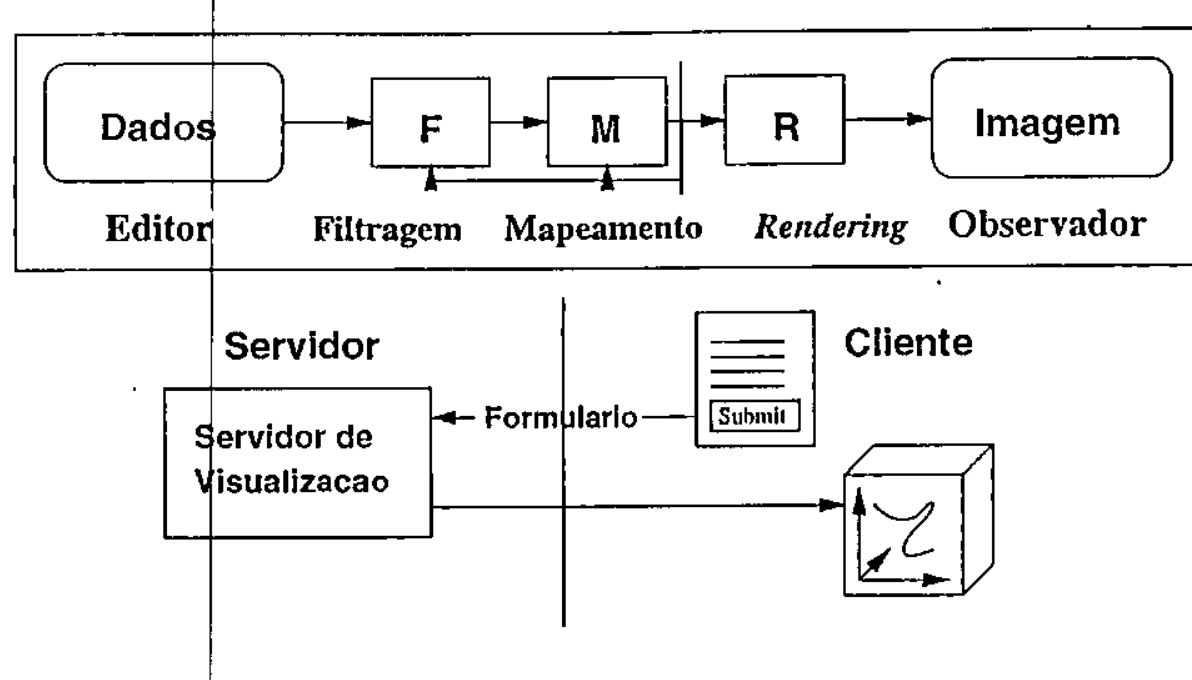

Figura 3.5: Cenário 4 - Criando visualizaçōes através da $W e b$

Nesse esquema, o pipeline é executado em um servidor, mas o controle desse pipeline fica com o cliente, que tem, assim, total responsabilidade pelo rendering da visualização.

Componentes de Web e Plug-Ins vêm sendo usados para que se possa eliminar as linitações na WWW tanto de um cliente thin quanto fat através da criação de um esquema intermediário. Como exemplo disso, pode-se citar a linguagem Java, que permite a criação de "applets" e "JavaBeans". Esses componentes, juntamente com algoritmos de redução de dados, podem ser indispensáveis para aumentar o grau de interação de dados entre o usuário e a aplicação cliente.

O modelo adotado para visualização na $W e b$, pode então estar associado a diversos esquemas de distribưição de processamento e armazenamento, tanto no cliente como no servidor.

A próxima seção apresenta algumas formas de se disponibilizar uma visualização na $W c b$, e suas linnitaçōes.

\subsection{Visualização na $W e b$}

O principal benefício introduzido pela WWW é a habilidade de troca de informações entre pessoas, em qualquer lugar do mundo, de forma mais rápida e eficiente. Assim, informações podem ser compartilhadas quase no mesmo instante em que são adquiridas. A interface gráfica dos Web Browsers permite que pessoas possam "navegar" com facilidade pcla rede acessando informações ou mesmo interagindo com uma determinada aplicação. Essa interação é uma característica desejável em sistemas de visualização. 
Esta seção tem como objetivo dar uma visão introdutória das tecnologias empregadas na $W e b$, que tornam possível a visualização pela Internet.

\subsubsection{Primórdios da Visualização na Internet}

A WWW, cuja origem remonta de dćcadas anteriores aos anos 90 , quando foram criadas a Internet c a ARPanet, ganhou a partir na década de 90 uma grande importância na vida das pessoas. Um dos principais motivos dessa popularização foi o desenvolvimento de algumas ferrarnentas visuais padronizadas para troca de informação, entre as quais podese citar os web-browsers como Mosaic, Netscape Navigator e Microsoft Internet Explorer.

$\mathrm{O}$ primeiro tipo de conteúdo a ganhar aceitação na $W e b$ foi a linguagem HTML. A linguagem HTML (Hypertext Markup Language) fornece uma maneira de formatar textos e imagens em um documento que pode ser compartilhado na $W e b$, permitindo também incluir links ativos que levam o leitor (observador) a outros documentos. No caso da visualização de dados, o uso de documentos HTML com imagens ajuda a solucionar problemas de compartilhamento de resultados, mas ainda limita o usuário a observar imagens estáticas [1].

A limitação ao uso na $W e b$ de iinagens estáticas foi resolvida com o advento de $W e b$ Browsers capazes de aceitar outros tipos de conteúdo, além de textos, imagens e links. Essas novas características incluíam suporte a formatos de animação como MPEG, AVI e QuickTime. Com esses recursos, um link em um documento HTML pode carregar um tipo de animação, inicializada de acordo com o interesse do usuário que a estará observando.

O próximo passo era o de possibilitar ao usuário controle sobre a geração da seqüência de animações no servidor. Para facilitar essa tarefa, um mecanismo de envio de inforInações do cliente ao servidor foi introduzido. O CGI (Common Gateway Interface) juntaunente com o formulário HTML, coleta informações do cliente, passa essas informações ao servidor, executa um script CGI-BIN e então envia os resultados ao cliente.

Como exemplo de utilização dessas tecuologias pode-se citar a geração de uma animação MPEG, que pocle ser ligada a documentos HTML e é visualizada pelos usuários. Essa animação pode corresponder, por exemplo, à extração de isosuperfícies em um conjunto de dados volumétricos. Maiores detalhes podem ser encontrados em [1] e [40].

$\mathrm{O}$ uso dessas tecnologias para visualização de dados compromete, principalmente, o grau de interação do usuário com suas visualizações. Assim, o tempo de espera entre uma alteração do usuário na visualização e a visão dos resultados pode ser bastante considerável, dependenclo do tamanho da animação e da velocidade de transmissão de daclos na rede. 
Algumas soluções mais atuais para a visualização na WWW são apresentadas nas próximas seções.

\subsubsection{VRML}

VRML (Virtual Reality Modeling Language) é um padrão para descrição e interação de objetos $3 D$ na Internet. VR.ML ć, de uma maneira mais simples, uma coleção de objetos arranjados em uma ordem particular. Um código fonte VRML é um arquivo em ASCII que ern geral tem a extensão .wrl, e esse pode ser editado em qualquer editor de texto [44]. Para visualizan um programa VRML é necessário um "Browser VRML", ou seja, um programa que interprete o arquivo .wrl. Existem vários browsers na rede disponíveis para este firn.

A idéia básica por trás de VRML foi criar um padrão de definição para transmissão de conteúdo $3 D$ na $W e b$. O conteúdo de um documento VRML é descarregado do servidor, e a interação com o usuário pode ser feita no lado do cliente. Com isso, tanto o problema de carga excessiva no servidor, quanto o alto tempo de interação associado à abordagem anterior de gerar animações MPEG no servidor podem ser amenizados. Muitos sistemas de visualização, incluindo o VTK - Visualization Toolkit [1], permitem a exportação de cenas para arquivos NRML.

\subsubsection{Visualização com Java}

As ferramentas discutidas até agora ilustram maneiras de se gerar visualizações baseadas na $W c b$, tanto na forma de apresentação de imagens e animações pré-construídas através cle príginus IITML como ın criação cle mundos interativos en VRML. Cada estratégia tem seus benefícios, porém falham no que diz respeito à flexibilidade dos sistemas desenvolvidos para executar tais tipos de visualização, e é aí que se destaca a linguagem Java. Essa linguagem foi projetada para traballhar em uma ampla variedade de hardware sem a necessidade de recompilação de código e com alta confiabilidade, o que garante flexibilidade. Essas qualìdades são extremamente valiosas para programação na $W e b$, onde programas devem executar em diferentes tipos de máquina sem falhas [1]. Um material completo sobre Java (tutoriais, APIs, compiladores, artigos) pode ser encontrado em [42].

Um dos tipos de programas Java, os applets, possuem a capacidade de executar a partir de browsers. Isso significa que se pode criar um applet Java e inseri-la em uma página HTML, de forma que qualquer pessoa (ou grupo seleto, dependendo do caso) possa accssar o programa. Os applcts suportam as APIs de interface gráfica do Java (janelas, 
botões, menus), que incluem diversas primitivas gráficas $2 D$. Dessa forma, a construção de programa de visualização $2 D$ na $W e b$ torna-se uma tarefa mais simples. Vale lembrar que isso pode ser aliado à capacidade do HTML de apresentar vídeos e imagens.

Eubora Java seja uma linguagem interpretada e portátil, seus projetistas perceberam a importância de ter um mecanismo para que desenvolvedores fizessem chamadas à rotinas escritas cın outra linguagem de programação. Essa interface é chamada JNI (Java Native Interface), e perınite o acesso a métodos nativos (escritos em $\mathrm{C}$ ou $\mathrm{C}++$, por exemplo). A utilização da JNI permite quc sistemas de visualização, como o VTK, possam ser utilizados com Java (e, naturalmente, com applets). Essa abordagem supre as deficiências da programação puramente Java para visualização que não provê primitivas e métodos para exploração de hardware gráfico $3 D$. A desvantagem é que JNI sacrifica a portabilidade dos programas Java. Como cliamadas à métodos nàtivos são realizadas, e esses inétodos estão ligados a um sistema operacional em particular, a característica multiplataforma deixa de existir. Mais detalhes podem ser encontrados em [1][43].

: O trabalho desenvolvido por Alves [40] é um exemplo de como se pode utilizar a linguagem Java no desenvolvimento de processos de visualização na Internet. Nesse traballı, é apresentada uma implementação que apóia a visualização interativa de dados na Internet através da criação de applets Java.

\subsubsection{Java3D}

O uso de código nativo (como por exemplo, uma implementação do VTK) em um ambiente Java fornecc un mecanismo para explorar a aceleração oferecida pelo hardware gráfico. Esse tamıém é o objetivo do Java $3 D$, que tenta produzir tal suporte como parte da API padrão de Java.

A API Java $3 D$ ainda não está consolidada, mas grande parte de sua estrutura básica já foi finalizada [1] [42]. Java $3 D$ oferece tanto rendering baseado no grafo de cena, de forma sinilar a VRML, quanto um modo de rendering imediato cle alto nível. O suporte ao modo de rendering imediato não é tão completo quanto em bibliotecas como a OpenGL, mas oferece um bom subconjunto dessa funcionalidade. Uma vantagem significativa de usar Java $3 D$ ao invés de JNI é que as applets de visualização podem ser escritas puramente em Java, sem necessidade de código nativo. 


\subsubsection{Novas Tendências}

Apesar da existência de novos tipos de dados e tecnologias, a maioria dos desenvolvedores de aplicações em visualização remota ainda faz uso de formatos padrões corno HTML, GIF e VRML [35]. A principal razão disso é a garantia de que um grande número de pessoas seja capaz de acessar essas informações e dados. O problema principal de se trabalhar com essas tecnologias é que não se pode, através delas, conseguir a renderização de visualizações em tempo-real devido principalmente a baixas velocidades de transmissão na rede e possíveis sobrecargas no servidor.

Uma maneira de interação em tempo-real com os dados é através do uso de ferramentas que dispensem o uso de mapeamentos para documentos HTML e VRML. A idéia principal dessas ferramentas é a de mover parte do processo de rendering dos dados do servidor para o cliente [35]. Algumas dessas ferramentas são os "Visualization Plug-Ins", Java applets e os controladores ActiveX.

Módulos Plug-Ins são programas escritos especificamente para rodar em um browser particular. Plug-Ins de visualização podem ser usados para permitir que o usuário (cliente) leia uma linguagem de script que controla o tipo, os parâmetros e os dados da visualização. O web-browser sabe da existência do Plug-In de visualização e o executa assim que termina de transferir os dados.

Controladores ActiveX são componentes (ou objetos) que podem ser inseridos em uma página $W e b$ ou em qualquer aplicação capaz de armazenar controladores ActiveX com o objetivo de reutilizar a funcionalidade de pacotes que já foram programados. Por exemplo, utilizando controladores ActiveX, programadores podem incrementar páginas da $W e b \mathrm{e}$ aplicações Office 97 com avançadas ferramentas de visualização $3 D$.

Essas tecnologias vêm sendo empregadas em conjunto com ferramentas de comunicação distribuída. Um resumo desse tema é apresentado a seguir.

\subsection{Recursøs de Distribuição na Área de Visualização}

A utilização de objetos distribuídos tem como principal objetivo estender a funcionalidade cle sistemas de progfamação orientada a objetos. Através da criação de componentes em ambientes de recle distribuídos, usuários podem realizar a comunicação de ou entre processos localizados numa mesina máquina ou em máquinas remotas. Assim, é possível a criação de sistemas e bases de dados que funcionem, interajam entre si e compartilhem os recursos de uma rede de computadores.

Objetos distribuídos podem ser armazenados em diferentes computadores por toda a 
rede, "trabalhando" dentro de scus próprios espaços de endereçamento e isolados de uma aplicação específica. Isso permite que diversas operações possam acessar e fazer uso das aplicaçōes implementadas nesses objetos de uma forma transparente ao usuário. Assim, usuários de aplicações distribuídas podem acessar esses componentes sem a necessidade de saber como eles foram implementados ou onde estão armazenados.

Os três mais populares paradigmas de objetos distribuídos são o DCOM, da Microsoft, o CORBA, da OMG e o Java/RMI, da Sun.

Essa seção apresenta um estudo sobre cada uma dessas ferramentas. Informações adicionais podem ser encontradas nos trabalhos [45][46].

\subsubsection{COM/DCOM}

O COM (Component Object Model) e seu sucessor DCOM (Distributed COM), desenvolvidos pela Microsoft, são metodologias para criação de componentes de software. Através do uso de COM, desenvolvedores podem criar pacotes de software que podem ser utilizados por seus clientes sem a necessidade de um grande conhecimento sobre o componente.

O DCOM, freqüentemente é chamado de "COM distribuído", suporta objetos remotos executando ein um protocolo de comunicação chamado de Object Remote Procedure Call (ORPC). A camada ORCP é construída acima da comunicação RPC e interage com os serviços run-time dos objetos COM.

Um servidor DCOM é um corpo de código capaz de servir diferentes tipos de objetos. Cada objeto servidor DCOM pode suportar múltiplas interfaces, cada uma representando um diferente comportamento do objeto. Um cliente DCOM realiza chamadas à funções, adquirindo un ponteiro para as interfaces do objeto servidor. Assim, o objeto cliente inicir umin cliamada aos métodos do oljeto servidor como se o objeto servidor residisse 120 seu espaço de endereçaınento. O fato de que a especificação COM está no nível binário, permite cuc componentes serviclores DCOM possam ser escritos em diversas linguagens como $\mathrm{C}++$, Java, Delphi, Visual Basic e até mesmo COBOL.

Se uma plataforma suporta serviços COM, DCOM poderá ser usado também. O DCOM é nestc momento bastante utilizado sobre plataforma Windows, mas tambérn há opçōes para UNIX, LINUX e plataformas mainframes.

\subsubsection{JAVA/RMI}

Remote Mcthod Invocation. RMI permite que programadores Java acessem métodos de objetos e cntão executern esses métodos em máquinas virtuais Java (JVM) localizadas 
remotamente.

Quando trabalhando com serviços remotos, clientes RMI podem acessar versōes recentes de serviços Java assim que estes se tornarem disponíveis (não laá necessidade de distribuição de código a todos os clientes que podem querer se conectar ao objeto). $\mathrm{O}$ código de um objeto pode ser acessado a partir de um sistema de arquivos local, remoto, ou mesmo através de servidores de $W e b$, o que torna sua distribuição bastante simples [45]. R.MI também possui suporte a um registro que permite que usuários façam consultas em busca de urn seryidor específico.

O diagrama da figura 3.6 mostra um esquema de comulicação entre os vários conıponentes de um sistema RMI. Clientes que sabem da existência de um serviço podem descobrir sua localização através de um registro e então acessá-lo. Se uma nova classe for necessária, ela pode ser "baixada" de um servidor Web.

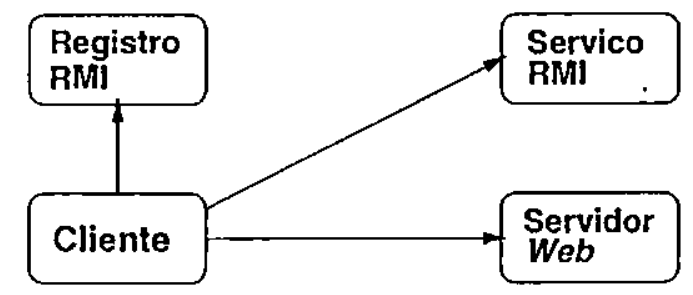

Figura 3.6: Comunicação entre objetos RMI - Adaptada de [45]

Devido à sua flexibilidade, o RMI tem se tornado uma ferramenta muito importante para desenvolvedores Java que desejam implementar sistemas distribuídos. Entretanto, a criação de uma interface entre RMI e programas escritos em outras linguagens como $\mathrm{C} / \mathrm{C}++$ ou Fortran pode ser difícil.

\subsubsection{CORBA}

O CORBA (Common Object Request Broker Arquitecture) é uma tecnologia para o desenvolvimento de sistemas distribuídos que conta com um protocolo de comunicação chamado de Internet Inter-Or $b$ Protocol (IIOP) para objetos remotos.

Todas as funções dentro da arquitetura CORBA dependem de objeto denominado Object Request Broker (ORB). O ORB age como um canal de comunicação central no qual cada objeto CORBA interage transparentemente com outro objeto CORBA localizado tanto localmente quanto remotamente. Cada objeto servidor tem uma interface e revela o conjunto de métodos que ela implementa. Para requisitar um serviço, um cliente CORBA adquire uma referência a um objeto servidor CORBA e então pode realizar as chamadas 
dos métodos na referência do objeto de maneira transparente, ou seja, como se o objeto servidor CORBA residisse no espaço de endereço do cliente.

O ORB é o responsável por encontrar uma implementação do objeto CORBA, preparando-o para receber requisições do cliente. Un objeto CORBA interage com o ORB tanto pela interface ORB quanto pelo Object Adapter (Basic Object Adapter - "BOA" ou Portablc Olject Adapter - "POA").

$O$ fato de não ser ligado a nenluma plataforma nem linguagem específica, perınite (jue o CORBA seja utilizalo em várias plataformas gue vão descle mainframes UNIX a nláquinas Windows.

A figura 3.7 mostra um esquema simplificado de comunicação entre objetos CORBA.

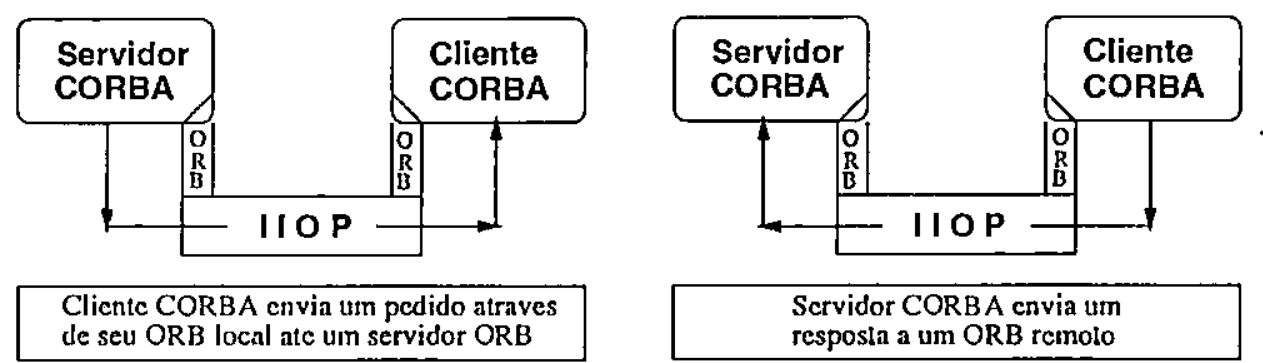

Figura 3.7: Comunicação entre objetos CORBA - Adaptada de [45]

No contexto deste trabalho foi decidido utilizar a especificação CORBA, por fornecer uma melhor adaptação às características do DSVol e do projeto PowerVis no qual ele se insere. Uma dessas características é o acesso à módulos ein $\mathrm{C}++$ a partir de código Java. Ontro fator determinante para a escolha do CORBA foi sua característica multiplataforina.

A próxima seção é dedicada à apresentação de trabalhos já realizados nas áreas de visualização distribuída e tambéin na Web.

\subsection{Sistemas de Visualização Distribuída e na Internet}

O recente crescimento da $W c b$ e necessidades de idéias e soluções distribuídas para a área de visualização incentivaram muito os estudos nessas áreas nos últimos anos. A seguir, são ą̧reseutados alguns traballios que estão sendo desenvolvidos utilizando essas abordagens.

Un traballo muito inportante para o desenvolvimento do presente projeto foi o realizado por Ahrens [37]. Esse trabalho utiliza a visualização distribuída e busca expandir 
a biblioteca VTK, utilizada neste trabalho de mestrado, para permitir processamento paralelo e distribuído, com os seguintes objetivos:

Escalabilidade: Habilidade de utilizar um número crescente de recursos computacionais para um processamento mais eficiente de grandes conjuntos de dados.

Portabilidade: Flexibilidade para a execução dos processos na plataforma nais acessível.

Funcionalidade Suporte à maioria das funções da biblioteca básica do VTK, oferecendo versões paralelas dos algoritmos disponíveis.

Abstração de Cpmplexidade: Encapsulamento dos detalhes de programação paralela e distribuição tornando a programação mais transparente e de alto nível.

Abstraçōes de processos e formas de comunicação foram adicionadas para permitir o paralelismo de tarefas, processos e dados. $\mathrm{Na}$ distribuição dos dados residentes em diferentes processos (ou processadores), foi utilizado um esquema de codificação para os objetos do VTK. Dessa forma, os objetos a serem enviados sāo codificados em strings e enviados a outros processos que então decodificam essas strings novamente em objetos do VTK. Essa idéia da "troca" de objetos do VTK entre processos através da codificação strings serviu de base para o desenvolvimento dos módulos e implementações distribuídas do presente trabalho.

Simulações para treinamento têrn sido desenvolvidas em diferentes áreas cirúrgicas, como, por exemplo, as áreas de cirurgia endo-vascular e dos olhos, entre outras. Brodlie, El-Khalili e Li desenvolveram duas aplicações em simulação cirúrgica baseadas na Web [38]. Essas aplicações utilizam Java e VRML e concentram-se nas áreas da neurocirurgia e cirurgia vascular. Em ambos os simuladores, a visualização na Web é feita utilizando EAI (External Authoring interface). A seguir são apresentados detalhes dos dois simuladores desenvolvidos.

A neurocirurgia é uma área que requer operações bastante complexas [38]. Observando isso, foi desenvolyido um simulador para o tratamento da dor facial incurável. Um tratamento aceitável é a destruição parcial da parte sensorial que provoca a dor facial, através de um aparelho cirurgicamente inserido na face do paciente. A aplicação desenvolvida permite o treinamento da marcação de pontos na pele do paciente (procedimento realizado para a determinação do ponto de inserção do aparelho), além da inserção da ferramenta cirúrgica e seu manuseio através de um furo no crânio. O simulador realiza conıbinações de três "mundos" VRML. Um "mundo" age como um painel de controle, 
manipulando a simulação de operações realizadas pelo cirurgião. Os outros dois "ınundos" VRML mostram visões do paciente: uma visão externa da face do paciente, e uma visão interna que mostra a posição cla ferramenta cirúrgica. A interação é feita através do mouse, que simula os movimentos do instrumento cirúrgico. Nesse caso, a deteç̧ão de colisões é muito importante e é realizada através da transmissão de informações da visão interna aos outros mundos VRML.

O outro simulador citado nesse traballıo [38] é o utilizado em cirurgias vasculares. Esse simulador foi desenvolvido para o tratamento de aneurisma da aorta abdominal, caso que requer um treinamento de aproximadamente 10 anos. Esse tratamento envolve a inserção cle um cateter na artéria através cle una incisão, que é então manipulado através da artéria até que encontre a aorta. Esse simulador foi considerado mais complexo que o anterior pela necessidade de modelagem da deformação do cateter em uma colisão com as paredes da artéria. Novamente, forain utilizados "mundos" VRML que contêm modelos da aorta e dos instrumentos cirúrgicos. Dessa forma, o primeiro "mundo" apresenta uma visão geral da artéria, o segundo "mundo" simula uma visão interna do cateter, um terceiro simula os movimentos que podem ser realizados pelo cateter e o último mostra fatias bidimensionais da norta, que podem ser selecionadas pelo usuário. Para esse simulador, a interação também é feita através do mouse, que simula os movimentos do cateter.

O traballıo desenvolvido no ICMC por Alves [40] citado na seção 3.3 também enfoca a visualização interativa na $W e b$. A funcionalidade clesse ambiente para visualização na WWW inclui um módulo para extração de superfícies, um módulo para a execução de rendering volumétrico direto e un módulo para visualização de campos vetoriais.

A utilização de visualização na $W e b$ para aprendizagem foi abordada por Brodlie, LoveGrove e Wood [39] em um trabalho que simulou o ensino do sistema de visualização IRIS Explorer para alunos de mestrado da Univerșity of Leeds, Inglaterra, através de applets Java. O trabalho foi desenvolvido para ser utilizado no trabalho prático do curso de "Visão, Visualização e Aunbientes Virtuais" da School of Computer Studies da University of Leeds. O motivo disso foi que essa disciplina era oferecida a alunos de mestrado de cliferentcs departamentos que, com certeza, estudavam em diferentes horários e locais. Como um primeiro passo, era fornecido aos estudantes um tutorial online que permitia - estudo a qualquer tempo ou lugar. Quando surgiam dúvidas, os alunos passavam a utilizar o aprendizado colaborativo, onde professores e alunos podiam compartilhar dados, controles, módulos e mapas. O módulo de apren dizado colaborativo utilizado nesse traballino funciona cla seguinte forma: o estudante primeiramente entra com os detalhes da visualização em um formulário apresentado via Web Brouser; os dados desse formulário 
são então passados a um servidor $W e b$ que executa um script CGI e passa os dados do formulário a um servidor de visualização; esse servidor, por sua vez, cria um mapa apropriado do IRIS Explorer para o problema. testes realizados com alunos selecionados indicaram um aprepdizado colaborativo bem sucedido.

Este capítulo apresentou alguns conceitos e ferramentas fundamentais para o entendimento e desenvolvirhento de aplicações e, mais especificamente, de sistemas de visualização distribuídos e na internet.

Os conceitos apresentados nesse capítulo foram utilizados na seleção e implementação de uma arquitetura remota e também distribuída para o SVol.

O próximo capítulo apresenta a implementação do sistema DSVol, criado como uma extensão do sistema SVol [9]. Esse sistema utiliza os conceitos e estuclos apresentados ncste traballıo na criação de um ambiente que possibilite, principalmente, a o uso do som como apoio a tarefas de visualização de dados em um sistema acessível pela internet que inclui uına versão inicial de arquitetura distribuída para sonificação e visualização. 


\section{Capítulo 4}

\section{DSVol - Implementação}

A etapa da implemẹntação do software DSVol põe em prática os conceitos de sonificação, visualização \& distribuição apresentados nesta dissertação. O objetivo principal desse sistema é o de disponibilizar ferramentas sonoras que auxiliem o entendimento e investigação de dadớs apresentados em uma forma multi-modal (gráficos e som simultaneamente). Além disso, outras características importantes ao sistema são: o acesso remoto, que possibilita que pessoas de diversas localidades tenham acesso às funções implementadas, e também a aplicação de conceitos de processamento distribuído a algumas partes do sistema, como por exemplo, o módulo de geração de sons e uma parte do módulo de geração de imagens.

O DSVol pode ser dividido, em linhas gerais, em duas grandes partes: a sonificação e a visualização. A visualização faz uso da biblioteca VTK [1] e a sonificação faz uso da SoundTools, uma biblioteca de geração de sons implementada também em projeto desenvolvido no ICMC-USP. A biblioteca. VTK foi apresentada no capítulo 1 e a Sound'Tools será esclarecida no decorrer deste capítulo.

No DSVol, existem dois tipos principais de sonificação: aquelas associadas unicamente a mapcamentos gráficos, e aquelas ligadas à interação do usuário com o sistema (que podem estar associadas aos dados, operações ou mesıno gráficos). O primeiro tipo, chamado de sonificação passiva, é "tocado" durante a formação e apresentação dos gráficos. Nesse tipo de sonificação, o usuário não interfere no processo sonoro, exceto para cancelá-lo. No scgundo tipo de processo de sonificação, os sons são produzidos em resposta a ações clo usuário, que exarpina e busca informações particulares no conjunto de daclos ou nos gráficos.

No sistema foram implementados 3 processos de sonificação de dados que poclem ser clnssificarlos da forma ajresentada acima. Esses processos são apresentados neste capítulo, 
juntamente com os demais módulos implementados no DSVol. A seção 4.1 apresenta uma introdução à implementação do sistema. O módulo do sistema que cuiclam das tarefas de interface de entrada de parâmetros com o usuário (interface indireta) é apresentado 11a seção 4.2. As inlplementaçõcs dos métodos de visualização, sonificação e interação direta com o usuário são descritas nas seções $4.3,4.4$ e 4.5 respectivamente. A seção 4.6 apresenta uma implementação do sistema na internet. Um estudo da implementação distribuída de um módulo de sonificação e um de visualização são apresentados na seção 4.7 .

\subsection{Implementação do DSVol - Visão Geral}

A etapa cle implementação do sistema foi destinada à extensão da implementação anterior (SVol) desenvolvida em um projeto de mestrado [9] para um ambiente orientado a objetos organizado de forma a distinguir módulos de interface indireta, visualização, sonificação e interação do usuário com os sons e imagens gerados. Essa subdivisão do sistema possibilita uma nelhor organização do código e, principalmente, futuras alterações e extensões de cada módulo de forma independente.

Alén da extensão na funcionalidade das funções já existentes na primeira versão do SVol [9], novas técnicas de visualização e sonificação foram incluídas ao sistema. Neste traballıo também foram implementados novos métodos que facilitam a interação do usuário com o sistema e possibilitam uma exploração mais eficiente dos dados. Uma explicação mais detalliada sobre as técnicas e métodos incluídos em DSVol pode ser encontrada no decorrer do capítulo.

Uma outra característica importante introduzida no sistema foi a capacidade de gerar sons e imagens mapeando diferentes características dos dados. Isso permite que o som possa ser utilizado de forma ambígua, reforçando o tipo de informação apresentado visualmente, ou como uma op̧̧ão para o mapeamento de informações adicionais na exploraçã̃o dos dados. Detalhes sobre tal capacidade podem ser encontrados nas seções que descrevem os módulos de visualização e sonificação do sistema.

$\mathrm{Na}$ implementação do DSVol foi utilizado o software $\mathrm{C}++$ Builder $4.0 \mathrm{da}$ Borland, juntannente com as funções de visualização do VTK 3.1. O C++ Builder foi escolhido como o ambiente de programação por ser un compilador bastante conhecido e testado para a linguagem $\mathrm{C}++\mathrm{e}$, principalmente, por facilitar a criação da interface do sistema conl a usuário. Para a compilação do código em $\mathrm{C}++$ de $\mathrm{DSV}$ ol acessado a partir do nódulo para internet fni ntilizado o compilador MS Visual $\mathrm{C}++$. 
A versão atual do DSVol permite a visualização e sonificação de escalares armazenados em malhas regulares (vtkStructuredPoints). Os tipos de visualização implementados no sistema são: a extração de isosuperfícies e o rendering volumétrico direto. No módulo de sonificação, o sistema implementa três processos distintos, que são o Display Progressivo (sonificação passiva), a Sonda Sonora (sonificação "ativa") e o Display de Malha (que mapeia diretamente os valores de dados para sons).

Dessa forma, o sistema o DSVol foi dividido em quatro módulos distintos: o módulo de interface indireta, o módulo de visualização, o módulo de sonificação e o módulo de interação com o usuário (interface direta). A organização geral do sistema é descrita a seguir.

O módulo de interface indireta é implementado na classe TParam que funciona como a função principal do sistema (main). Assiun, este módulo é responsável pela passagem de parâmetros de entrada selecionados pelo usuário ao resto do sistema. Para realizar tal tarefa, a classe TParam possui objetos responsáveis pela comunicação com os módulos de visualização e sonificação do sistema.

O módulo de visualização do DSVol é composto de três classes. A primeira é a classe SV_Visual quc funciona como uma classe pai para os métodos de visualização em DSVol. O método de extração de isosuperfícies é implementado na classe SV_Visual_Iso derivada a partir de SV_Visual e contém métodos e variáveis que geram a visualização das isosuperfícies definidas pelo usuário através da interface de entrada de claclos do sistema. O segundo método de visualização em DSVol é o de rendering volumétrico direto. A implementação dlesse método é feita na classe SV_Visual_DVR, também derivada de SV_Visual.

O módulo de son ificação é composto por quatro classes. A primeira delas é a classe SV.Sound que servel como classe pai para as demais classes cle sonificação. Essa classe possui objetos que se comunicam com a biblioteca de sons SoundTools responsáveis pela definição dos parânetros de som (como o timbre) e também pela reprodução dos sons gerados através das soțificações. A classe SV_Sound possui um objeto da classe SV_Visuab, responsável pela realização da comunicação entre os módulos de visualização e sonificação. Essa "ligação" entre módulos é fcita através do método Set_Sender (SV_Visual*) que passa para a classe \$V_Sound um ponteiro para o objeto de visualização que estará sendo executado. A seggunda classe do módulo de sonificação é a classe SV_Sound_Coord que deriva de SV_Sound e implementa o método do Display Progressivo em DSVol. A classe responsável pela implcinentação da Sonda Sonora é a classe SV_Sound_Probe que também deriva de SN_Sound. A última classe do módulo de sons é a SV_Sound_Grid que 
implementia o método do Display de Malha e assim como as demais classes de sonificação, deriva de SV_Sound.

: Para o módulo de interação em DSVol foram implementadas quatro classes. A primeira delas é a classe SV_Interactor, que deriva da classe vtkWin32RenderWindowInteractor clo VTK. Objetos da classe SV_Interactor são criados em módulos de visualização sem a presença de sonificação. As demais classes de interação do DSVol derivam de SV_Interactor e foram criadas para implementar a interação para cada um dos métodos de sonificação clo sistema. Organizado dessa forma, o sistema implementa a interação para o Display Progressivo na classe SV_Interactor_Coord, para a Sonda Sonora em SV_Interactor_Probe c para o Display de Malha em SV_Interactor_Grid.

Assin, cada nétodo de sonificação em DSVol possui uma classe que o implementa. Dentro de cada uma dessas classes, e de acordo com o método que a classe implementa, é criado um objeto responsável pela interação do usuário com a sonificação e passado para esse objeto um ponteiro para a classe de sonificação que o criou. Isso é feito através do método Set_Sender () implementado em cada uma das classes de interação de DSVol.

Por trás de um método de sonificação tem-se sempre um método de visuạlização associado. Assim, na implementação de uma sonificação em DSVol deve-se primeiro criar um objeto de visualização e, a esse objeto, associar a sonificação através do método Set_Sender () implementado nas classes do módulos de sonificação.

Uin esquema das clesses do DSVol e da maneira com que elas estão organizadas no sistema é apresentado na figura 4.1.

As próximas seções são destinadas à descrição detalhada de cada um dos módulos do DSVol.

\subsection{Módulo de Interface Indireta}

Para o DSVol, foi implementada uma versão para a interface indireta em Java e uma versão "stand-alone" em $\mathrm{C}++$ com as mesmas funcionalidades. As figuras apresentadas nessa seção mostram a interface Java do sistema.

No DSVol foi implementada uma interface unificada que fornece ao usuário opções para entrada e manipulação clos parâmetros de sonificação e visualização do sistema. Através dessa interface o usuário pode abrir o arquivo de dados em estudo, definir parâmetros de som e controlar a visualização e sonificação que deseja utilizar (ver figura 4.2). Os parâmetros de som que podem ser alterados em DSVol são o timbre e o intervalo de frequiência dos sons tocados (figura 4.3). $\mathrm{Na}$ parte de sonificação pode-se escolher entre 


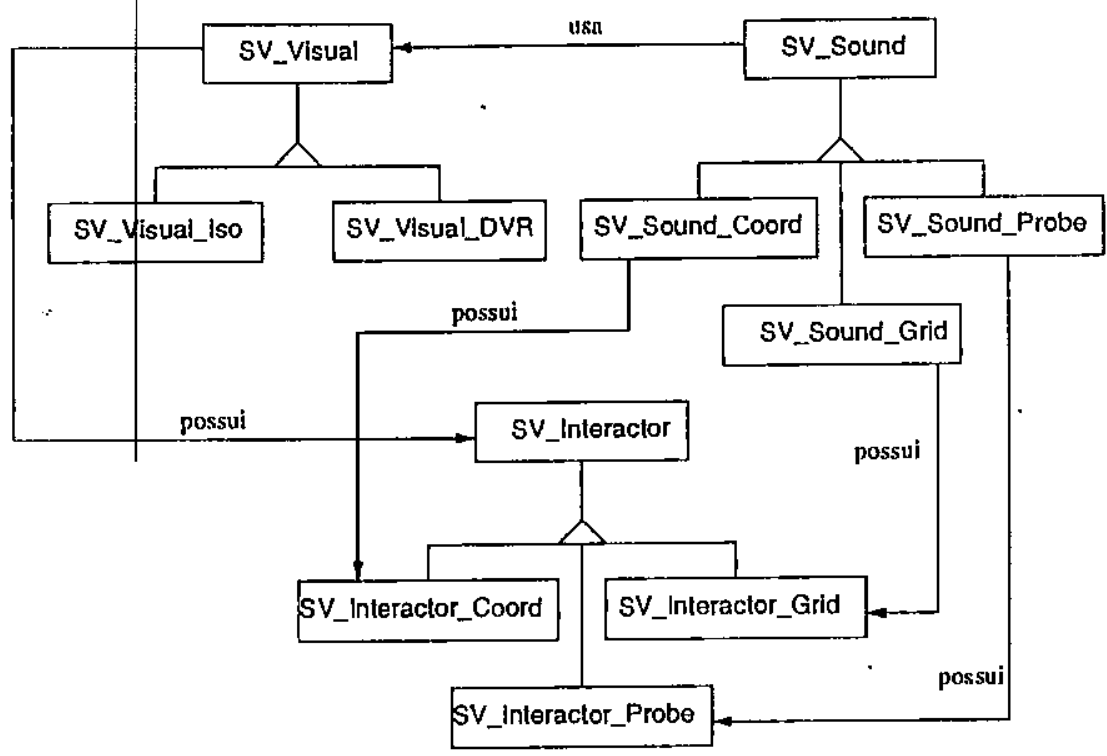

Figura 4.1: Esquema Geral de Classes de DSVol

os 3 métodos de sohificaçāo disponíveis (Display Progressivo, Sonda Sonora ou Display de Malha), cada um com parâmetros específicos. A parte de visualização possui os métodos de extração cle superfícies e de rendering volumétrico direto. Através da interface, o usuário pode optay por gerar a visualização acompanhada ou não de sonificação. 


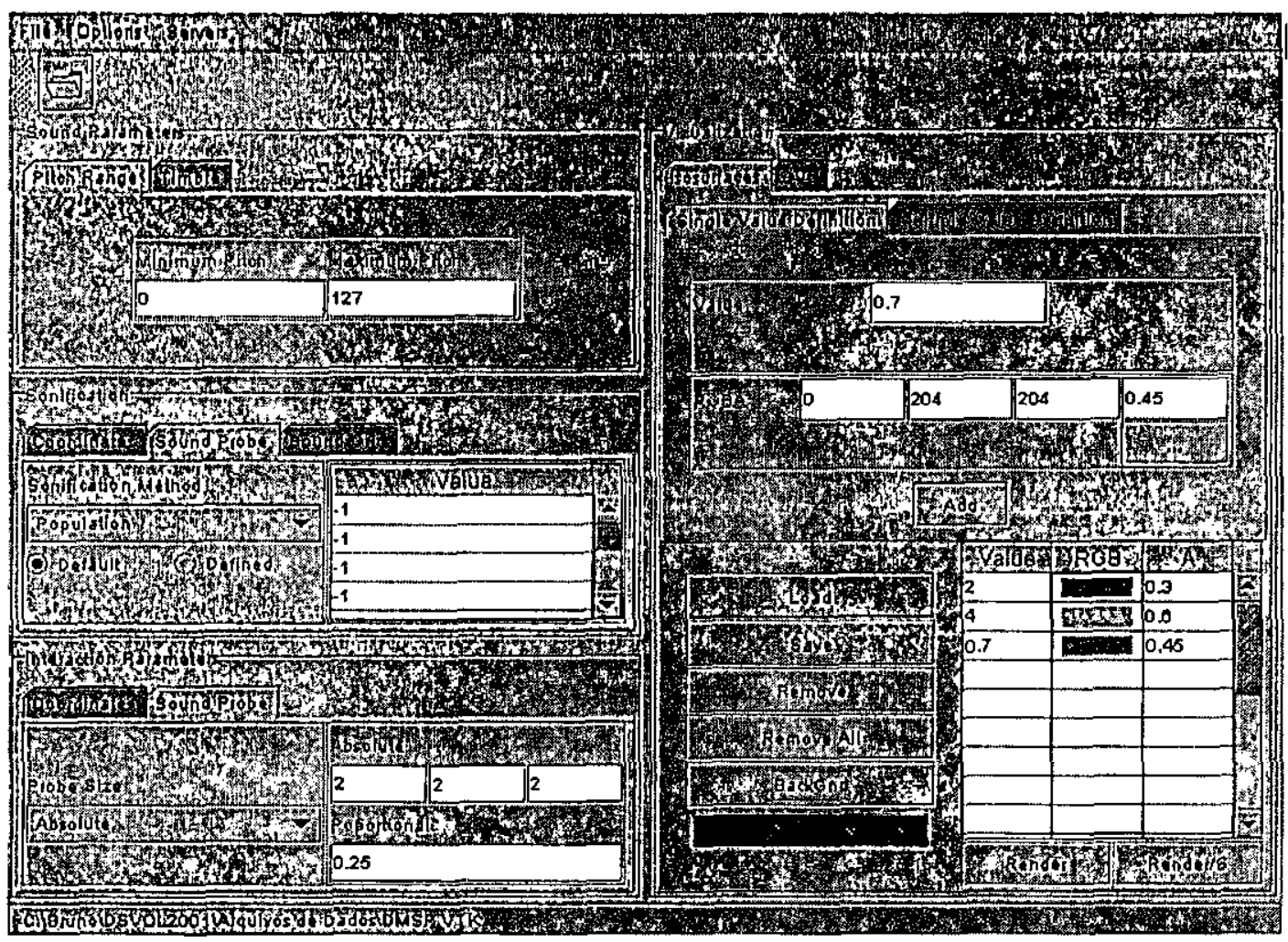

Figura 4.2: Interface de Entrada de Parâmetros de DSVol

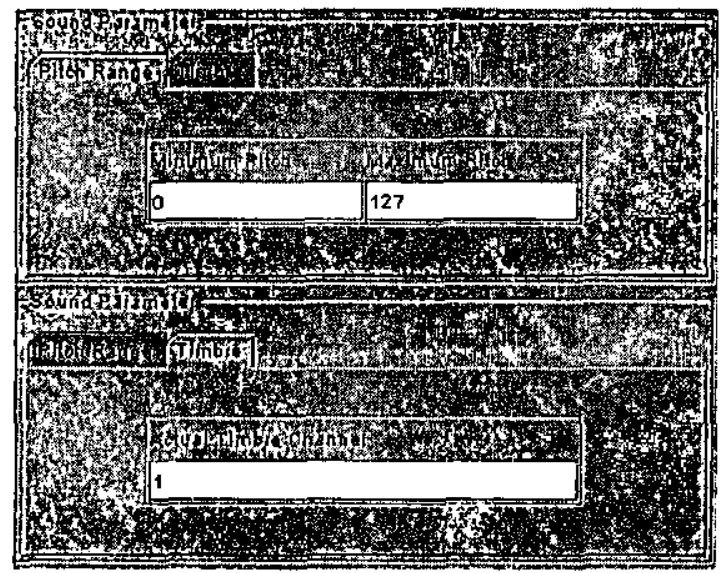

Figura 4.3: Interface de Definição de Parâmetros de Som

Como já foi dito, a interface indireta pode ser vista como o módulo principal do sisteına. A classe a que implementa ć a TParam. Nessı classe, estão incluídos objetos responsáveis pela execução de todos os tipos de visualização e sonificação em DSVol, além das funções c objetos que cuiclan dn "cintura" e tratamento de eventos provenientes do usuário (como clique do mouse em um botão). 
$\mathrm{Na}$ execução de um determinado processo de visualização e sonificação pelo usuário, sẽo instanciados objetos em TParam responsáveis por implementar tal processo. Depois clisso, os parâmetros de entrada escolhidos pelo usuário são "capturados" e "enviaclos" a esses objetos. A partir daí é realizada uma chamada aos objetos que implementam a visualização e sonificação para que essas sejam executadas. O pseudo-código incluído na tabela 4.1 demonstrá como é realizada a chamada a uma visualização de isosuperfícies juntamente com sonificação através do Display Progressivo.

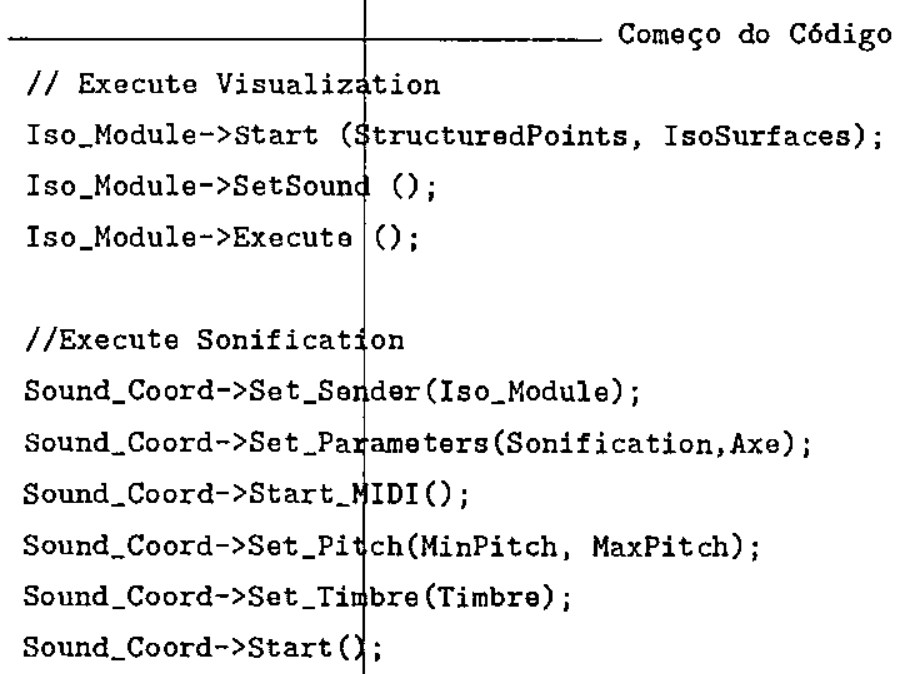

Tabela 4.1: Pseudo-Códligo - Visualização com Sonificação em DSVol

Detallies de corno atuam no sistema e quais os parâmetros que podem ser clefinidos e manipulados podem ser encontrados nas seções 4.3 e 4.4 .

\subsection{Módulo de Visualização}

Esse é o módulo responsável pela criação das visualizações no sistema. Nessa classe estão definidas variáveis e implementadas funções comuns a todas as classes e métodos de visualização no DSVol. A classe SV_Visual foi implementada como una classe pai para as clcmais classes que implementam os métodos de visualização, e possui um objeto do tipo SV_Interactor (seção 4.5) quc é responsável pcla intcração do tısuário com a cena. de visunlização (com recursos como rotação e zoom). A definição completa da classc SV_Visıal pode ser chicontracla no arquivo SV_Visual_Kcrnel.lı contido no apêndice $\Lambda$.

Cada mét.odo de visualização foi implementado como uma subclasse de SV_Visual. Organizado dessa forma, o sistema permite que novos métodos de visualização sejam 
adicionados de forma mais simples, aunentado assim sua funcionalidade.

Atualmente, existein duas técnicas de visualização implementadas como classes do DSVol: uma para extração de superfícies de interesse e uma para rendering volumétrico direto.

\subsubsection{Extração de Isosuperfícies}

A classe SV_Visual_Iso inplementa o método de extração de superfícies de interesse apresentado no capítulo 1. Nesse método, para cada valor de interesse definido pelo usuário é geracla uma isosuperfícic que corresponcle a esse valor clentro do conjunto de dados. A essa superfície é atribuída uma cor e opacidade. A extração das isosuperfícies em DSVol utiliza a classe vtkContourFilter do VTK. A forma através das quais as superfícies de interesse são definidas e os parâmetros que podem ser acessados pelo usuário na geração da visualização foran totalmente redefinidos e reimplementados em relação à versão anterior do sistema. Un dos motivos para isso foi a utilização da nova versão do VTK (3.1 em relação a 1.3 da versão anterior de DSVol). Outro motivo para isso foi a necessidade de adequar o sistema à especificação em módulos proposta para sua implementação. $O$ pseudo-código da extração de isosuperfícies é fornecido na tabela 4.2.

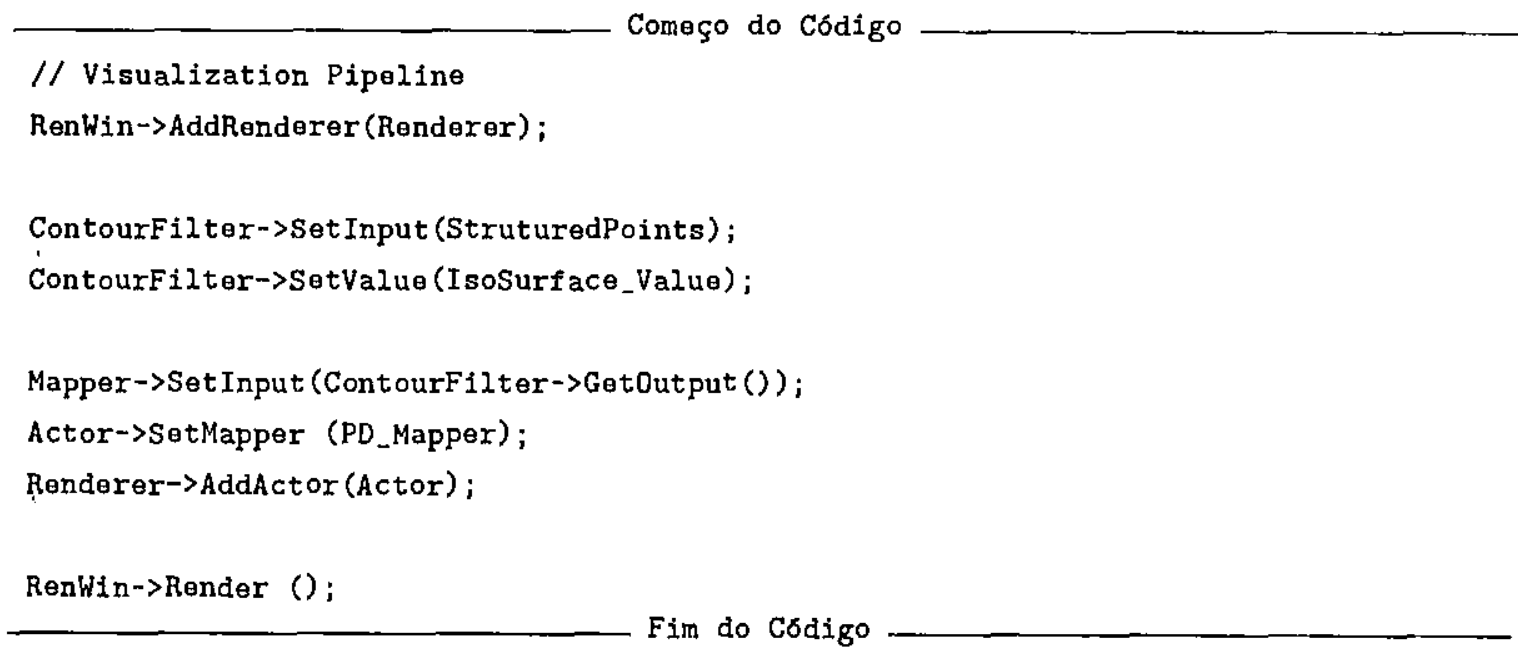

Tabela 4.2: Pseudo-Código - Isosuperfícies

A interface indireta para esse tipo de visualização permitè que as isosuperfícies sejarn definidas de duas formas distintas: uma através da cspecificação de um valor específico e outra através da cspecificação de un intervalo de valores. (figura 4.4). Na primeira, para cada valor de interesse deve ser especificada uma cor e opaciclade. A segunda forma 
perunite a especificadão de $u$ m intervalo de valores de iuteresse, onde o usuário espccifica $11 n$ valor inicial, un linal, a quantidade de valores que descja gerar ucsse intervalo e a opacidacle das isosuperfícics. Dentro de SV_Visual_Iso, a cor de cacla isosuperfície definida conno un intervalo de valores é mapeada em corcs através de uma tabcla de cores do VTK. O usuário tambćn pode, atravćs da interface de entrada de parâmetros para o mćtodo de isosuperfícics, def̣inir a cor-cle-fundo para a visualização.

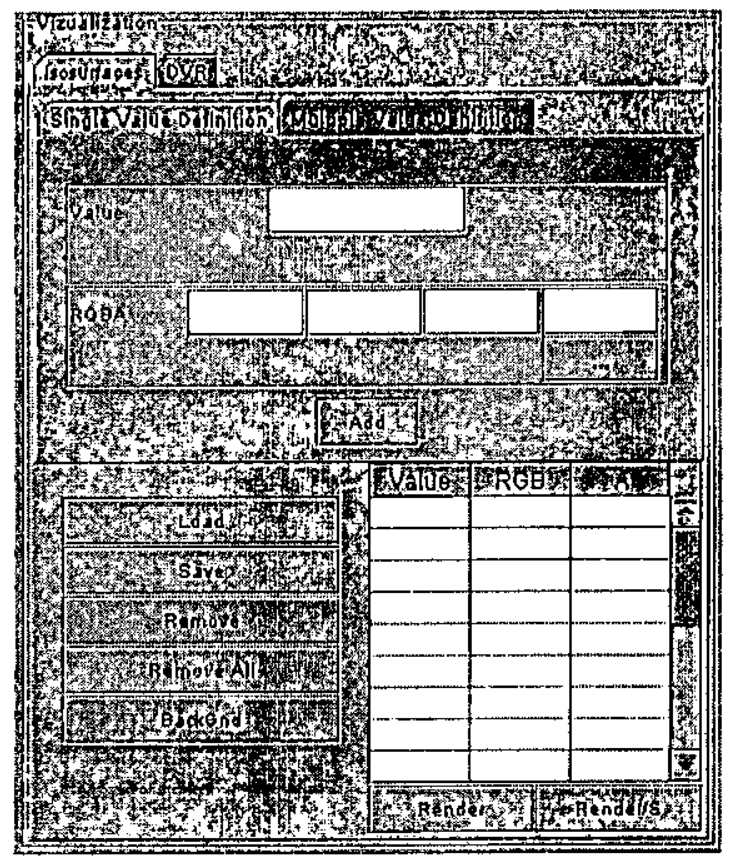

Figura 1.4: Interface do Mćlodo Visualização de Isosuperlícies

Uma nova opsǘ insericla cu DSVol foi a capacidade do usuário salvar c carregar os parânetros de visualização definiclos (valores de interesse e cores R.GBA), o que é

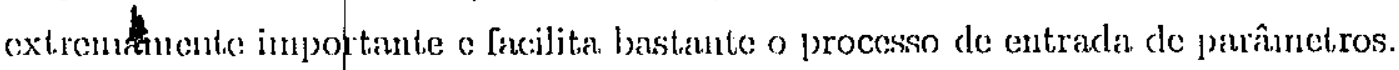

Os principais mótodos de SV_Visual_Iso são aprescutados na tabela 1.3. Sua defunição completa pode ser encontrada no arquivo SV_Visual_lso.h, listado no a.pêrudicc $\Lambda$. 


\begin{tabular}{|l|l|}
\hline Método & Descrição \\
\hline \hline Start () & $\begin{array}{l}\text { Utilizado para passagem de parâmetros para a visualização } \\
\text { de isosuperfícies }\end{array}$ \\
\hline Execute () & $\begin{array}{l}\text { Método que executa o pipeline de visualização e renderiza a } \\
\text { cenia contendo as isosuperfícies definiclas pelo usuário }\end{array}$ \\
\hline Free () & $\begin{array}{l}\text { Método que libera a memória alocada pelo método Execute } \\
0\end{array}$ \\
\hline
\end{tabular}

Tabcla 4.3: Principais Métodos de SV.Visıal_Iso

Uma visualização cle isosuperfícies gerada pelo DSVol pode ser observada na figura 4.5 .

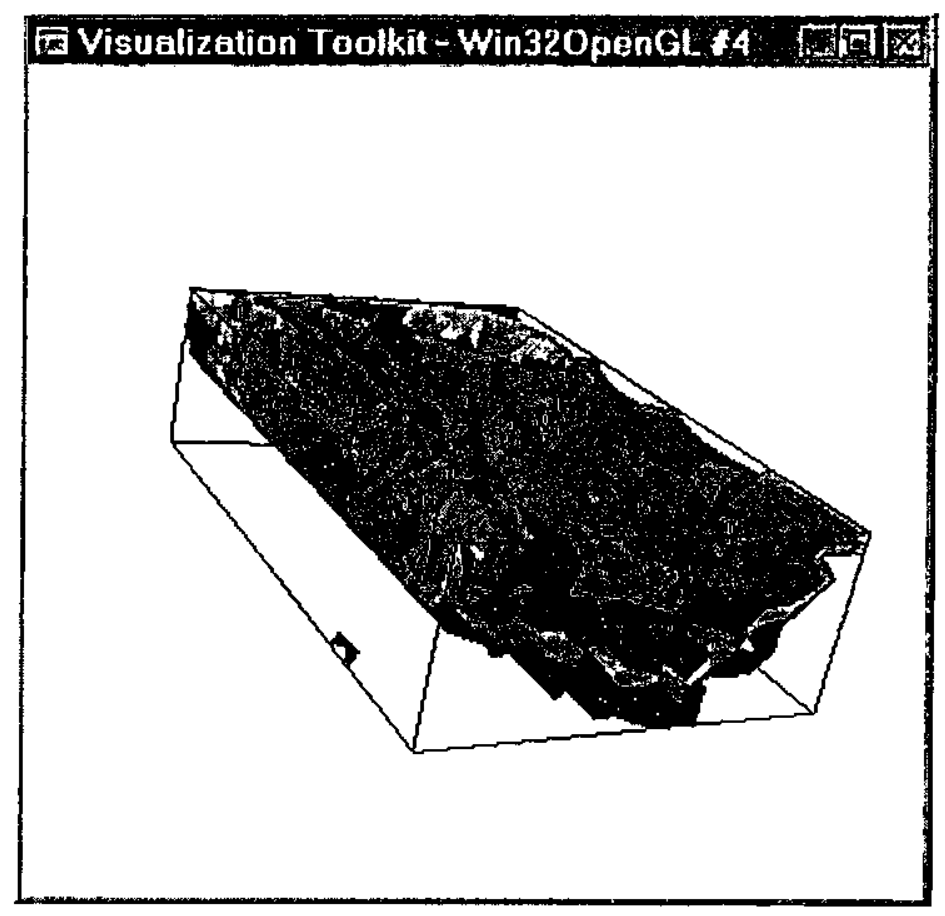

Figura 4.5: Visualização de Isosuperfícies

\subsubsection{Rendering Volumétrico Direto}

O método de rendering volumétrico direto (apresentado no capítulo 1) é implementado na classe SV_Visual_DVR e não estava presente na implementação anterior do sistema. Pelo fato cle nño criar estruturas geométricas intermediárias como na extração de superfícies, csse método permite ao usú́rio visualizar estruturas do volıme de dados ausentes na extração de isosuperfícies. O método de rendering volumétrico direto adicionado foi o 
de disparo de raios (ray-casting). Esse método consiste em traçar raios que cortem o volume de dados para cada pixel la tela, colhendo informações de cor e opacidarle para a coloração desse pixel. A implementação deste método utilizou algumas funções do VTK e foi realizada como mostra o pscudo-código da tabela 4.4 .

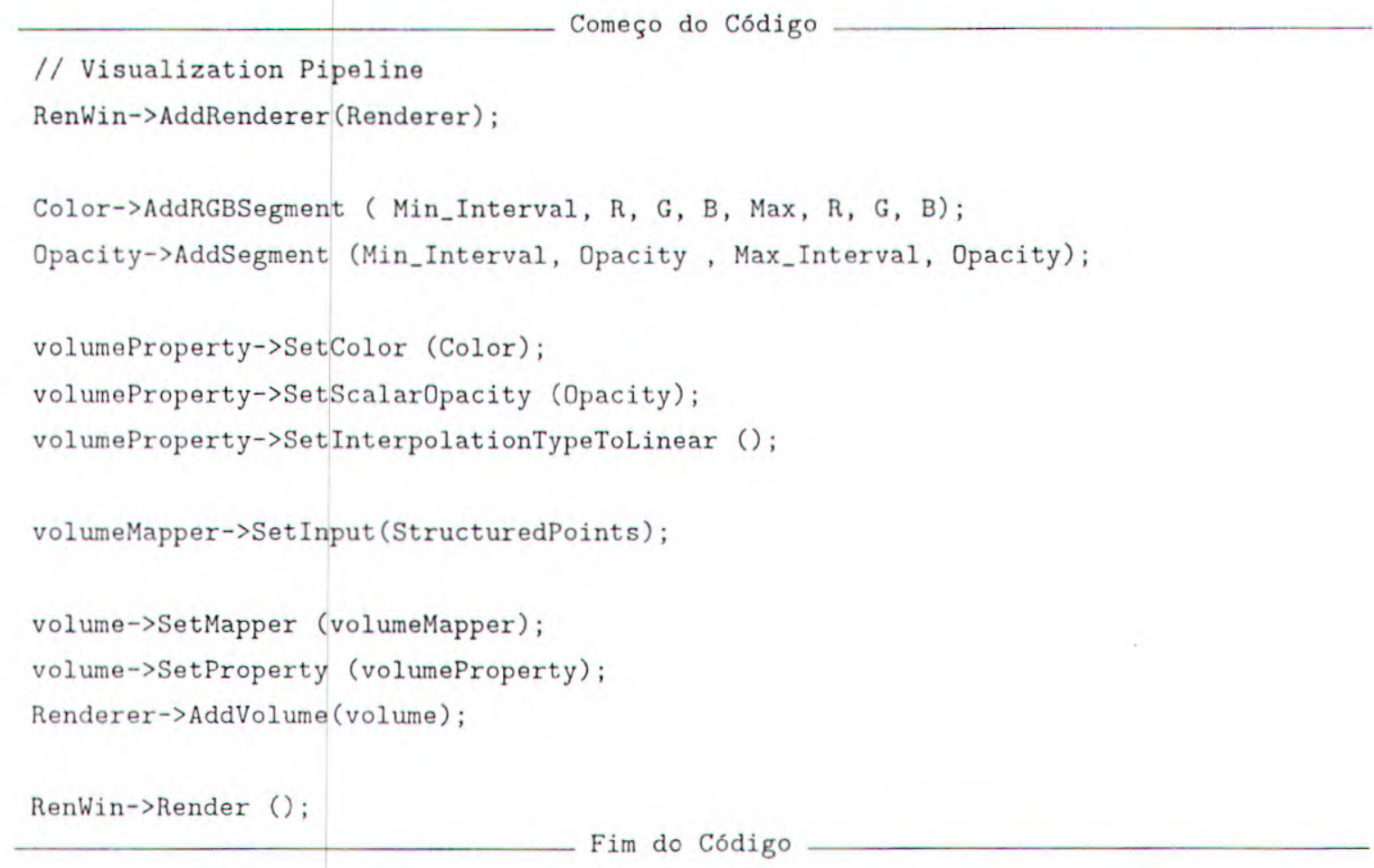

Tabela 4.4: Pseudo-Código - Rendering Volumétrico Direto

\section{Uso da Placa VolumePro}

Dentro da classe SV_Visual_DVR também foi implementado o rendering volumétrico direto utilizando o hardware da placa VolumePro (da RTVIZ - http://www.rtviz.com). Para utilizar os métodos do VTK que fazem acesso a essa placa, é necessário que o código seja compilado juntamente com a biblioteca "vli.lib" distribuída juntamente com a placa VolumePro. Outro arquivo necessário para a utilização da VolumePro é o arquivo "vli.dll" que deve estar presente e acessível em algum diretório do sistema operacional (como c: \windows \system). $\mathrm{O}$ acesso às funções implementadas na VolumePro é feito através de um mapeador do VTK denominado vtkVolumeProMapper. Una das principais vantagens de se utilizar recursos de hardware como a VolumePro para realização do rendering volumétrico é o enorme ganho em velocidade de rendering e, consequientemen-

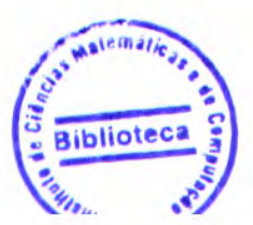


t.c, o ganlo na velocidade de interação do usuário com a visualização e também com o processo cle sonificação.

O módulo de interface indireta para o método de ray-casting permite que o usuário defina intorvalos de valores dentro do conjunto de dados. Para cada intervalo, deve scr especificada uına cor RGB e una opacidade (figura 4.6). O usuário também pode, através clessa interface, definir a cor-de-fundo para a visualização. Assim como no método de isosuperfícics, o usulúlio ć ciupaz de salvar e carregar os parâmetros de visualização definidos (intervalos de interesse e corcs RGBA). Unna outra característica incluída en DSVol é a capacidade do usuário definir parâmetros de iluninação da cena e de espaçamento entre os raios traçados (figura 4.7 ).

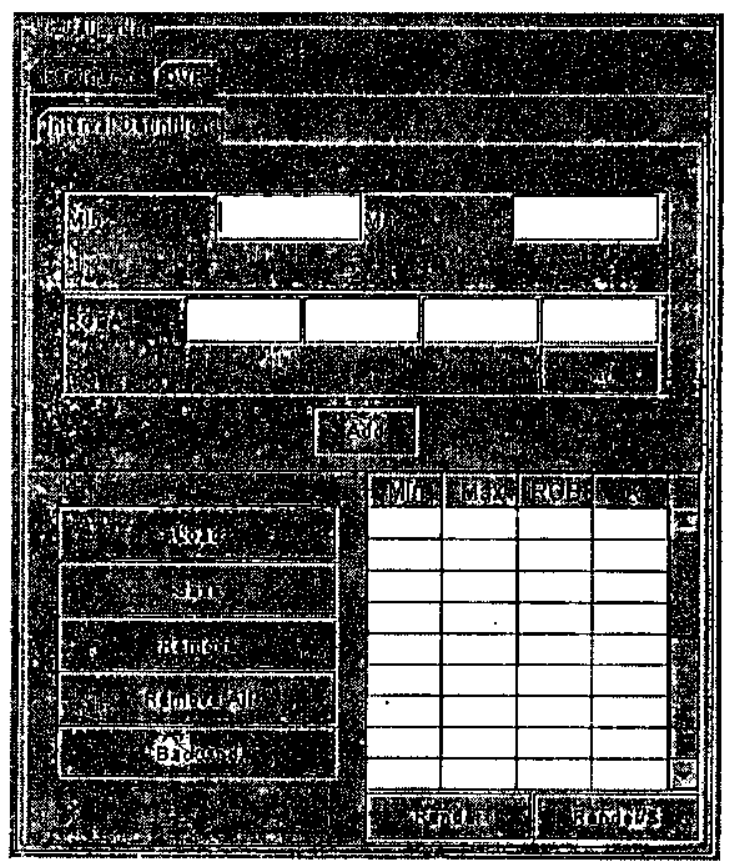

Figura 4.6: Interface de Visualiza.ç̃̃o através do Método de Rendering Volumétrico Direto 


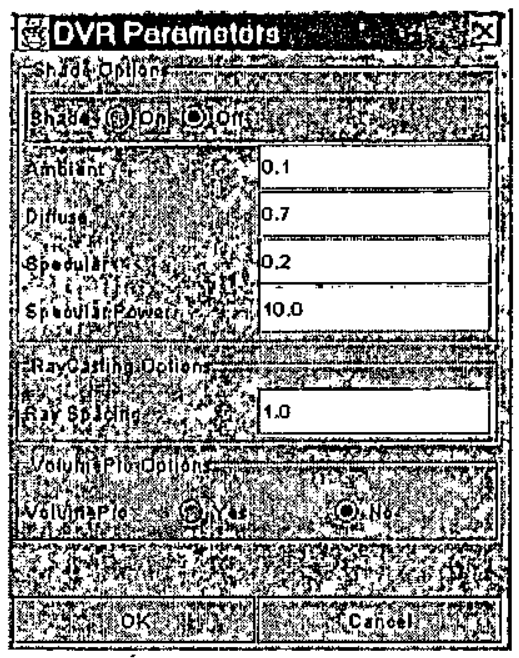

Figura 4.7: Defuição de Parâmetros para o Rendering Volumétrico Dircto

Unı visualizaçăp gerada alravés desse método ć apresentada na figura 4.8. Os principitis métodos de SVEVisual_DVR são apresentados na tabela 4.5. Sua definição completa pode ser encontracla no arquivo SV_Visual_Kerucl.h contido no apêndice $\Lambda$.

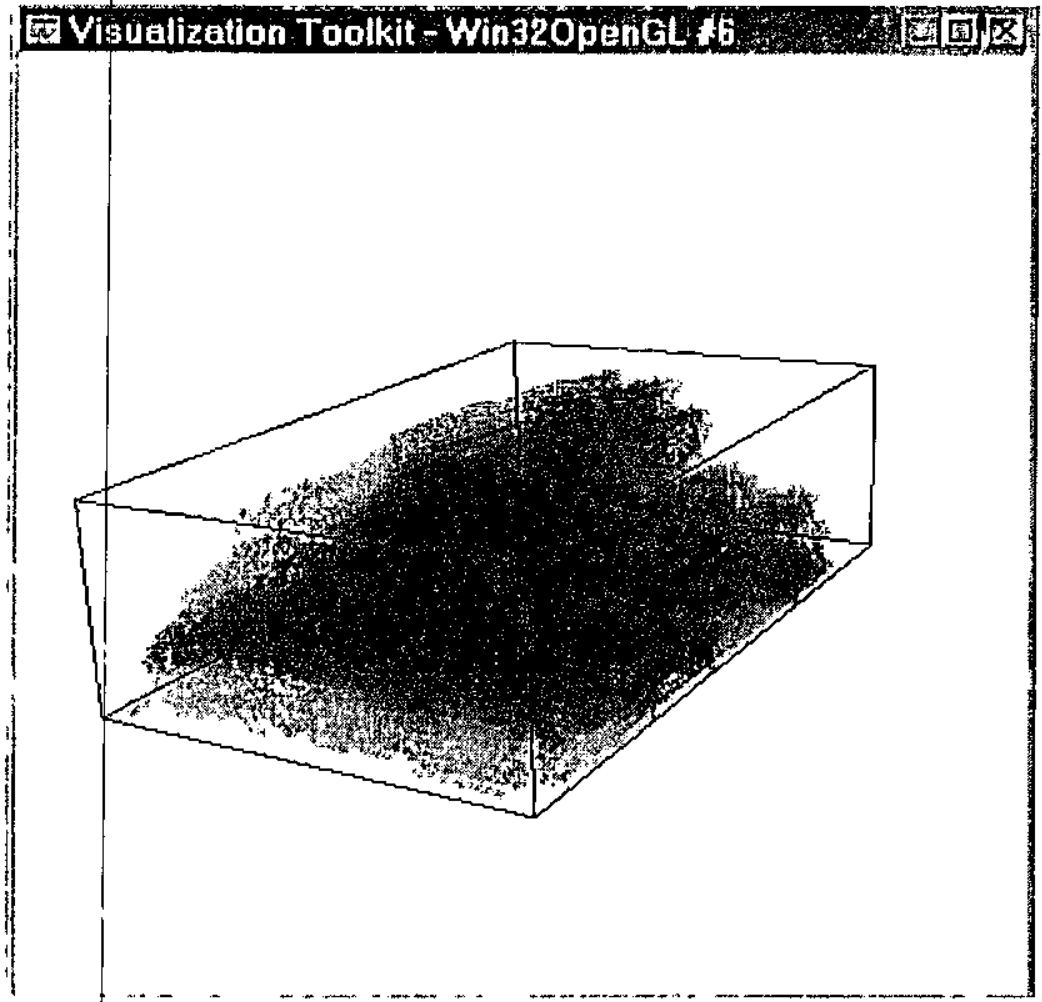

Figurn 4.8: Rendering Volumétrico Direto 


\begin{tabular}{|l|l|}
\hline Método & Descrição \\
\hline \hline Start () & $\begin{array}{l}\text { Utilizado para passagem de parâmetros para a visualização } \\
\text { através do rendering volumétrico direto }\end{array}$ \\
\hline Scalar_Convcrsion () & $\begin{array}{l}\text { Método que converte os cscalares armazenados no conjunto } \\
\text { de dados do tipo float para o tipo unsigited short, para que } \\
\text { possa ser realizada o DVR }\end{array}$ \\
\hline Execute () & $\begin{array}{l}\text { Método que executa o pipeline cle visualização e renderiza a } \\
\text { cenis através do DVR. }\end{array}$ \\
\hline Free () & $\begin{array}{l}\text { Método que libera a memória alocada pelo método Execute } \\
\text { () }\end{array}$ \\
\hline
\end{tabular}

Telbela 4.5: Principais Métodos de SV_Visual_DVR

A seguir, são apresentadas as classes e funções de sonificação implementadas em DSVol.

\subsection{Módulo de Sonificação}

Assin como no módulo de visualização, a parte do sistema que cuida da sonificação possui uma classe chamada SV_Sound responsável por implementar métodos e variáveis comuns ฉn todas as demais classes de sonificação de DSVol. Cada uma dessas classes é, por sua vez, responsável por implementar um dos métodos de sonificação utilizados no sistema.

A classe SV_Sound é a responsável por criar e manipular os objetos através dos quais serão reproduzidos os sons em DSVol. Para isso, a classe possui um objeto do tipo INITIALISATION_CALIBRATION. Através desse objeto a classe SV_Sound é capaz de accssar a biblioteca sonora (SoundTools) e reproduzir os sons gerados pelos métodos de sonificação. Detalhes sobrc a biblioteca SoundTools são apresentados no decorrer deste capítulo.

Através de um objeto da classe SV_Visual contido em SV_Sound é realizada a comunicação entre os módulos de sonificação e de visualização. $\mathrm{Na}$ classe SV_Sound está implementado o método Set_Sender (SV_Visual*) responsável por atribuir ao objeto de visualização de SV_Sound o endereço do objeto visual criado. A definição completa dessa classe pode ser encontrada no arquivo SV_Sound_Kernel.h contido no apêndice A.

Cada un dos métodos de sonificação em DSVol é implementado em uma classe derivada de SV_Sound c possui um objeto responsável pela interação do usuário com a sonificrção e visualização. Esse objeto é descrito na seção 4.5.

As próximas seções são destinaclas a apresentar os vários elementos de sonificação descritos acima. Inicialmcnte, a biblioteca utilizada pelo sistema na construção dos sons 
nota, e taunbén "tocar" várias notas de várias formas. Além clisso, também é possível realizar o controle de canais, timbre, volume e silêncio.

Maiores detallies da reprodução de sons cin DSVol podem ser encontrados em trabalhos anteriores desenvolvidos pelo \$rupo de pesquisa [9][8].

As próximas seções são destinadas à apresentação e descrição de cada um dos métodos de sonificação implementados em DSVol. No final da seção é apresentado um resumo das sonificaçōes implementadas nq sistema (tabela 4.9).

\subsubsection{Display Progressivo}

Nesse processo, a sonificação dos dados depende e é sincronizada com a formação dos gráficos na tela. A parte gráfica foi insplementada de forma que o volume de claclos seja apresentado por partes e fenderizado em uma direção escollida pelo usuário. Dessa fornn, "fatiits" do volume sĩo apresentadas consecutivamente enquanto sonificações são calculadas e apresentadas. Esşe tipo de sonificação permite que o usuário observe a cena conforme ela vá se formando sẹm que sua atenção seja desviada do processo gráfico, o que aumenta sua capacidade de interpretação dos dados.

A figura 4.9 ilustra o processo Display Progressivo. Ela mostra um conjunto de daclos que representam valores de gases específicos medidos no Mar do Norte por um certo periodo de tempo. A coorclenada $X$ representa longitude, $Y$ representa latitude e $Z$ representa o tempo. Nessa figura, fatias clos dados são mostradas sucessivamente na clireção $X$ (ou seja, longitude). 
(SoundTools) é apresentada.

\subsubsection{Síntese de Som em DSVol}

A construção dos sons quc representam informações em DSVol é implementada por uma biblioteca que realiza a comunicação MIDI construindo pacotes de sons e comandos, e fornecendo o mapeamento de valores para parâmetros sonoros. Essa biblioteca é implementada por um conjunto de classes (Single_Stream, Multiple_Stream, Mapping, Kernel e Initialisation_Calibration), que são usadas por processos de DSVol para realizar as sonificações.

MIDI (Musical Instrument Digital Interface) é uma especificação criada com o objetivo clc pachronizar a forma de rcprodução de sons entre diversos sistemas de síntese cle sons. O uso de MIDI para controlar equipanentos de síntese sonora fornece um bom grau de generalização para os algoritmos de síntese com a garantia de uma boa qualidacle de reprodução a um custo razoável [3].

Para realizar as construções de sons em DSVol, foram utilizadas as implementações das bibliotecas SoundTools e MIDIKernel implementadas em SSound [4]. Essas bibliotecas estão descritas nos próximos tópicos.

\section{MIDIKernel}

Essa biblioteca é a responsável pela construção de pacotes de mensagens MIDI e de parâmetros que sejam aceitos pelo módulo sonoro. A MIDI Kernel implementa funções que realizam a inicialização e finaljzação da comunicação coin o dispositivo MIDI, a definição dc un pacote coun meusagens MIDI, a inclusão de mensagens em um pacote já inicializado, a definição de um canal inicial, e o envio de mensagens.

\section{SoundTools}

Um sistema sonoro foi desenvolvido para fornecer um número de objetos com operações sonoras básicas, aléłn de cstruturas sonoras para apoiar os processos de sonificação. Esse sistema gerencia a comunicação entre os processos de sonificação e a classe MIDI Kernel, além do timbrc e do status dos componentes sonoros e das suas temporizaçõcs. Através da utilização desses objetos pode-se realizar várias funções em DSVol, entre elas, fazer o mapeamento de valorcs para freqüências, calcular correspondência de acordes, gerar distribuiçño do canal estéreo, mapear valores numéricos para propriedades do som (como distorção de entouação), "tocar" uma nota por um curto período, iniciar ou finalizar uma 

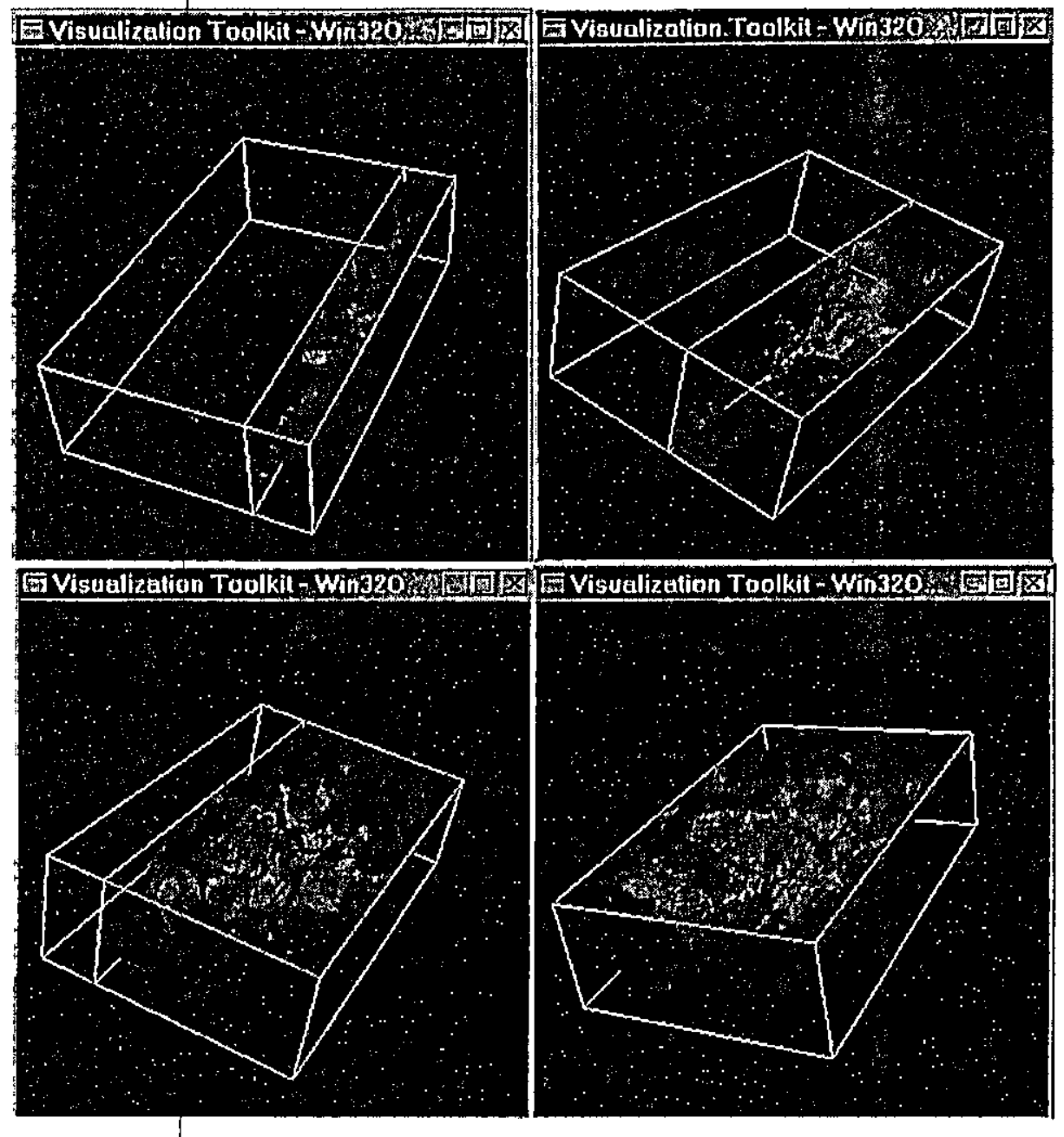

Figura 4.9: Sonificação de Coordenadas

No sistema DSVol, todas as sonificaçõcs passivas são implementadas através do Display Progressivo. Una dessas sonificações é a sonificação de coordenada, onde uma das coordenadas dos pontos apresentados é mapcada para sons durante a apresentação das fatias do volume.

Atualmente, dois tipos de sonificação de coordenada estão implementadas en DSVol.

Una dclas sonifica valores máximo e mírimo de coordenadas para uma fatia do volume (cabendo ao usuário escolher qual a coordenada a ser sonificada; $x, y$ ou $z$ ). O processo de sonificação consiste $\mathrm{cm}$, para cacla fatia do volume de dados apresentada na coordenada escolhida pelo ustúrio, percorrer o plano do volume correspondente a esse valor calculando os valores mńximo e inínimo desse plano.

Assiın, conforme as fatias vão sendo apresentaclas, valores máximo e mínimo da conrdenada sclecionada tão sendo mapeados cm valores de frcqüência (quanto maior o valor, 
Inaior a frequiência). Com isso, o usuário pode ter noção, pelo som, dos intervalos de valores presentes nas "fatias" e de sua progressão [4].

A segunda forma de sonificação no processo de Display Progressivo é a sonificação da coordenada corrente (cin um mapeamento para freqütência), onde o som apenas marca o início de uma nova fatia do volume. Isso aumenta a noção de referência do usuário.

As funções do Display Progressivo estão implementadas na classe SV_Sound_Coord que é derivada da classe SV_Sound. A interação do usuário com a sonificação gerada por um objeto dessa classe é realizada através do objeto de interação da classe SV_Interactor_Coord incluído em SV_Sound_Coord (ver seção 4.5). Os principais métodos de SV_Sound_Coord são apresentados na tabela 4.6. A definição completa dessa classe pode ser encontrada no arquivo SV_Sound_Coord.h incluído no apêndice A.

\begin{tabular}{|l|l|}
\hline Método & Descrição \\
\hline \hline Start () & $\begin{array}{l}\text { Utilizado para inicialização do objeto de sonificação, de in- } \\
\text { teração e para a conexão entre os objetos de som e visual }\end{array}$ \\
\hline Sonify () & $\begin{array}{l}\text { Método chamado a partir do objeto que realiza a interação } \\
\text { do usuário com a sonificação, cuja função é a de realizar a } \\
\text { chamada à sonificação escolhida pelo usuário }\end{array}$ \\
\hline Coord_Sonification () & $\begin{array}{l}\text { Método que implementa a sonificação de coordenadà corren- } \\
\text { te }\end{array}$ \\
\hline MinValue_Sonification () & $\begin{array}{l}\text { Método que implementa a sonificação do valor mínimo de } \\
\text { uma fatia do volume de dados }\end{array}$ \\
\hline MaxValue_Sonification () & $\begin{array}{l}\text { Método que implementa a sonificação do valor máximo de } \\
\text { uma fatia do volume de dados }\end{array}$ \\
\hline
\end{tabular}

Tabela 4.6: Principais Métodos de SV_Sound_Coord .

$\mathrm{N}$ a apresentação do volume de dados em "fatias" para esse método de sonificação, foi utilizado o filtro vtkStructuredPointsSubVolume desenvolvido como uma derivação das çlasses de filtros do VTK em um projeto de iniciação científica no ICMC-USP. Esse filtro possibilita a criação de um subvolume que corresponde a uma parte do volume de dados original. O filtro vtkStructuredPointsSubVolume recebe como entrada uma estrutura de dados do tipo pontos estruturados (vtkStructuredPoints), que representa o volume total de dados. Para realizar a definição do subvolume é utilizado o método SetExtent $(x \min$, $x$ max, $y$ min, $y \max , z \min , z \max )$, que gera como saída um subvolume que mantém a organização original dos pontos estruturados.

A interface indireta, que define os parâmetros para o Display Progressivo é apresentada 
na. figura 1.10. Através dessa interface ć possível que o usuário escollia qual o métoclo de sonilicaçāo a ser utilizado e também a coordenada a ser sonificada. A definição do valor cle incrcmento para a apresentação clas "fatias" pode ser feito através cla especificação de valores absolutos on relativos, como mostra a interface apresentada na figura 4.11.

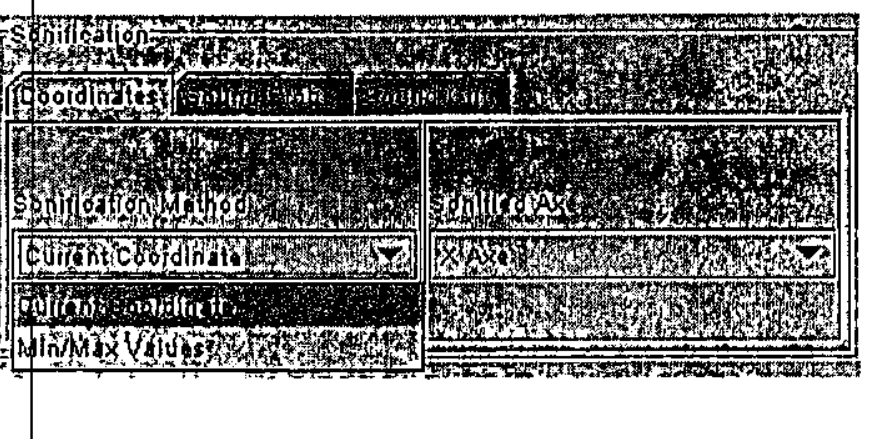

Figura 4.10: Interface do método de Sonificação de Coordenadas

Figıra 4.11: Intcrface de definição de incremento para o Display Progressivo

$\Lambda$ próxima seçĩo tlescreve os processos de sonificaçẽo associados à Sonda Sonorâ.

\subsubsection{Sonda Sonora}

O segundo proccsso \$ráfico em DSVol é o da Sonda Sonora. Nesse processo, um bloco de limuauho vautível é insericlo no volune (figura 4.12) com o objetivo de collıer informações e aprescutrí-las na fołma de som. 


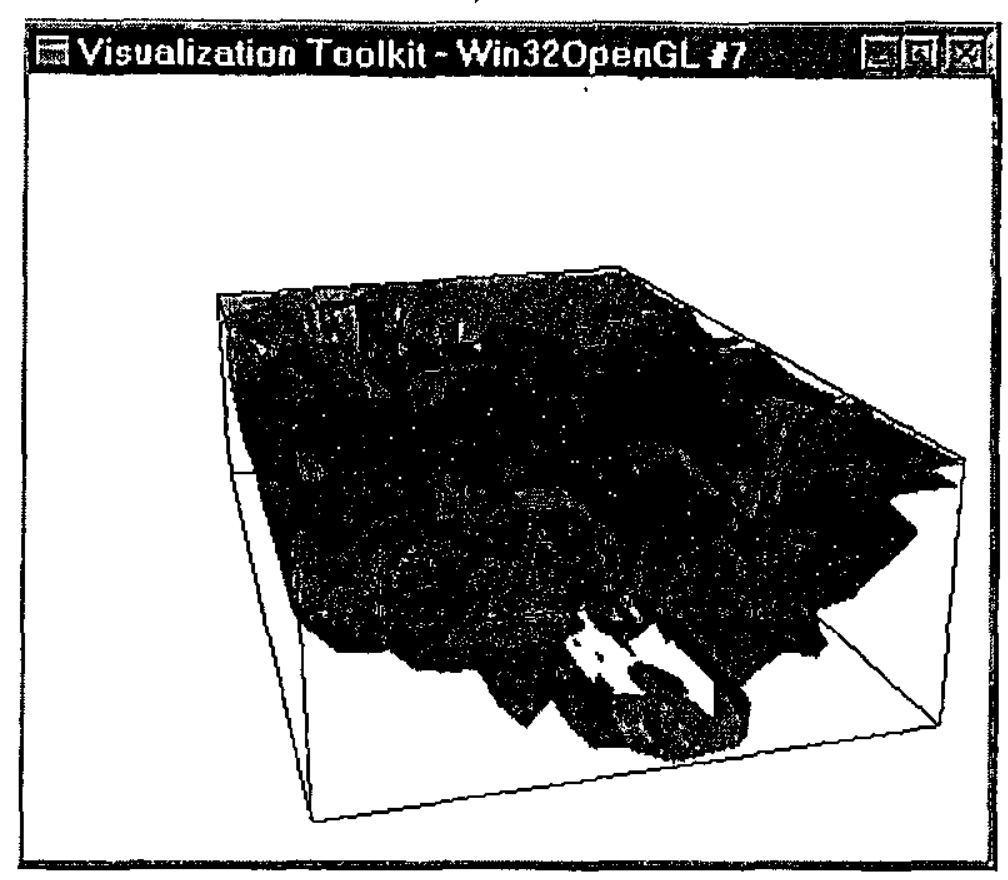

Figura 4.12: Sonda Sonora

Durante esse processo, o usuário pode mover a sonda pelo volume, redimensioná-la e sonificar o conteúdo da sonda de acordo com o método de sonificação escollido. Através dessa ferramenta o usuário pocle investigar regiões particulares de interesse no volume através de valores que não são necessariamente visíveis. A nova versão do sistema DSVol permite também que a sonda seja utilizada como uma ferramenta poderosa na interação do usuário com os dados visualizados. Uma vez definida a sonda dentro do volume de dados, o usuário é capaz de recortar a porção de dados contida na sonda e visualizar ou mesmo salvar esse novo conjunto de dados como sendo o volume total de dados. Dessa forma, o usuário pode selecionar regiões de maior interesse ou mesmo descartar regiões de "ruído" clentro de seu volume de dados. O controle da interação do usuário com a sonda é feito através de um objeto da classe SV_Interactor_Probe (ver seção 4.5) incluído na classe SV_Sound_Probe, derivada de SV_Sound, que implementa as funções da Sonda Sonora.

\section{Sonificações Associadas à Sonda Sonora}

Três classes de sonificaçōes estão disponíveis no contexto da Sonda Sonora. Duas delas utilizam, para calcular a presença de valores de interesse na sonda, o mesmo processo utilizado pelo algoritmo Marching Cubes apresentado no capítulo 1. Tal processo consiste em calcular a intersecção das isosuperfícies com cada unidade do volume de dados. Esse 
cálculo é realizado atfavés da avaliação do valor dos vértices para cada unidade do volume. Dessa forma, se um dado vértice possui valor maior que a o da isosuperfície investigada e um vértice adjacente possui valor menor, pode-se concluir que a isosuperfície corta a aresta que liga esses dois vếrtices. No caso de um vértice possuir valor igual ao do isosuperfície, pode-se concluir que esse é intersectado por ela.

Una vez clescobcrta as areslas de uma unidade de volume cortadas pela isosupcrfície ć possível calcular o nứmero de triângulos que n poligonalização dessa isosuperfície irá produzir. Esse número é utilizado nos dois processos dentro do conceito da Sonda citados para inclicar ocupaçấo de volumes por valores de interesse. Esses processos são descritos a seguir.

\section{Densidade Local}

A primeira função sonora implementada pela sonda sonora é a densidade local, isto é, a ocupação cla sonda. O cálculo do conteúdo ocupado pela sonda em relação ao conteúdo máximo possívcl para ela representa a ocupação, e indica o quão "cheia" ou "vazia" está a sonda.

A cada novimento da sonda, sua densidade local é calculada, mapeada para freqüência e sonificada. Freqüêficias baixas (sons graves) representam alta ocupação da sonda enquanto altas freqüências (sons agudos) representam baixa ocupação.

\section{População}

A segunda função sonora implementada é a população da sonda sonora, isto é, a relação eutre o conteúdo da sonda e o volume total analisado. Para essa sonificação, a cada movimento da sonda o valor é calculado, mapeado para frequência, e em seguida sonificaclo. Frequiências alittas representam pouca quanticlade cle valores de interesse na sonda em rclação ao volume total. Baixas freqüências indicam grande quantidade de valores de interesse encontrados na soncla em relação ao volume total.

No caso da sonificação da população da sonda, o usuário consegue identificar, no volume total, os locais de maior ou menor concentração dos valores de interesse, e pode utilizar esse resultado para refinar sua análise do volume.

\section{Quantidade de Valores de Interesse}

Uma nova função sonora foi incluída na nova versão do DSVol e consiste em calcular e sonificar a quantidaque de valores de interesse dentro da sonda. Para essa sonificação o 
usuário define um conjunto de valores que deseja investigar. A quàntidade desses valores clentro do volume limitado pela sonda é calculada e então mapeada para freqüência como nos métodos anteriores.

O filtro vikStructuredPointsSubVolume também é utilizado nesse processo cle sonificação. Ele é o responsável por definir o subvolume representado pela sonda sonora, ou scja, a porção do volunic de cládos em análise através da sonda.

Dentro do proccsso de exploração através da Sonda Sonora, é possível que o usuário decicla por realizar a sonificação com os mesmos valores de isosuperfícies (valor de interesse clefinidos para a visualização de isosuperfícies) ou com valores independentes definidos através da interface apresentada na figura 4.13 (defined) que realiza a entrada de parâmetros para a Sonda Sonora. Essa opção não existia na versão anterior do sistema e permite que o usuário utilize o som para mapear características dos dados diferentes das mapeadas por imagens. Quando estiver utilizando a visualização por DVR, o usuário deve sempre selecionar os valores sonificados pela Sonda Sonora uma vez que, nesse método não se definem valores de isosuperfícies a serem visualizados.

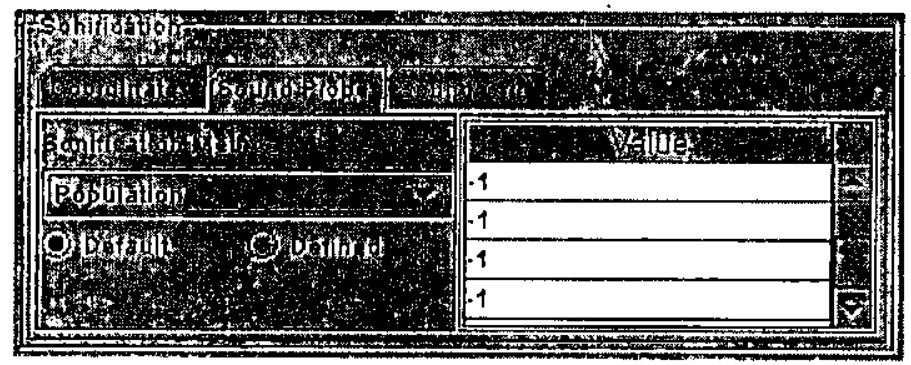

Figura 4.13: Interface clo método de Sonda Sonora

Uma outra opção incluída na nova versão do sistcma foi a possibilidade de definição do tarnanho inicial da sonda sonora através cla especificação de valores absolutos ou relativos em relação ao volume total de dados, como mostra a interface na figura 4.14.

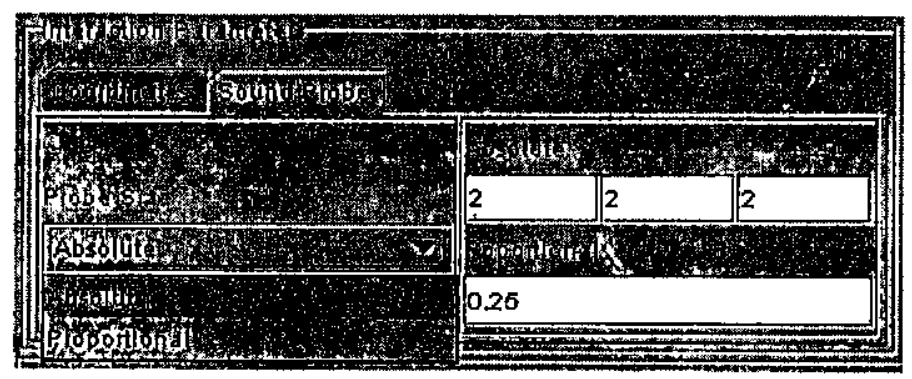

Figura 4.14: Interface de'definição do tamanho inicial da Sonda Sonora 
Os principais unétodos de SV_Sound_Probe são apresentadas na tabela 4.7. A definição completa clessa classe pode ser encontrada no arquivo SV.Sound.Probe.h incluído no apêndicc $A$.

\begin{tabular}{|c|c|c|}
\hline Método & & Descrição \\
\hline Stiart () & & $\begin{array}{l}\text { Utilizado para inicialização do objeto de sonificação, de in- } \\
\text { teração e para a conexão entre os objetos de som e visual }\end{array}$ \\
\hline Sonify () & & $\begin{array}{l}\text { Mćtodo chamado a partir do objeto que realiza a interação } \\
\text { do usuário com a sonificação, cuja função é a de realizar a } \\
\text { chamada a sonificação escollida pelo usuário }\end{array}$ \\
\hline New_Window () & & $\begin{array}{l}\text { Método que cria uma nova janela de visualização c sonifi- } \\
\text { caçāo representando o volume da sonda }\end{array}$ \\
\hline PopDens_Sonification & () & $\begin{array}{l}\text { Métoclo que implementa as sonificações de População e Den- } \\
\text { sidade da Sonda }\end{array}$ \\
\hline Values_Sonification () & & Método que implementa a sonificação de valores da Sonda \\
\hline Conta_Triangulos () & & $\begin{array}{l}\text { Método utilizado para contar o número de triângulos dentro } \\
\text { da Sonda Sonora, pela estratégia Marching Cubes }\end{array}$ \\
\hline
\end{tabular}

Tabela 4.7: Principais Métodos de SV_Sound_Probe

A próxima seção apresenta o processo de Display de Malha.

\subsubsection{Display de Malha}

Esse processo de sonificação leva en consideração o fato de que alguns dados e valores importantes podem ser perdidos durantc o inapeamento gráfico. Uin auxílio para a detecção desses valorés é a investigação direta da malha de dados, quando a malha é reløtivamente pequena. Yalores escalarcs armazenados na malha de dados são mapeados em diversas formas de sons, permitindo ao usuário identificar valores, padrões e estruturas nos dados. A classe responsável por implernentar os métodos do Display de Mallıa é a SV_Sotund_Grid, derivada da classe SV_Sound.

Nesse processo, a mallia, assim como os gráficos, são projetados na em uma janela de visualização. Uma segunda jancla é criada nesse método, contendo uma visualização $3 D$ clc isosuperfícics do conjunto de dados.

Conforme o usuário move o mouse sobre a janela da malla, um som representando o valor armazenaclo ha posição da mallıa ć tocado. A terceira dimensão da malha é mapenda entre as liul|as, como ó mostrado na figura 4.15. Nessa sonificação, valores altos 
sĩo mapcaclos parn frequiências altas e valores baixos para baixas freqüências, da mesina forma que no Display Progressivo.
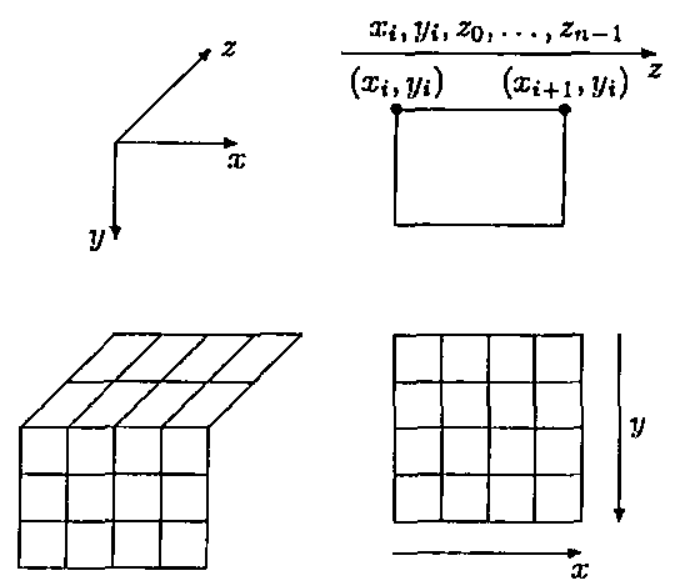

Figura 4.15: Orientação no Display de Malha - Adaptada de [9]

Nessa sonificação o usuário pode conseguir perceber padrões, como espelhamento e concentração de valores de interesse. Através da sonificação de malha, o usuário pode definir os valores que deseja investigar dentro do volume de dados.

Assim como no processo da Sonda Sonora, é possível que o usuário decida por realizar a sonificação com os mesmos valores de isosuperfícies (valor de interesse) definidos para a visualização, ou como valores independentes definidos através da interface de entrada de parâmetros para esse método.

A classe SV_Sound_Grid rcaliza a interação com o usuério através de um objeto de interação. Nessa clnsse, a variável que controla essa interação é um objeto da classe SV_Interactor_Grid.

Na implementação clesse processo foi utilizado o filtro vtkProjectionFilter desenvolvido no ICMC-USP. Esse filtro realiza a projeção da cena visualizada em um determinado plano $(x, y$ ou $z)$ e foi utilizado na criação na repreșentação $2 D$ para navegação no volume de dados.

Os principais métodos de SV_Sound_Probe são apresentados na tabela 4.8. A definição completa dessa classe pode ser encontrada no arquivo SV_Sound_Grid.h incluído no ậêticlice $\Lambda$. 


\begin{tabular}{|c|c|}
\hline Método & Descrição \\
\hline Start () & $\begin{array}{l}\text { Utilizado para inicialização do objeto de sonificação, de in- } \\
\text { teração e para a conexão entre os objetos de som e visual }\end{array}$ \\
\hline Sonify () & $\begin{array}{l}\text { Método chamado a partir do objeto que realiza a interação } \\
\text { do usuário com a sonificação, cuja função é a de realizar a } \\
\text { chamada a sonificação escolhida pelo usuário }\end{array}$ \\
\hline Render_Projection () & $\begin{array}{l}\text { Método que cria a janela de visualização } 2 D \text { que representa } \\
\text { a malha de dados }\end{array}$ \\
\hline Grid_Sonification () & $\begin{array}{l}\text { Método que implementa a sonificação de um determinado } \\
\text { valor dentro do volume de dados }\end{array}$ \\
\hline Inicializa () & $\begin{array}{l}\text { Método que realiza os cálculos para posicionamento e ma- } \\
\text { peamento da malha de dados apresentada em } 2 D \text { para os } \\
\text { valores reais em } 3 D\end{array}$ \\
\hline
\end{tabular}

Tabola 4.8: Principais Métodos de SV_Sound_Grid

A figura 4.16 apresenta um exemplo de sonificação utilizando o método da Sonificação de Malha. A interface de entrada de parâmetros para esse método é apresentada na figura 1.17.

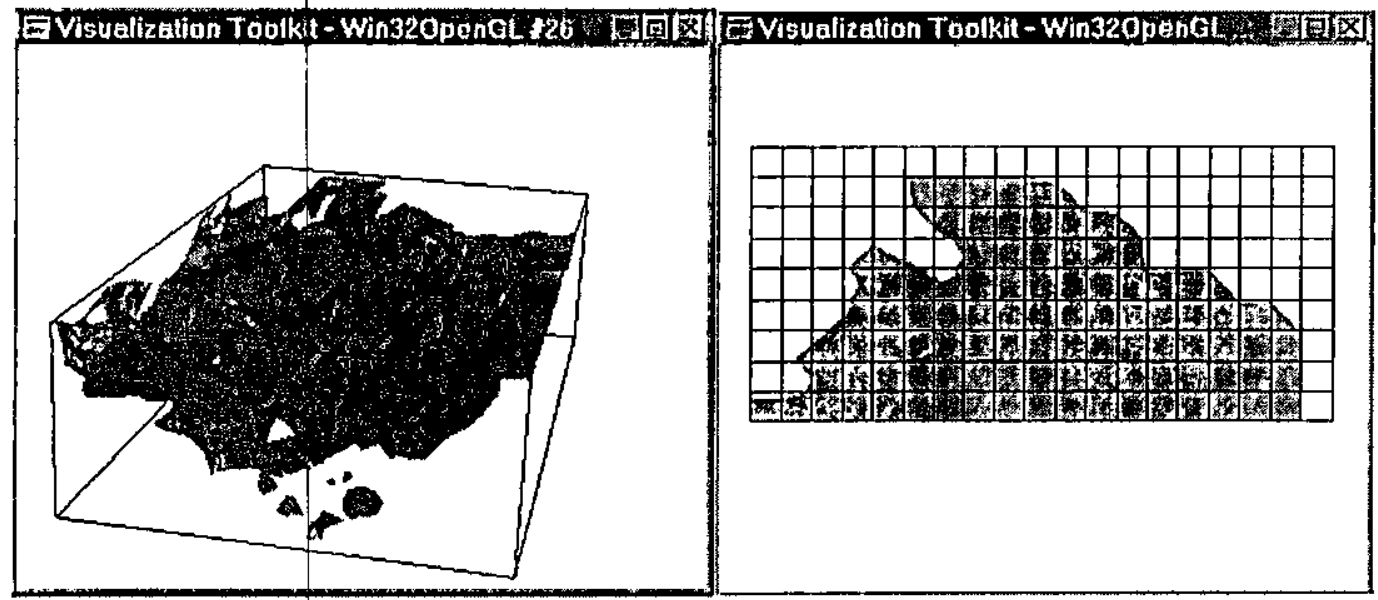

Figura 4.16: Sonificação de Malha 


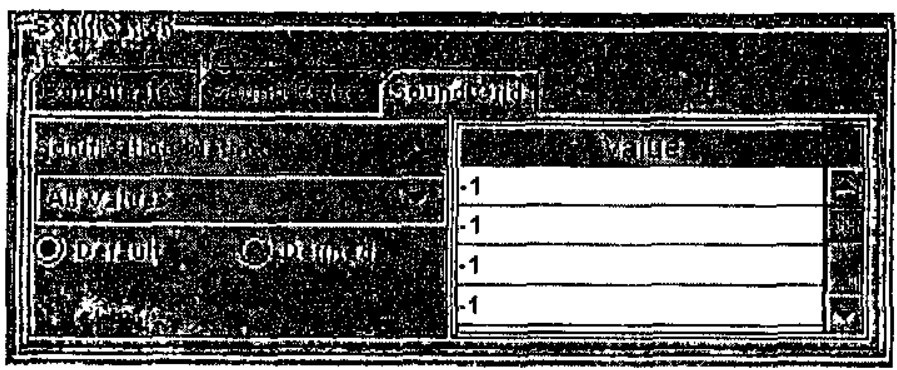

Figuma 4.17: Intcrface do método de Sonificação de Mallıa

A tabela 1.9 apresenta um resumo das sonificações implemenitadas em DSVol, ınostrando, além das sonificações, os processos gráficos nos quais elas estão associadas e sua utilidade. A tabela 4.10 mostra os mapeamentos sonoros para freqüência implementados.

\begin{tabular}{|l|l|l|}
\hline Sonificaçōes & Processo Gráfico & Utilidade \\
\hline \hline $\begin{array}{l}\text { 1. Sonificação de Valores } \\
\text { Máximo e Mínimo }\end{array}$ & Display Progressivo & $\begin{array}{l}\text { Percepção de intervalos entre } \\
\text { valores máximos e mínimos de } \\
\text { uma coordenada. }\end{array}$ \\
\hline $\begin{array}{l}\text { 2. Sonificação da Coordenada } \\
\text { Corrente }\end{array}$ & Display Progressivo & $\begin{array}{l}\text { Informação de progressão de } \\
\text { uma variável, ou seja, no mo- } \\
\text { mento em que uma fatia é de- } \\
\text { senhada. }\end{array}$ \\
\hline 3. Densidade Local & Sonda Sonora & $\begin{array}{l}\text { Distinção de quão "cheia" ou } \\
\text { "vazia" está a sonda. }\end{array}$ \\
\hline 5. Sonificação de Valores & Sonda Sonora da Sonda & $\begin{array}{l}\text { Percepção da proporção de } \\
\text { valores de intereșe em uma } \\
\text { regiäo do volume. }\end{array}$ \\
\hline $\begin{array}{l}\text { 6. Sonificação dos valores da } \\
\text { Malha }\end{array}$ & Display da Malha & $\begin{array}{l}\text { Percepção direta da quantida- } \\
\text { de de valores de interesse con- } \\
\text { tidos na soda. }\end{array}$ \\
\hline
\end{tabular}




\begin{tabular}{|c|c|c|c|c|c|}
\hline Sonificações & & Freq. & Justificativa - Percepção & Sup. & DVR \\
\hline $\begin{array}{l}\text { 1. Sonificaçāo } \\
\text { Máximo e Mínimo }\end{array}$ & de Valores & alta & $\begin{array}{l}\text { Sons agudos têm associação } \\
\text { direta com valor absoluto al- } \\
\text { to } \\
\text { Sons graves têm associação di- } \\
\text { reta com valor alssoluto baixo }\end{array}$ & $\mathrm{X}$ & $\mathrm{X}$ \\
\hline $\begin{array}{l}\text { 2. Sonilicação de } \\
\text { Corrente }\end{array}$ & Coordenada & alta & $\begin{array}{l}\text { Sons agudos têm associaçāo } \\
\text { direta com valor absoluto al- } \\
\text { to } \\
\text { Sons graves têm associaçāo di- } \\
\text { reta com valor absoluto baixo }\end{array}$ & $\mathrm{X}$ & $\mathrm{X}$ \\
\hline 3. Densidade Lo & & $\begin{array}{l}\text { alta } \\
\text { baixa }\end{array}$ & $\begin{array}{l}\text { Sons agudos dão a idéia de } \\
\text { baixa ocupação } \\
\text { Sons graves dāo idéia de ocu- } \\
\text { pação alta }\end{array}$ & $\mathrm{X}$ & $\mathrm{X}$ \\
\hline 4. População da & Sonda & $\begin{array}{c}\text { alta } \\
\text { baixa }\end{array}$ & $\begin{array}{l}\text { Sons agudos dão a idéia de } \\
\text { baixa ocupação } \\
\text { Sons graves dão idéia de ocu- } \\
\text { pação alta. }\end{array}$ & $\mathrm{X}$ & $\mathrm{X}$ \\
\hline 5. Sonificação de & valores & $\begin{array}{l}\text { alta } \\
\text { baixa }\end{array}$ & $\begin{array}{l}\text { Sons agudos dão a idéia de } \\
\text { baixa ocupação } \\
\text { Sons graves dão idéia de ocu- } \\
\text { pação alta }\end{array}$ & $\mathrm{X}$ & $\mathrm{X}$ \\
\hline $\begin{array}{l}\text { 6. Sonificação de } \\
\text { Mallia }\end{array}$ & e valores da & alta & $\begin{array}{l}\text { Sons agudos têm associação } \\
\text { direta com valor absoluto al- } \\
\text { to } \\
\text { Sons graves têm associação di- } \\
\text { reta com valor absoluto baixo }\end{array}$ & $\mathrm{X}$ & \\
\hline
\end{tabular}

Tabela 4.10: Percepção de mapeamentos para frequiência em DSVol

A próxima seção é destinada à apresentação do módulo de interação do usuário com as visualizaçōes e sonificaçōes de DSVol.

\subsection{Módulo de Interação}

O módulo de interacão do ustário com as visualizações e sonificações utiliza as funçōes de intcração do VTK, possibilitando uma interação através do teclado e do mouse. Para 
cada um dos métodos cle sonificação do sisteına foram implementadas funções de interação que permitem ao usuário acessar e interagir com as sonificaçōes.

A interação no DSVol é realizada através da classe SV_Interactor derivada da classe vikWin32RenderWindowInteractor do VTK. Para realizar esta interaçño, a classe SV_Interactor reimplonicnta algumas funções definidas em vikWin32RenderWindowInteractor. Dentre essas fuuções, as unais importantcs parı a interaçño em DSVol são as funções OnCliar () que é responsável por tratar eventos do teclado e OnLMouseDown () respomsnivel por tratmu o cliçuc do botño escucrelo mouse. Uma descrição completa das dcmais funções e variáveis de SV_Interactor posle ser encontrada no apêndice $A$, arđuivo SV_Interactor_Kernel.h.

A interação do sistema com as diversas sonificações foi implementada em classes que derivam de SV_Interactor. Essas classes são: SV_Interactor_Coord, SV_Interactor_Probe c SV_Interactor_Grid. A classe SV_Interactor é utilizada quando se gera uma visualização sen sonificação. O restante deste capítulo é destinado à descrição cle cada uma das implementações de classes de interação para o sistema DSVol.

\subsubsection{Display Progressivo}

Á classe de interação inluplementada para o método do Display Progressivo é a SV_Interactor_Coord. Essa classe utiliza a tecla "u" (user) para interromper a interação do VTK com a visualização e capturar o controle da cena. Depois de digitada a tecla "u", o usuário pode iniciar o processo de sonificação através da tecla " $\mathrm{s}$ " (sonify). Assim, acionada a tecla " $\mathrm{s}$ ", o proccsso de sonificação tem início. Digitando a tecla " $\mathrm{x}$ " o usuário passa a interação clo sistema de volta ao VTK.

A classe SV_Interactor_Coord possui um objeto da classe SV_Sound_Coord que é iniciado através da furç̧ão Set_Sender() implementada cm SV_Interactor_Coord. Através desse objcto, são feitas as chamadas à classe de sonificação que executa alguma função cun resposta a alguma ação de interação do usuário. A definição completa desta classe pode ser encontrada. no arquivo SV_Interactor_Coord.h no apêndice A.

\subsubsection{Sonda Sonora}

Assim como para o método do Display Progressivo a implementação da interação para a Sonda Sonora utiliza a tecla " $u$ " para interromper o VTK e capturar o controle de interação. Depois de digitada a tecla " $u$ " o usuário pode movimentar e redimensionar a sonda na cena, procurando a melhor forma de explorar o volume de dados. Para esse tipo 
de interação foi realizado um mapeamento de teclas que permitem que o usuário navegue ıa visualização de forma natural. A idéia desse mapeamento é a de utilizar teclas que possibilitem ao usuário associá-lns ǹ navegação em um mundo $3 D$ pelos eixos $x, y$, e $z$. Para isso, foi utilizado o teclado numérico (tecla NumLock ativada) da seguinte forma:

- Teclas 2 e 8 - Navegação no eixo $x$.

- Teclas 4 e 6 - Navegação no cixo $y$.

- Tecliss 1 e 9 - Navegação no eixo $z$.

A forma de alteruar a interação com a sonda entre o modo de movimentação e o de redimensionamento é através da tecla " $\mathrm{n}$ ". Para realizar a sonificação das informações na sonda é utilizada a tecla " $\mathrm{s}$ ". A tecla " $\mathrm{x}$ " indica o retorno do controle da interação da cena ao VTK.

Através da interação com a sonda sonora é possível que o usuário escolha uma região de interesse (delimitada pela sonda) e visualize e sonifique essa região separadamente. Para realizar tal função é necessário que o usuário digite a tecla "z". A pós digitada essa tecla, una nova visualização do volume contido dentro da sonda é apresentado na tela (figura 4.18). O usuário pode interagir com esse novo volume da mesma forma que interagia com o volume anterior. Depois de fechada a janela representando o novo volume, o usuário pode continuar com a interação com seu volume de dados original. Esse processo pode scr acessado para cada novo volume apresentado até que o volume total de dados esteja representado en uma única célula. Essa nova capacidade de interação da sonda com o volume da clados não estava presente na versão anterior de DSVol.

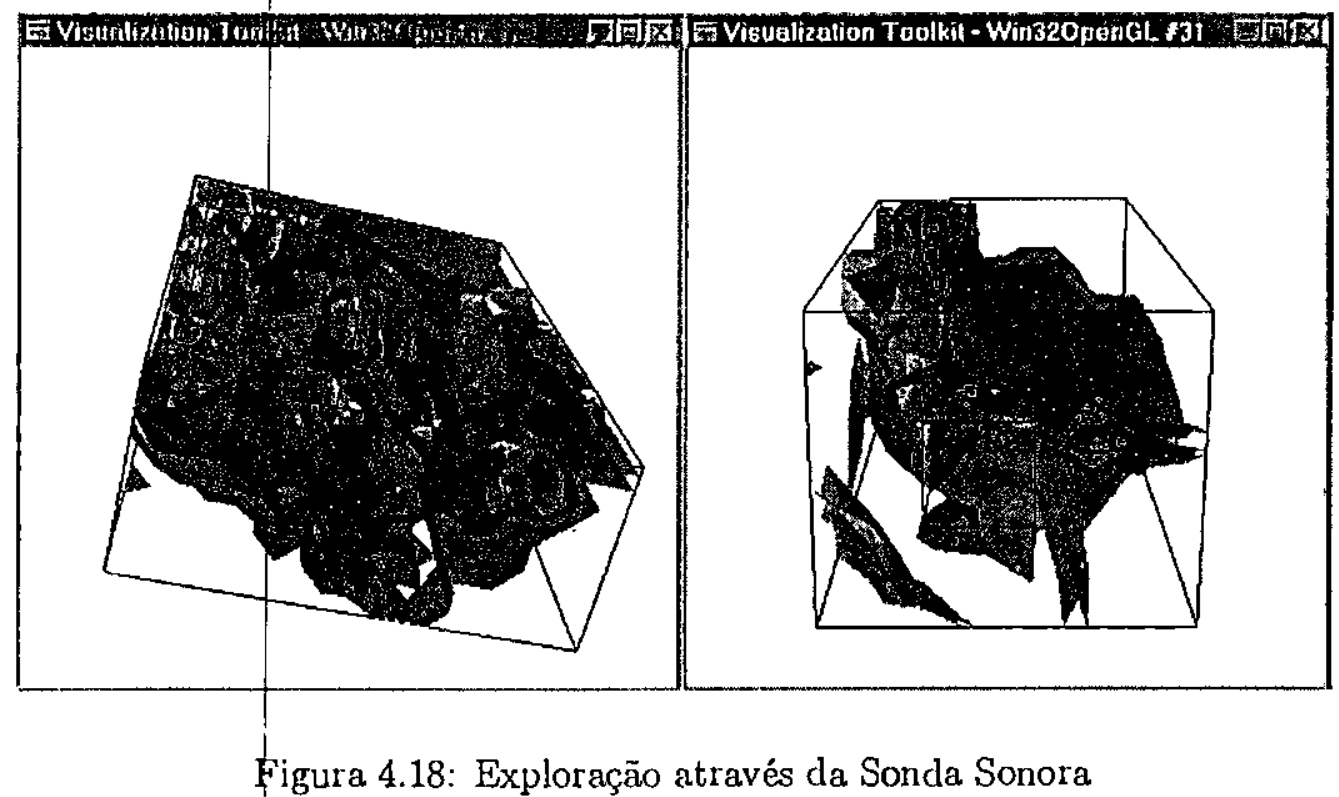


Utilizando a sonda sonora é possível também que o usuário defina o conteúdo da soncla como seu novo conjunto de dados. Através da interface de entrada de parâmetros cle DSVol o ısuário tem a opção de salvar esse novo volume de dudos, ou mesmo de rcstaurar o volume de dados original através de opções inclúdas na interface de entrada de parn̂nctros de DSVol.

Una nova função de interação também desenvolvida neste trabalho é a capacidade de aumentar ou diminuir o incremento para redimensionamento e juovimentação da sonda. Esse incremento ten valor inicial igual a 1, e pode ser aumentado ou diminuído utilizando respectivamente as teclas "+" e "-" do teclado.

A tabela 4.11 mostra um resumo da utilidade de todas as teclas para o processo da Sonda Sonora. Durante todo o tempo, as interações do VTK com a cena visualizada (rotação, translação, escala) são acessíveis através do mouse.

\begin{tabular}{|c|c|}
\hline Operaçäo & Acesso \\
\hline Assume interação & "u" \\
\hline Canninla no senticlo positivo de $x$ ou aumenta o tamanho da sonda em $x$ & "6" \\
\hline Caminha no sentido negativo de $x$ ou diminui o tamanho da sonda em $x$ & “4" \\
\hline Caminla no sentido positivo de $y$ ou aumenta o tamanho da sonda em $y$ & "8" \\
\hline Caminha no sentido negativo de $y$ ou diminui o tamanho da sonda em $y$ & "2" \\
\hline Caminla no sentido positivo de $z$ ou aumenta o tamanho da sonda em $z$ & $" 9 "$ \\
\hline Caminha no sentido negativo de $z$ ou diminui o tamanho da sonda em $z$ & "1" \\
\hline Alterna entre a movimentação e redimensionamento da sonda & "m" \\
\hline $\begin{array}{l}\text { Abre uma nova janela com o conteúdo da sonda representando o volume total } \\
\text { de dados (realiza um zoom da sonda) }\end{array}$ & "z" \\
\hline Define o conteúdo da sonda como o volume total de dados & "n" \\
\hline Devolve a interação do VTK & $" x "$ \\
\hline
\end{tabular}

Tabela 4.11: Teclas de acesso à interação através do processo da Sonda Sonora

A classe SV_Interactor_Probe possui um objeto da classe SV_Sound_Probe que é iniciado através da função Set_Sender() implementada em SV_Interactor_Probe. Através clesse objeto, são feitas as chamadas à classe de sonificação que executa alguma função em resposta a alguma ação de interação do usuário. A definição completa dessa classe pode ser encontrada no arquivo SV_Interactor_Probe.lı no apêndice A. 


\subsubsection{Display de Malha}

Para cacla una das janelas crialas pelo método de Display de Malha é implemcutado um tipo diferente de intęração com o usuário. A primeira janela contém a visualização $3 D$ de isosuperfícies e é controlada pelas fuuções de interação do VTK. O controle da janela de visualização que conkém a projeção da malha e das isosuperfícies é realizada por funções cla classe SV_Interactor_Grid. A interação para essa janela é feita através de movimontos c cliques do mouse da seguinte forma: a cada clique do mouse dentro de uma posição da mallia de dados, o vialor escalar correspondente 'aquela posição é mapeado para sorn e então tocado.

Assim como as demais classes cle sonificação, a classe SV_Interactor_Grid possui um objeto da classe SV_Sound_Grid que ć iniciado através da função Set_Sender() implementada em SV_Interactor_Grid. Através desse objeto, são feitas as chamadas à classe de sonificação que executa alguma função em resposta à alguma ação de interação do usuário. A definição completa dessa classe pode ser encontrada no arquivo SV_Interactor_Grid.h no apêndice $A$.

A próxima seção é destinada à apresentação do módulo implementado para o DSVol que permite o acesso às suas funções através da Internet.

\subsection{DSVol ha Internet}

Como dito anteriormente, um dos principais objetivos do presente projeto foi a disponibilização do software DSVol na internet, principalmente para garantir que um número maior de usuários tenham acesso às funções de visualização e de sonificação implementadas no sistema. Estra seção é destinada à apresentação cla versão para internet do sistema.

$\mathrm{Na}$ imıplementaçăo do DSVol na Internet foi utilizada a linguagem de programação Java para a criação de uma interface indireta (figura 4.2) que fosse capaz de ser acessada através de um browser de navegação para a $W e b$ e que pudesse fazer acesso e executar funções de visualização e sonificação do sistema implementadas em $\mathrm{C}++$.

Através da tecnologia JNI (Java Native Interface) do Java [42], foi possível realizar a conexão entre a interface Java e o código do DSVol, escrito em C++. O JNI tem como principal função criar uma "ponte" que liga uma clramada a uma função no código Java à sun implementação escrita $\mathrm{cm}$ linguagem nativa (por exemplo, $\mathrm{C}++$ ).

$\Lambda$ inplementaçä́ clessa versão do sistema coloca o DSVol em consonância com as demais partes do PowerVis [5] [7], cujos traballos estão sendo progressivamente adiciomados a un arcabouco de visualização na internet (ver http://www.lcad.icmc.sc.usp. 
br/־powervis).

A interface Java para o sistema DSVol foi criada com a ajuda da ferramenta Forte da Sun. Depois de criada a interface, o código que faz acesso ao JNI e às funções do DSVol em $\mathrm{C}++$ foi adicionado ao prograna Java. A forma através da qual são feitas chanadas atravćs clo JNI é descrita a seguir:

Passo 1 - O primeiro passo é declarar o cabeçallıo das funções implementadas em códligo nativo e chamadas no código Java. A definição de cada função deve ser feita clin seguinte forma:

public native void nome_função (parâmetros);

A palavra native indica ao compilador que a função estará inplementada em linguagem nativa $(\mathrm{C}++)$. Um exemplo para o DSVol é:

public mative void SetIsoParameters ( int Num_Surfaces, float] Surfaces );

Passo 2 - Depois de compilado o programa Java, deve ser executado o comando do jdk:

javah -jni "nome arquivo java"

$\mathrm{O}$ download do pacote jdk pode ser feito pelo site http://www. java. sun.com.

Como saída desse comando, o JNI gera o arquivo "nome arquivo java.h" que será o arquivo hcader para a implementação das funçōes em $\mathrm{C}++$. A implementaçāo dessas funções deve ser feita no arquivo "nome arquivo java.cpp" e deve utilizar os cabeçallıos das funções definidas no seu arquivo header. No caso de DSVol, os nomes desses arquivos são: VTKThread.h e VTKThread.cpp (apêndice A).

Passo 3 - Esse passo consiste em criar uma dll para o código que implementa as funções em $\mathrm{C}++$ definidas no processo anterior. $\mathrm{Na}$ compilação desse código deve ser adicionada a bibliotcca jni.h do jdk.

Passo 4- Depois de gerada a dll, deve-se adicionar ao código Java uma chamada no sistemn operacional que carregue essa dll. Isso permite ao código Java poder ter acesso e utilizar as funções implementadas na dll. Essa chamada deve ser realizada da seguinte forma:

System.loadlibrary ("nome do arquivo.dll"); 
Depois rle executados esses passos, o programa Java deve ser compilado novarncnte e pode crtão ser utilizado para realizar chamadas ao código $\mathrm{C}++$.

Obs: O arquipo dll gerado para a clramada ao código $\mathrm{C}++$ deve estar localizado ein um local acessível ao sistema (como por exemplo no diretório cle sistema do Windows) para que possam ser acessados pelo programa Java.

As chamadlas à funções nativas dentro do código Java do DSVol são implementadas cm uma classe chamada VTKThread criada nesse trabalho de mestrado, que deriva da classe Thread do Jaya. Essas chamadas são criadas nesta classe derivada da classe Thread para permitir que a chamada às funções em $\mathrm{C}++$ não interfiram em chamadas a eventos padrão realizados pelo Java, como por exemplo o evento de "redesenhar" (repaint) os elementos cle interface. Um objeto instanciado de uma classe derivada de Thread possui uma função chamada run(), que realiza a inicialização e execução de seu código como uma nova thread no programa Java. Dessa forma, foi necessário que cada chamada a função nativa tivesse um método que indicasse que seria esta a função a ser executada dentro do código da função run(). Detalhes sobre essas chamadas podem ser encontrados mais adiante nesta seção.

A intcrface de entrada de parâmetros em Java para o DSVol é implementada ein uma classe chamada Interface_SVol que deriva cla classe javax.swing.japplet do .Java. Isso permite quc essa intcrface possa ser inserida e executada a partir de uma browser.

As cliamadas às funçōes nativas são feitas a partir da classe Interface_SVol através cle um objeto da VTKThread contido na classe. A forma de acesso à função run() da. classe VTKTHread (é através da função start() implementada na classe Thread do Java. É importante dizer que as clramadas não são realizadas diretamente através de chamadas às funções nativas do objeto VTKThread, mas sim através de funções que definem parânetros indicandlo qual função nativa deve ser clıamada dentro do código da função min() cm VTKThread. Um exemplo de acesso à uma função nativa a partir da classe Intcrface_SVol é apresentada no pseudo-código da tabela 4.12. 


\section{Começo do Código}

VTKThread vtkThread = new VTKThread () ;

// Seta a funcao "nativa" a ser chamada pelo metodo start ()

vtkThread.SetRenderIsoSound ();

// Realiza a chamada da funcao nativa

vtkThread.start();

Fin do Código

Tubelu 4.12: Pseudo-Código - Chamada a uma função nativa $\mathrm{C}++$ a partir do Código Java

Renlizada essa clianada ao objeto da classe VTKThread, o código executado dentro cla classe é o apresentado na tabela 4.13 .

Começo do Código

// Funcao SetIsoSound da Classe VTKThread

public void SetRenderIsoSound ()

\{

IsoSound = true;

\}

$\ldots$

// Funcao run() da classe VTKThread chamada quando temos o

// metodo start() chanado para algum objeto dessa classe

public void run()

Ł

...

else if (IsoSound)

i

RenderIsoSound ();

IsoSound = false;

\}

. .

\}

Fin do C6digo

Tabela 4.13: Pseudo-Código - Exemplo de como realizar chamadas em DSVol a partir da classe VTKThread

O código geraclo após a compilação com a opção JNI do programa Java está incluído no arquivo VTKThread.h (apêndice $\mathrm{A}$ ). O arquivo VTKThread.cpp contém a implementação clas funções nativas acessadas a partir de Java. Dessa forma, esse arquivo funciona como o 
progrinna principal pira o código C++ accssado do Java. Esse arquivo deve ser compilado juntamente com as demnis classes de DSVol para gerar a dll que será acessada a partir do Java (C_DSVOL.(ll1).

A tabela 4.14 ap resenta uma descriçño de cada uma das funções "nativas" clefinidas em VTKThread, e shras respectivas funçōes que indicam a método start() sua chamada.

A tabela 1.15 aprescnta uma descrição de cada uma das funções "nativas" definiclas cm VTISThreacl, chamadas diretamente a partir do código da classe Interface_SVol, sem a ncccssidade de utilização do método start() de VTKThread (não necessitam chamar esse método pois sua execução não exige muito esforço computacional).

\begin{tabular}{|c|c|c|c|}
\hline Define Execução & & Método Nativo & Descrição \\
\hline SetOpenFile () & & OpenFile () & $\begin{array}{l}\text { Método que realiza a abertura de } \\
\text { nm arquivo de dados }\end{array}$ \\
\hline SetSaveFile () & & SaveFile () & $\begin{array}{l}\text { Método que salva um conjunto de } \\
\text { dados em um arquivo }\end{array}$ \\
\hline SetRenderIso () & & RenderIso () & $\begin{array}{l}\text { Método que realiza a visualização de } \\
\text { isosuperfícics }\end{array}$ \\
\hline SetRenderDVR () & & RenderDVR () & $\begin{array}{l}\text { Mćtodo que rcaliza a visualizaçāo } \\
\text { através de DVR }\end{array}$ \\
\hline SetRenderIsoSound & () & RenderIsoSound () & $\begin{array}{l}\text { Método que realiza a visualização de } \\
\text { isosuperfícies com a presença de so- } \\
\text { nificação }\end{array}$ \\
\hline SetRenclerDVRSoun & d 0 & RenderDVRSound () & $\begin{array}{l}\text { Método que realiza a visualização } \\
\text { através de DVR com a presença de } \\
\text { sonificação }\end{array}$ \\
\hline
\end{tabular}

Tabcla 4.14: Funções Nativas Acessadas a partir do código Java 


\begin{tabular}{|c|c|}
\hline Método Nativo & Descrição \\
\hline SetDVisunl () & Mćtodo que inicializa o cliente de visualização \\
\hline SotDSound () & Mćtodo cque inicializa o clicute de sonificação \\
\hline SctIsoParamaters () & $\begin{array}{l}\text { Método que seta os parâmetros de visualizaçāo de iso- } \\
\text { superfícics }\end{array}$ \\
\hline SetDVRParamaters () & $\begin{array}{l}\text { Mátodo que seta as parâmetros de visualização através } \\
\text { cle DVR }\end{array}$ \\
\hline SetSoundParannaters () & $\begin{array}{l}\text { Método que seta os parâmetros de pitch e timbre do } \\
\text { som }\end{array}$ \\
\hline SetSoundCoordParamaters () & $\begin{array}{l}\text { Método que seta os parâmetros para o método do Dis- } \\
\text { play Progressivo }\end{array}$ \\
\hline SetSoundProbeParamaters () & $\begin{array}{l}\text { Método que seta os parâmetros para o método da Son- } \\
\text { da Sonora }\end{array}$ \\
\hline SetSoundGridParamaters () & $\begin{array}{l}\text { Método que seta os parâmetros para o método do Dis- } \\
\text { play de Mallia }\end{array}$ \\
\hline RestoreData () & $\begin{array}{l}\text { Método que carrega novamente o volume de dados ori- } \\
\text { ginal lido o arquivo de StructuredPoints }\end{array}$ \\
\hline SetCoordincrementP () & $\begin{array}{l}\text { Método que seta o incremento proporcional para o } \\
\text { Display Progressivo }\end{array}$ \\
\hline SetCoordIncrementA () & $\begin{array}{l}\text { Método que seta o incremento absoluto para o Display } \\
\text { Progressivo }\end{array}$ \\
\hline SetProbeIncrementP () & $\begin{array}{l}\text { Método que seta o tamanho proporcional da Sonda } \\
\text { Sonora }\end{array}$ \\
\hline SetBackGround () & $\begin{array}{l}\text { Método que seta cor de fundo para visualização de } \\
\text { isosuperfícies }\end{array}$ \\
\hline SctBackGroundDVR () & $\begin{array}{l}\text { Método que seta cor de fundo para visualização } \\
\text { através de DVR. }\end{array}$ \\
\hline
\end{tabular}

Tabela 4.15: Funções Nativas Acessadas a partir do código Java

A próxima seção é clestinada à descrição da implementação de uma versão distribuída de DSVol que pode utilizar servidores de sons e imagens para a geração das visualizações e sonificaçōes do sistema. 


\subsection{Distribuição do DSVol}

A distribuição cle recursos (dados, simulação e processamento) em rede, aparece comı uma tentativa cle solticionar o problema de sobrecarga dos recursos na máquina do usıário em visualização. Nфs casos em que os recursos computacionais de um usuário não são suficientes para processos de visualização, computadores externos mais poderosos podem oferecer os recursos necessários para que esses usuários possam utilizar seus processos de visualização.

Na área de sonificação, o maior custo computacional está no cálculo dos parâmetros de síntese durante a sonificação. Esse não é o caso da atual versão do DSVol, mas certannente será quando novas alterações no sistema forem realizadas (como a utilização de síntese de sons por software). Por essc motivo, foi implementado um servidor de som responsável por realizar tais cálculos. Esse servidor foi implementado utilizando a especificação CORBA e a ORB Visibroker 4.0. Também foi desenvolvido neste projeto, um protótipo de um servidor de visualização. A figura 4.19 apresenta a arquitetura atual da distribuição em DSVol. A descrição dos servidores e das modificações no sistema para atıar de forma distribuída são apresentadas a seguir.

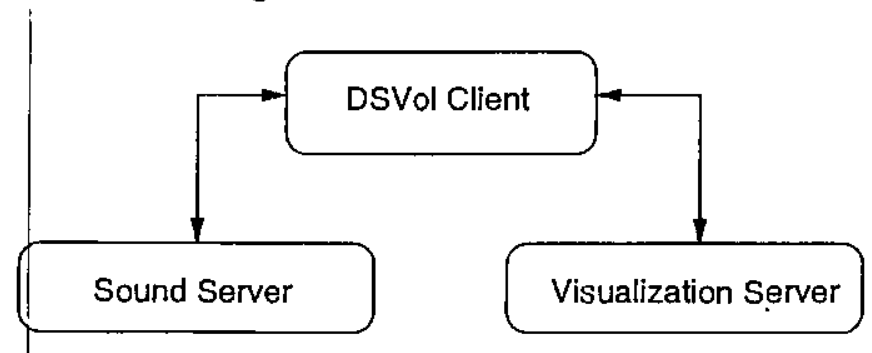

Figura 4.19: Esquema Simplificado da Arquitetura Distribuída de DSVol

\subsubsection{Definiçāo da Interface IDL}

O primeiro passo da implementação de uma aplicação cliente/servidor em CORBA é a definição do arquivo IDL (.idl). IDL é a linguagem usada para especificar as operações que um determinado objeto irá disponibilizar e como essas operações podem ser acessadas. A linguagem IDL tem sintaxe similar ao $\mathrm{C}++$. Maiores detalhes sobre a especificação IDL para DSVol são dados a seguir.

\section{Servidor de Sonificação}

Para o DSVol, foi driada uma interface CORBA chamada 1DL_Sound que contém o cabeçalho para cada um dos métodos de cálculo de sonificação para o sistema, juntamente 
com algumas estrutumas e funções para a passagem de parâmetros. Estas especificações podern ser encontradas no arquivo IDL_Sound.idl incluído no apêndice $\Lambda$.

\section{Servidor de Visualizaçāo de Isosuperfícies}

Para a utilização clo servidor de visualização foi utilizada a interface CORBA IDL_Visualization que contém o cabeçalho dos métodos implementados no servidor de visualização e que podcm ser acessados por algum cliente. Una informação importante é que somente funções cle visıalização de isosuperfícies foram definidas para essa interface IDL. O código IDL para esse servidor pode ser encontrada no arquivo IDL_Visualization.idl incluído no apênudice A.

\subsubsection{Definição dos Arquivos Stub e Skeleton}

Depois de descrito o inódulo IDL, o próximo passo é gerar os arquivos skeleton e stub. O código dos arquivos stub devem ser utilizados juntamente com o programa cliente para realizar chanıadas à niétodos implementados remotamente. Já os arquivos skeleton são usados, juntamente com a implementação criada para os métodos definidos pela IDL, para criar um servidor que implementa o objeto remoto.

Os arquivos skeleton e $s t u b$ são gerados automaticamente pela compilação do arquivo IDL (.idl) através da ferramenta presente no Visibroker "idl2cpp.exe".

Os arquivos gerados por esse executável geralmente são nomeados da seguinte forma: NomeIdl_c.hl e NomeIdl_c.cc para o cliente (stub); e NomeIdl_s.hh e NomeIdl_s.cc para o servidor (skeleton). Emı DSVol os arquivos gerados foram: IDL_Sound_c.cc, IDL_Sound_c.hlı, IDL_Sound_s.cc e IDL_Sound_s.hh para a implementação do servidor de sonificação; e IDL_Visualization_c.cc, IDL_Visualization_c.hl, IDL_Visualization_s.cc e IDL_Visualization_s.hh para a implcmentação do servidor de visualização.

\subsubsection{Definição do Servidor CORBA}

Um servidor CORBA é escrito utilizando-se os arquivos skeleton juntamente com o código que implementra as funçōes definidas pela interface IDL. Tal código deve estar contido em uma classe derivada da classe base para esse objeto definida dentro do arquivo skeleton. No Visibroker 4.0, essa classe utiliza o POA (Portable Object Adapter) para realizar a conexão entre clientc e servidor.

A seguir são descritas as implementações dos servidores de sonificação e visualização de DSVol. 
Servidor de Sonificação

A classe que implementa os métodos clefiniclos pela interface IDL_Sound é a Soundlmp). Tal classe é clerivada da classe POA_Sound::IDL_Sound definida no arquivo IDL_Sound_s.lih. A definiçẫo completa dessa classe pode ser encontrada no arcquivo SoundImpl.lı no apêndice $A$.

O código principal para o servidor de sonificação em DSVol foi escrito da segırinte forma:

Passo 1 - Inicializar a ORB.

Passo 2 - Criar um objeto POA.

Passo 3 - Criar um objeto servidor do tipo Soundlmpl.

Passo 4 - Ativar o objeto servidor.

Passo 5 - Ativar o gerenciador do POA.

Passo 6 - Aguıardar por requisições de algum cliente.

O servidor de sons para DSVol implementa todas as funções de sonificação para o sistema (Display Progressivo, Sonda Sonora e Display de Malha). Quando o usuário opta por utilizar o servidor de sons, o cliente realiza primeiramente a chamada à função que passa o arquivo de dados para o servidor. A forma utilizada por DSVol para a troca de dados entre cliente e servidor é através do mapeamento em strings desses dados. Emı scguicla, são realizadas as chamadas às funções de sonificação, de acordo com as opçõcs clo ısuário. Essas funções retornam o valor de freqüêucia correspondente à sonificação escollicla, e o processo cliente fica responsável por "tocar" o som calculado no servidor.

As principais funções implementadas no servidor de sons para DSVol podem ser encontradas na tabelal 4.16 . 


\begin{tabular}{|l|l|}
\hline Método & Descrição \\
\hline \hline SetFile () & $\begin{array}{l}\text { Utilizado para passagem do arquivo de dados (na for- } \\
\text { ma de string) para o servidor }\end{array}$ \\
\hline CoordSonification () & Sonificação da coordenada corrente \\
\hline MaxSonification () & $\begin{array}{l}\text { Sonificação do valor máximo dentro de uma fatia do } \\
\text { volume de dados }\end{array}$ \\
\hline MinSonification () & Sonificação do valor mínimo \\
\hline PopDenisSonification () & $\begin{array}{l}\text { Sonificação de Densidade Local e População para a } \\
\text { Sonda Sonora }\end{array}$ \\
\hline ValucsSonilication () & Sonificação de Valores para a Sonda Sonora \\
\hline GriclSonification () & Sonificação de Malla \\
\hline
\end{tabular}

Tabela 4.10: Servidor de Sonificação - Principais Métodos

Para a realização da compilação é necessário que o caminho para os arquivos ".lib" do Visibroker estejain acessíveis ao projeto do serviclor. O arquivo "vtkdll.lib", assim como o caminlo para os arquivos ".li" do VTK também devem estar acessíveis. Os arquivos utilizados nesse projeto são: SoundServer.cpp (arquivo principal), SoundImpl.h, SoundImpl.cpp (implennentação do scrvidor de sons), IDL_Sound_s.hlı (skeleton).

A compilação do código servidor gera o executável SoundServer.exe que, quando executado, aguarda que algun cliente solicite a execução de alguma das funções implementadas em SoundImpl. Em DSVol foi utilizado o software Microsoft Visual $\mathrm{C}++6.0$ para a compilação deste servidor.

\section{Servidor de Visualização de Isosuperfícies}

A classe que inplementa os métodos definidos pela interface IDL_Visualization é a Visualization Inpl. Tal classe é derivada da classe POA_Vistual::IDL_Visualization definida no arquivo IDL_Visualization_s.hh. A definição completa dessa classe pode ser encontrada no arcluivo VisualizationImpl.h no apêndice $A$.

Os passos para criação desse servidor são os mesmos descritos na criação do servidor de visualização. A única diferença é que o objeto servidor ativado deve ser do tipo VisualizationInipl.

O serviclor de visualização em DSVol inplementa o processo de filtragem das isosuperfícies, clentro do pipeline cle visualização do sistema. O cliente que faz o uso desse servidor deve primeiramente enviar o arquivo de dados e, em seguida, realizar a chamada à função relnota de filtragem de contornos passando para o servidor o valor da isosuperfície 
de interesse. A forma de envio do arquivo de dados na atual versão do sistema, tanto para enviar como receber dados é feita através de strings. Como resultado da função, é retornado ao cliente uma string contendo o contorno filtrado, que é então ligado a um mapeador para clue o pipcline de visualização tenha seqüêencia.

As principais funçōes implementadas por esse servidor podem ser encontradas na tabeln 4.17 .

\begin{tabular}{|c|c|}
\hline Método & Descrição \\
\hline SctFile () & $\begin{array}{l}\text { Utilizado para passagem do arquivo de dados (na for- } \\
\text { ma de string) para o servidor }\end{array}$ \\
\hline SctCountour () & Filtra o contorno escolhido pelo usuário \\
\hline GetString () & Retorna a string contendo o contorno filtraclo \\
\hline
\end{tabular}

Tabela 4.17: Servidor de Visualização - Principais Métodos

Assim como para o servidor de sons, na compilação é necessário que o caminho para os arquivos ".lib" do Visibroker estejam acessíveis ao projeto. $\mathrm{O}$ arquivo "vtkdll.lib", assim como o caminh arquivos utilizados no projeto do servidor de visualização são: VisualServer.cpp (arquivo principal), VisualizationImpl.h, VisualizationImpl.cpp (implementação do servidor de visualização), IDL_Visualization.hh (skeleton).

A compilação do código servidor gera o executável VisualServer.exe que, quando executado, aguarda que algum cliente solicite a execução de alguma das funções implementadas cm VisualizationImpl. Assim como para o servidor de sonificação, este executável foi criado através do software Microsoft Visual $\mathrm{C}++6.0$.

Nas próximas seçōes são apresentadas as formas através das quais foram implementados e adicionados ao código de DSVol objetos que fizessem acesso às funções implementadas nestes servidores.

\subsubsection{Definição do Cliente CORBA}

Um cliente CORBA é definido basicamente por um objeto definido dentro dos arquivos stub capaz de realizar chamadas à funções remotas implementadas em algum objeto servidor.

Una das funções mais importantes para um objeto cliente é função bind(), responsável por realizar a conexão entre um objeto clicnte e o objeto servidor que possui a implementação das funções do objeto cliente. 
Em DSVol, o passo de inicialização da ORB, que torna possível a comunicação entre servidores e clientes, é realizado dentro do módulo principal do sistema, assim que ele é inicializado. Para o cliente de sonificação foi criada a classe ClientSoundObj (Apêndice A) que tem como principal função criar um objeto do tipo iDL_Sound_var capaz de realizar chimuadas ao scrvidor de sonificação e realizar em sen construtor a chamada à função bind (). Parn o cliente de visualização foi criada a classe ClientVisualizationObj (A plêndice $\Lambda$ ) cuj̊ principal função é criar o objcto iDL_Visualization_var c realizar a clıamada à função bind() para asse objeto.

Uma função importante implementada nessas duas classes é a função GetID() que retorna o ponteiro para o objeto ao (qual foi realizado o método bind() no construtor da classe.

Organizado dessa forma, o sistema DSVol permite que sejam criados objetos das classes ClientSoundObj e ClientVisualizationObj dentro do programa principal. Através do unćtodo GetID o da declaração de ponteiros para as classes iDL_Sound dentro de cada uma clas classes de som em DSVol e iDL_Visualization dentro da classe SV_Visual_Iso é possível a utilização de objetos que realizam a chamada à funções remotas a partir de uma classe de visualização ou sonificação de DSVol. Isso é possível através da implemnentação da função SetIdlSound () para as classes de sonificação e SetIdlVisualization () para as classes de visualizaçĩo. Tais métodos tem como única função iniciar as variáveis contidas nas classes com o ponteiro retornado através do método GetID para um objeto cle sonificação ou visualização distribuído (ClientSoundObj ou ClientVisualizationObj).

A figura 4.20 apresenta um esquema geral de como estão organizadas as classes que permitem o acesso aos servidores distribuídos no DSVol.

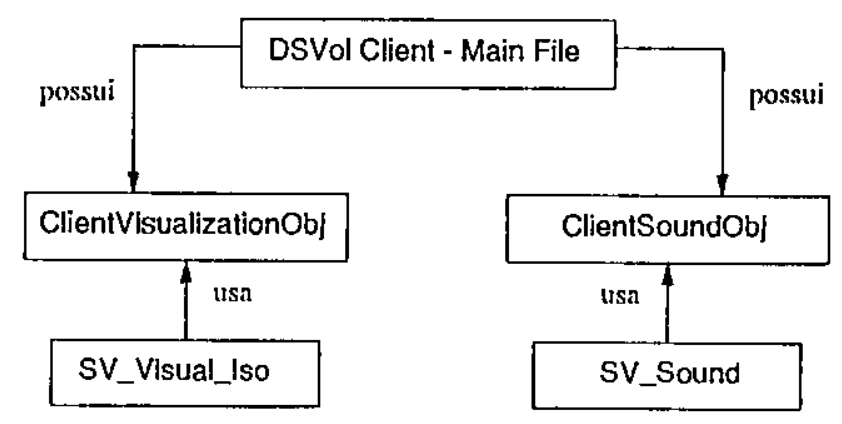

Figura 4.20: Esquema de Organização das Classes no Programa Cliente

Através da interface de entrada de parâmetros do sistema, o usuário pode optar por utilizar on não um serviclor de sons e um servidor de visualização. Quando a opção é por utilizar o servidor de sonificação, as chamadas às funções que realizam os cálculos 
de som são feitas através da variável iDL_Sound_var contida em cada uma das classes de sonificação de DSVol. Quanclo ć utilizado um servidor de visualização, são realizadas chamadas aos objetos remotos através da variável iDL_Visualization_var declarada em SV_Visual_Iso.

Parra a exccuçño tlo DSVol é necessário que o usuário autorize o códligo Java a executar cun sua máquina. Isso é feito através do download do arquivo .java.policy que contém a autorização para sua execução. Outros arquivos necessários para a exccução do sistema são: C.SVol.dll, vport_r.dll, orb_r.dll. Instruções mais delallıadas sobre a instalação e cxecução do DSVol podem sef encontradas em http://www.lcad.icmc.sc.usp.br/ powervis.

\subsection{Resumo dos Resultados Obtidos}

Neste capítulo foi apresentada a implementação de um sistema (DSVol), que incorpora alguns dos conceito\$, discutidos nos capítulos anteriores, de sonificação em visualização, visualização distribuída e visualização na internet.

Ncssa implementação, que se bascou cm um sistema de sonificação previamente desenvolvido [9], foram realizadas as seguintes tarefas:

- Mellioramento da organização e reimplementação total do sistema original utilizando conccitos e ferramentas de orientação a objetos.

- Melhoramcntó das interfaces direta e indireta do código original.

- Inclusão de novas funcionalidades ao sistema no módulos de visualização, sonificação e interação.

- Programação de uma versão do código, acessível pela internet.

- Programação de uma arquitetura distribuída para sonificação.

- Programação de uma arquitetura distribuída para uma parte do pipeline de visualização.

- Utilização de hardware próprio para a realização de DVR.

Com relação especificamente a funcionalidade das sonificações do sistema que deu origem ao DSVol, foram adicionadas:

- Possibilidade kle sonificaçño cm visualização para DVR. 
- Controle de timbre.

- Sonificações cle valores específicos no processo da Sonda Sonora.

- Possibilidade de deffiniçẽo de valores de interesse para sonificação diferentes dos definidos para visualização.

O sistcuna resultante é uma ferramenta poderosa para a exploração e análise de dados, que incorpora diversos conceitos ua teutativa de facilitar seu acesso e utilização por um maior número cle usuários. Isso é muito importante, pelo fato de possibilitar o trabalho em grupo o a fanıiliarização de mais usuários com os processos de visualização e sonificação.

O próximo capítulo é destinado à apresentação das conclusões deste projeto e de sugestões para traballos futuros. 


\section{Capítulo 5 \\ Conclusões}

Este traballıo de mestrado buscou reunir os conceitos de visualização, sonificação, distribuição e interação através da $W e b$ estudados na implementação de um sistema que possibilitasse o uso da sonificação na exploração conjuntos de dados apresentados por isosuperfícies ou DVR.

Como foi visto no capítulo 2, o uso de som em sistemas de exploração de dados tem se tornado cada vez mais comunn. Muitas vezes, usuários podem perceber e analisar informações mais facilmente através de sons. Mesmo quando as imagens são mais indicadas para a apresentação dessas informações, o som pode atuar de forma auxiliar às represcntação gráfica.

Através da dispon bilização do sistema DSVol na Web, este trabalho buscou um maior nivel de utilização dos recursos e técnicas desenvolvidas neste projeto pela facilidade que a $W c b$ proporciona para a comunicação de pesquisadores localizados remotamente. Isso permite que mais usuários tenlam acesso e compartilhem os resultados obtidos através de DSVol.

A criação clos servidores de som e de visualização em DSVol possibilitou ao sistema rcalizar acesso à funçōes e recursos remotos, característica muito importante na área de visualização atualınente. Dessa forma, foi criado uma base para realização de futuros traballıos na área de distribuição, tanto para DSVol como para o projeto PowerVis no qual se encaixa este traballho.

Dessa forma, este traballo de mestrado desenvolveu uma ferramenta bastante promissora para a cxploraçẫo de dados. Para isso, foi neccssária a utilização de vários recursos nas diversas áreas en que se enquadra o sistema, como sonificação, visualização, interação, programação na $W e b$ e distribuição. A necessidade de se criar um sistema que unisse una quantidade grande de diferentes ferramentas e conceitos talvez tenha sido a 
maior dificuldade encontracla durante o desenvolvimento deste traballı.

Em DSVol, foi utilizada da biblioteca VTK [1] para a criação das visualizações e interação com elas. Para a reprodução dos sons gerados através do sistema, foram utilizadas as finções da biblioteca SoundTools [3]." A implementação para o núcleo do sistema foi feita utilizando a linguagem $\mathrm{C}++$ orientada a objetos. Para a criação da interface na Web foi utilizada a linguagem Java e a interface JNI que permite acesso do código Java às funções do núcleo do sistema implementadas em $\mathrm{C}++$. Na criação dos módulos distribuídos foi utilizada a especificação CORBA. Existe uma versão "stand-alone" do sistema cuja interface foi programada utilizando o Borland $\mathrm{C}++$ Builder 4.0.

O sistema desenvolvido reimplementou totalmente o sistema de sonificação anterior (SVol [9]) devido principalmente à necessidade de criação de um sistema puramente orientado a objetos onde houvesse distinção entre seus diversos módulos (como por exemplo, módulo responsável por geração de imagens e módulo responsável pela sonificação). Somente dessa forma foi possível realizar as expansões na funcionalidade do sistema. Entre essas expansões estão incluídas novas técnicas de visualização, sonificação e interação com o usuário, além da implementação dos módulos distribuídos e para a Web do sistema. Ālém disso, o sistemna está mellıor adaptado para futuras alterações.

Trabalhos futuros relacionados ao sistema DSVol incluem:

- Expansão da capacidade de exploração para diferentes conjuntos de dados, como malhas não estruturaclas, e também para diferentes tipos de dados, como por exernplo dados vetoriais e tensoriais.

- Inclusão de novas técnicas de visualização.

- Inclusão de novas técnicas de sonificação.

- Inclusĩo do mapenmento sonoro para outros parânetros (como volume e timbre).

- Expansão da biblioteca SoundTools para que seja possível uma manipulação de um número maior de características sonoras.

- Expansão do servidor de sons, com a utilização de um sistema como o CSound [32][31] na síntese e apresentação dos sons.

- Melhoramentos das capacidades dos módulos distribuídos de visualizaçāo e sonificação, principalmente em relação ao envio de dados entre servidor e cliente.

- Realização das modificações necessárias parn compatibilização com a plataforma Unix. 
Além disso, um estudo do uso da sonificação no contexto da realidade virtual e da capacidade das ferramentas do DSVol operarem nesse contexto será necessária.

Trabalhos recentes mostram um grande crescimento na exploração de dados através

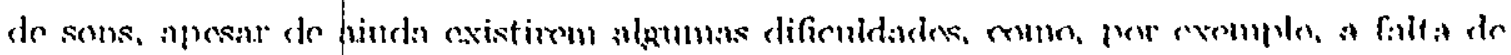
uma padronização na utilização de dispositivos de reproclução. A áreu de visualização distribuída e na $W e b$ também vem crescendo muito nos últimos anos juıtamente com a necessiclade de tornar o accsso a sistemas que realizam tal tarefa mais fácil para os usıários.

Dossa forma, o şistema aqui desenvolvido equipara a sonificação em ambiente de visualização coun a técnologia operante no momento na área de sistemas computacionais, viabilizando o fututo desenvolvimento do sistema e da área de sonificação para dados científicos. 


\section{Referências Bibliográficas}

[1] Schroeder W.J.; Martin K.; Lorensen W. The Visualization ToolKit - An ObjectOricntcd Approuch to 3D Graqlitics. Prentice-Hall, Segunda Edição, 1997.

[2] Brodlie K.W.; Carpenter L.A. ; Earnshaw R.. A.; Gallop J.R.; Hubbold R..J.; Mumford A.M.; Osland G̣.D.; Quarendon P. Scientific Visualization Techniques and Applications. Springer-Verlag, 1992.

[3] Minghim R. On Sound Support for Visualisation. Tese de Doutorado, School of Information Syştems, University of East Anglia, UKK, Março 1995.

[4] Minghim R.; Forrest A.R. An illustreted Analysis of Sonification for Visualization. Em Proceedings, of IEEE Visualization'95, pp. 110-117. IEEE CS Press, 1995.

[5] Minghim R.; Oliveira M.C.F. Powervis: Empowering the User with a Multi-modal Visualization System. Em II IEEE Workshop on Cybernetic Vision, pp. 106-111, IEEE CS Press, São Carlos - SP, 1997.

[6] Minghim R.; Oliveira M.C.F. Uma introdução à visualização computacional. Em JAI'g7 - Jornadas de Atualizaçâo em Informática. XVII Congresso da SBC, Agosto 1997.

[7] Oliveira M.C.F; Minghim R.; Tutida S.M.; Salvador V.C.L. Towards Perception Driven Visualization. Em Proceedings of SIB GRAPI'98, pp. 127-134. IEEE CS Press, 1998.

[8] Salvador V.C.L.; Minghim R.; Pacheco M.L. Sonification to Support Visualization Tasks. Ein Proceedings of SIBGRAPI'98, pp. 150-157. XI Simpósio Brasileiro de Computação Gráfica e Processamento de Imagens, IEEE CS Press, 1998.

[9] Salvador V.C.L. Sonificação para Apoio a Tarefas de Visualização. Tese de Mestrado, ICMC-USP, Abril 1998. 
[10] Salvador V.C.L.; Minghim R. Sonificação para Apoio a Tarefas de Visualização. Em Anais do IV WorkShop de Teses e Dissertações Defendidas. ICMC-USP, 1999.

[11] Barrass S.; Kramer G. Using Sonification. Multimedia Systems, 7, Janeiro 1999.

[12] Krneger M.; Gilden D. Knowwhere: An Audio/Spatial Interface for Blind Pcople. Em Proceedings of ICAD'97, Palo Alto, California, Novembro 1997. http://www. icad.org.

[13] Mitsopoulos E.; Exlwards A. A Principled Methodology for the Specification and Design of Non-Visual Widgets. Em Proccedings of ICAD'98, pp. 1-4. University of Glasgow, UK, Novembro 1998. http://www.icad.org.

[14] Jovnnov E. et al. Acoustic Renderig as Support for Sustained Attention During Biomedical Procedures. Em Proccedings of ICAD'98. University of Glasgow, UK, Novembro 1998. http://www.icad.org.

[15] Bussemakers M.; Haan A. Using Earcons and Icons in Categorisation Tasks to Improve Multimedia Interfaces. Em Proceedings of ICAD'98. University of Glasgow, UK, Novembro 1998. http://www icad.org.

[16] Martins A.C.G.; Rangayyan R.; Portela L.A.; Amaro E.; Ruschioni R.A Experimental Evaluation of Auditory Display and Sonification of Textured Image. Em Proceedings of ICAD'96, Novembro 1996. http://www. icad.org.

[17] Lodlı S.K.; Bealıin .J.; Heppe T.; Joseph A.; Zane-Ulman B. Muse: A Musical Data Sonification Toolkit. Em Proceedings of ICAD'97, Novembro 1997. http: //ww. icad. org.

[18] Pair J.; Kooper R. COOLVR: Implementing Audio in a Virtual Environments Toolkit. Em Proceedings of ICAD'97, Novembro 1997. http://www.icad.org.

[19] Saue S.; Fjeld O.K. A Platform for Audiovisual Seismic Interpretation. Em Proceedings of ICAD'97, Novembro 1997. http://www.icad.org.

[20] Madhyastha T.M.; Reed D.A. Data Sonification: Do You See What I Hear? IEEE Software, 12, pp. 45-56, Março 1995.

[21] Saue S. A model for Interaction in Exploratory Sonification Displays. Em Proceelings of ICAD'2000, 2000. http://www.icad.org/websiteV2.0/Conferences/ ICAD2000/ICAD2000 html. 
[22] Hermann T.; Meinicke P.; Ritter H. Principal Curve Sonification. Em Proceedings of ICAD'O000, 2000. http://www.icad.org/websiteV2.0/Conferences/ICAD2000/ ICAD2000.html.

[23] Sturm B.L. Sonification of Particle Systems via de Broglie's Hypothesis. Em Proceedings of ICAD'2000, 2000. http://www.icad.org/websiteV2.0/Conferences/ ICAD2000/ICAD2000.html.

[24] Dicbcrger A. A Sonification Enhanced Navigation Tool. Em Proceedings of ICAD'2000, 2000. http://www.icad.org/websitev2.0/Conferences/ICAD2000/ ICAD2000. html.

[25] Neuhoff J.G.; Kramer G.; Wayand J. Sonification and the Interaction of Perceptual Dimensions: Can Data Get Lost in the Map ? En Proceedings of ICAD'2000, 2000. http://www. icad.org/websiteV2.0/Conferences/ICAD2000/ICAD2000 . html.

[26] Lodha S.K.; Wilson C.M.; Sheehan R.E. Listen: Sound Uncertainty Visualization. Ein Proccedings of IEEE Visualization'96, pp. 249-261. IEEE CS Press, 1996.

[27] Massey H.; Noyes A.; Sliklair D. A Synthesist's Guide to Acoustic Instruments. Amsco Publications, 1987.

[28] Kaper H.G.; Wiebel E.; Tipei S. Data Sonification and Sound Visualization. Em Computing in Science and Engineering, 1(4), pp. 48-58. Julho, 1999.

[29] Kaper H.G.; Tipei S. Manifold Compositions, Music Visualization and Scientific Sonification in an Immersive. Em Proceedings of Int'l Computer Music Conference'98, pp. 399-405. Mighigall, 1998. http://www-fp.mcs.anl.gov/division/publications/ abstracts/absfracts $98 . \mathrm{htm}$.

[30] Welcome to the Scientific Sonification Project. http://www-unix.mcs.anl.gov/ appliedmath/Sonification.

[31] Virtual Sound - CSound Tutorial. http://web.tiscalinet.it/contempo/web/vs/ inglese/intro.html.

[32] Vorcoe B. The CSound Book: Perspectives in Software Synthesis, Sound Design, Signal Processing, and Programming. The MIT Press, 2000. 
[33] Upson C.; Faulhaber Jr.; T. A.; Kamins D.; Laidlaw D.; Schlegel D.; Vroom J.; Gurwitz R.; Dam A.V. The Application Visualization System: A Computational Environmont for Scientific Visualization. IEEE Computer Graphics and Applications, g(4), pp. 30-42, 1989.

[34] Wood J.; Brodlie K.; Wright H. Visualization Over the World Wide Web and its Application to Environmental Data. Ern Proceedings IEEE Visualization'96, pp. 81-86, Outubro 1996.

[35] Jcm M. Information Visualization on the Web. Em Proceedings IEEE International Confcrence On Information Visualization, pp. 2-7, IEEE CS Press, Julho 1998.

[36] Ilatse H.; Dai F.; Strassucr J.; Gobel. Inmersive Investigation of Scientific Data. Em Scicntific Visualization - Overviews, Methodologies, Techniques, pp. 35-58. IEEE CS Prcss, 1997.

[37] Alıens J.; Law C.; Schroeder W.; Martin K.; Papka M. A Parallel Approach for Efficiently Visualizing Extremely Large Time-Variant Datasets. 2000. http://www . kitware.com/vtkhtm1/vtkdata/pvtk.pdf.

[38] Brodlic K.; El-Klirdili N.; Li Y. Using Web-Based Computer Graphics to Teach Surgery. 11.24, 1p. 157-161, 2000.

[39] Brodlic K.; LoveGrove S.; Wood J. Harnessing the Web for Scientific Visualization. Fevereiro 2000. http://www.siggraph.org/publications/newsletter/ v34n1/columns/visfiles.html.

[40] Alvcs A.D.; Oliveira M.C.F; Minglim R.; Nonato L.G. Interactive Visualization Over the www. Ein Procecdings of SIBGRAPI'2000, pp. 259-266. IEEE CS Press.

[41] Saıtin R.V. Visualização e Exploração de Dados via Internet. Relatório Final de Iniciação Científica. ICMC-USP, Janeiro 2000.

[42] The Source for Java Technology. Copyright@1995-2000 Sun Microsystems. http: //java.sun.com.

[43] The Java Tutorial - A Pratical Guide for Programmers. Copyright(C1995-2000 Sun Microsystcms. http://java. sun.com/docs/books/tutorial.

[14] What is VRML. http://www.vrml.org/about. 
[45] David Reilly Copyright(C)1998. Java RMI \& CORBA a Comparison of Two Compctiug Tcclinolggies. http://www.javacoffeebreak.com/articles/rmi_corba/ index.html.

[46] RAJ Gopalan S. A Detailed Comparison of CORBA, DCOM and Java/RMI. http: //www . execpc . com/ gopala/misc/compare.html. 


\section{Apêndice A}

Arquivos .h de DSVol

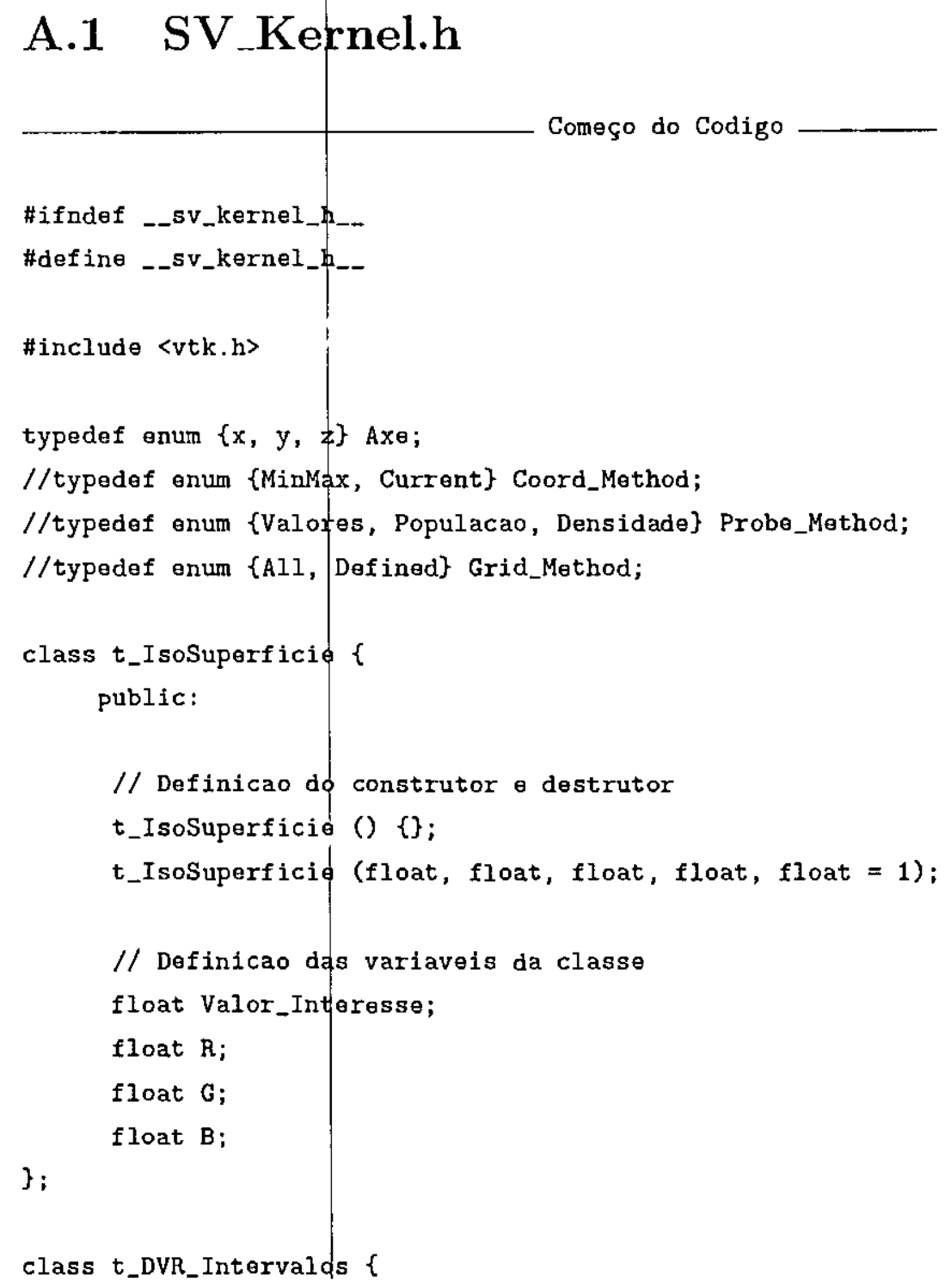


public:

// Definicao do construtor e destrutor

t_DVR_Intervalos () \{\} ;

t_DVR_Intervalos (float, float, float, float, float, float $=1$ );

// Definicao das variaveis da classe

unsigned short Min;

unsigned short Max;

float R;

float $G$;

float $B$;

float Opacidade;

\};

\#endif

Fin do Codigo

\section{A.2 SV_Visual_Kernel.h}

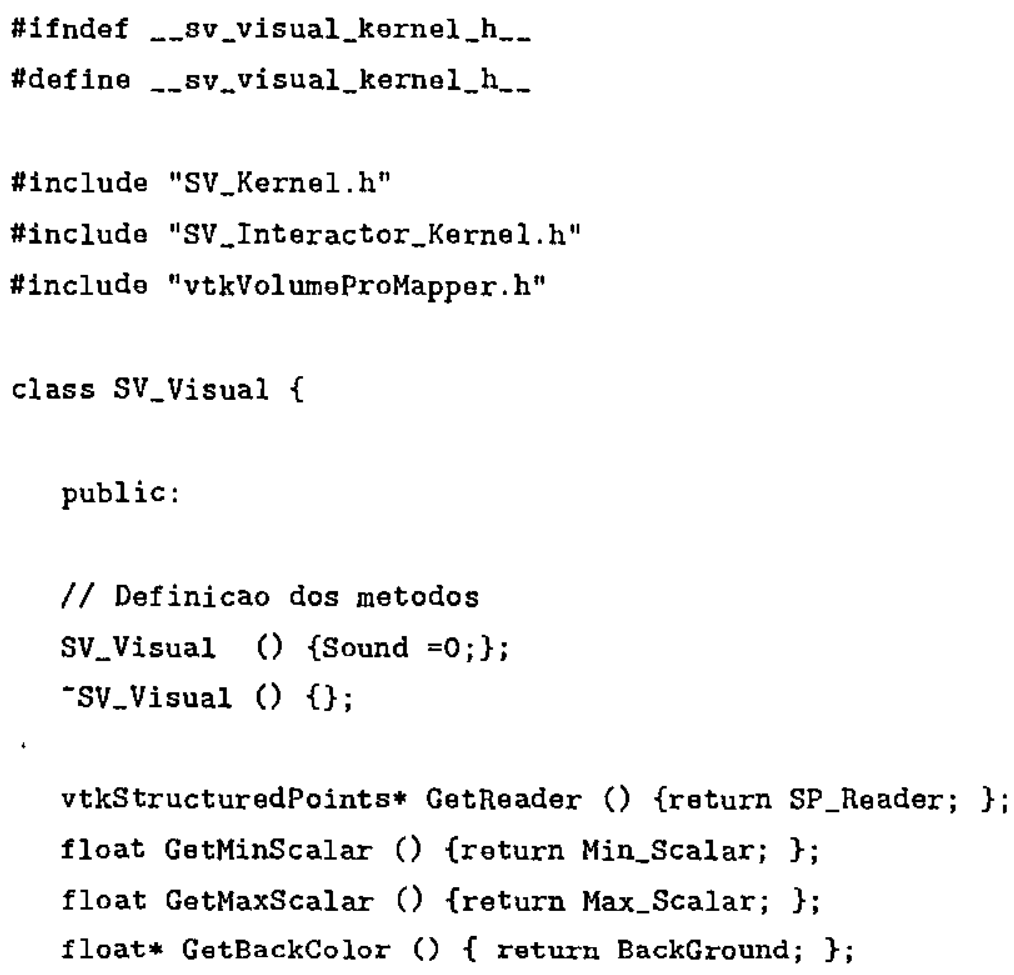




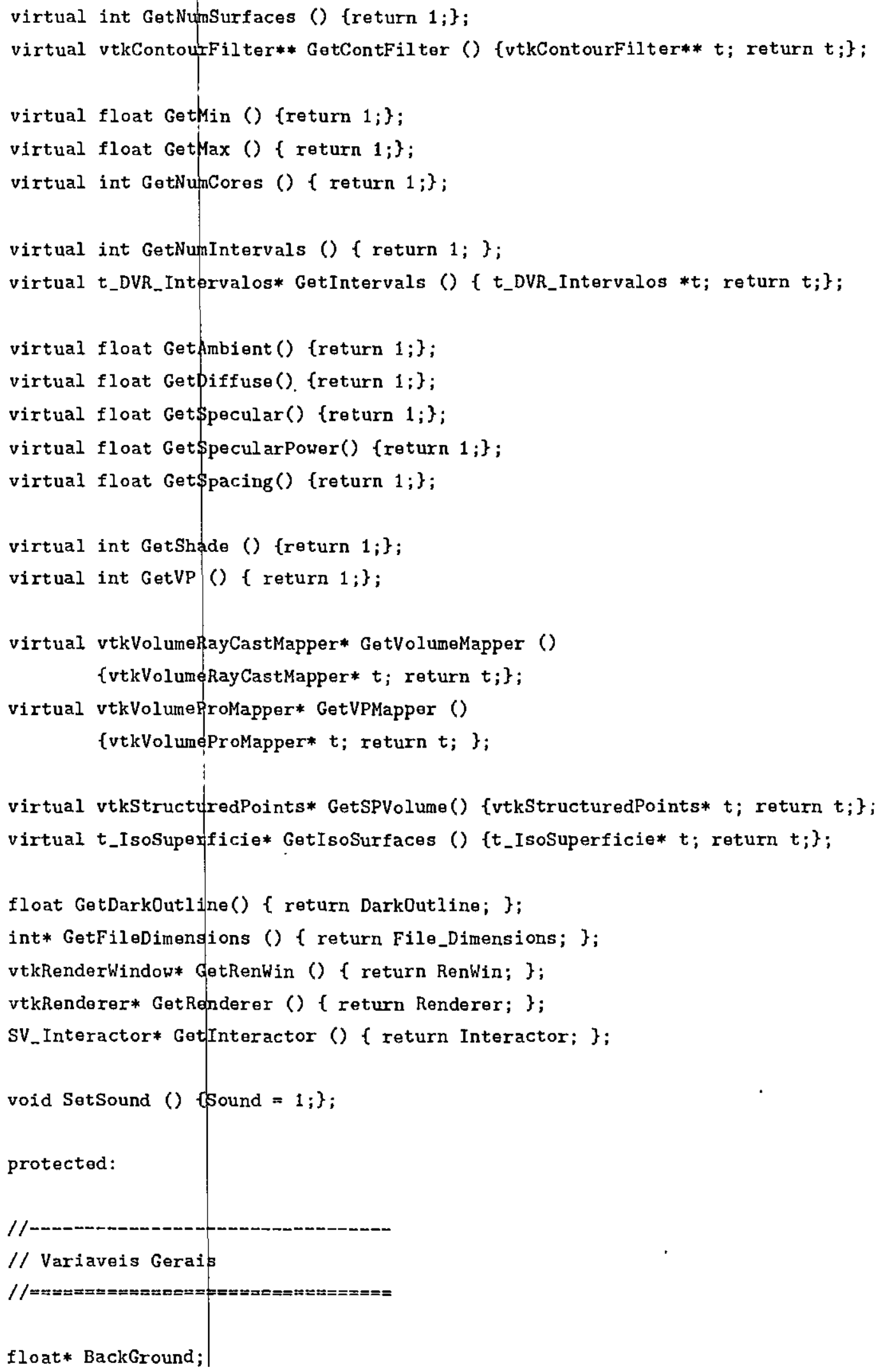


float OutlineColor [3] ;

int DarkDutline;

vtkStructuredPoints* SP_Reader;

vtkRenderer* Renderer;

vtkRenderWindow* RenWin;

double Max_Scalar, Min_Scalar;

int File_Dimensions [3];

// Variavel de Interacao

SV_Interactor* Interactor:

int Sound;

float Ambient, Diffuse, Specular, Power;

; ;

\#endif

\section{A.3 SV_Visual_Iso.h}

Começo do Codigo

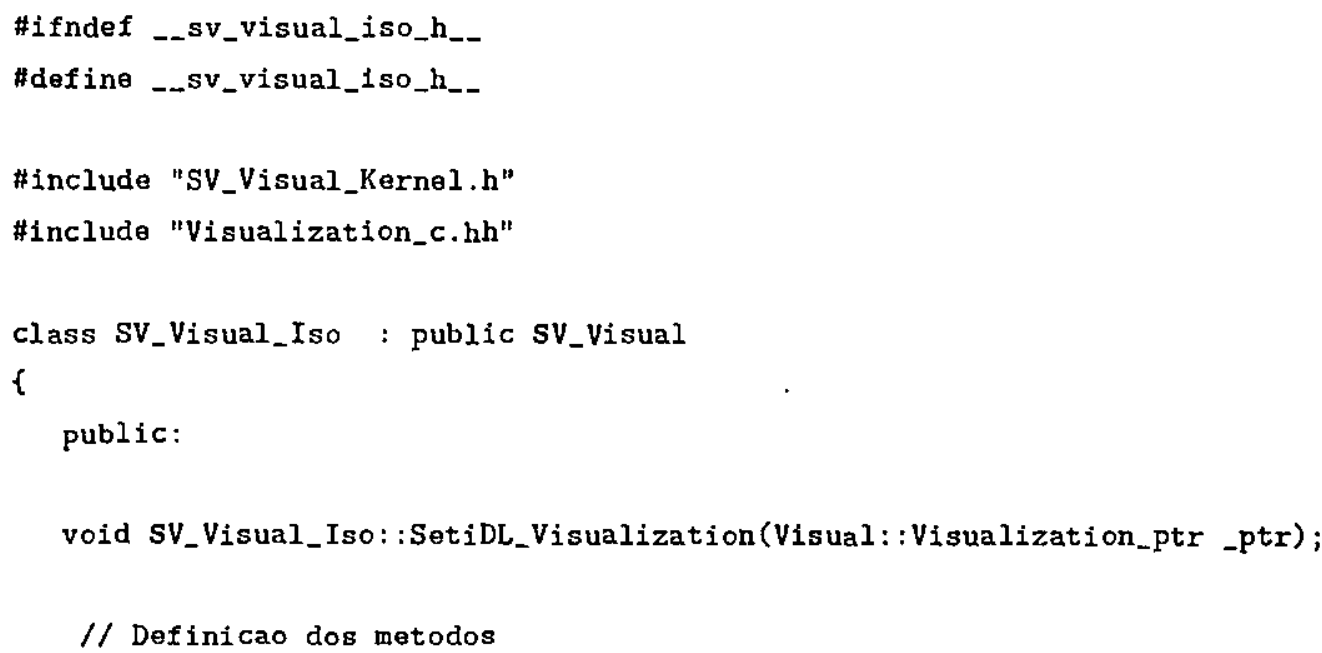




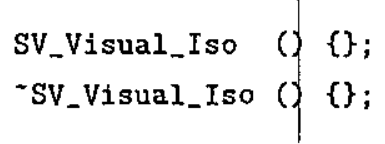




\section{A.4 SV_Visual_DVR.h}

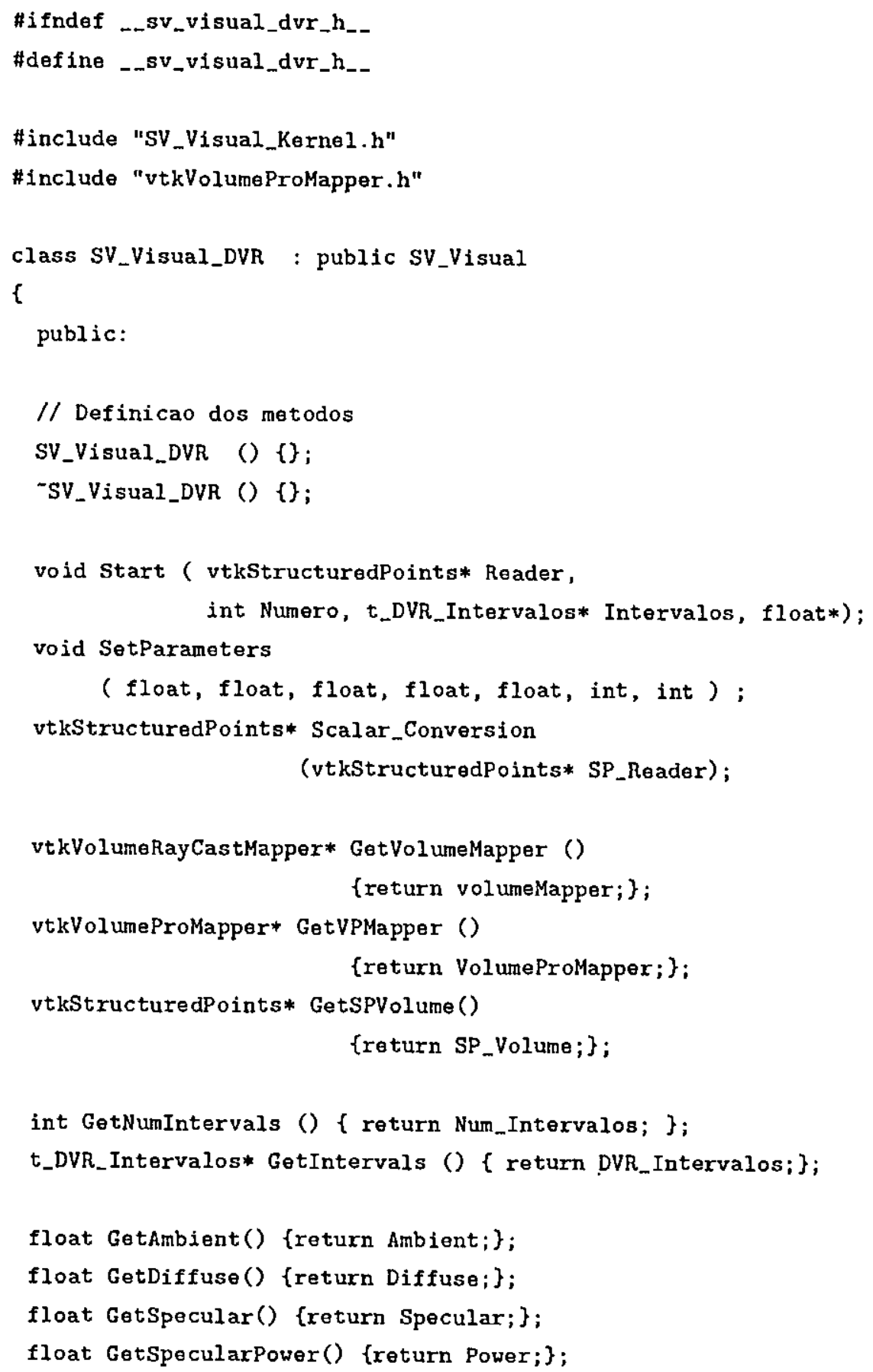




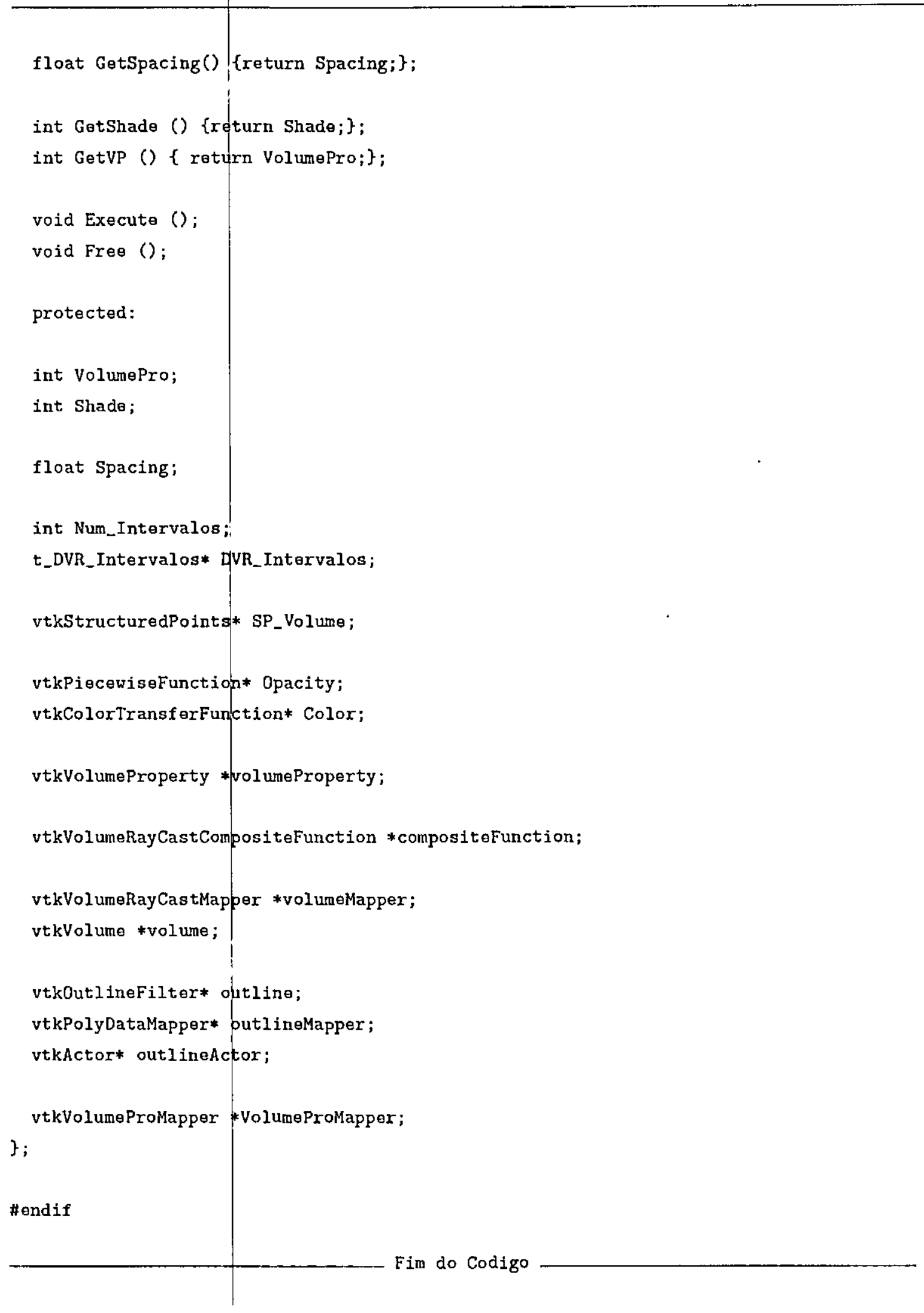




\section{A.5 Sound_Tool.h}

Começo do Codigo

\section{Sound_Tool.H}

Biblioteca implementada a partir de sSound, o sistema de sonificacao de superficie desenvolvido por Minghim e Forrest

Șound Tools Library - conjunto de fun $\backslash c\{c\} \backslash^{-}\{0\}$ es de geracao e playback de som para fornecer as ferramentas para o programa de visualizacao

//Incluir WINMM.LIB no projeto

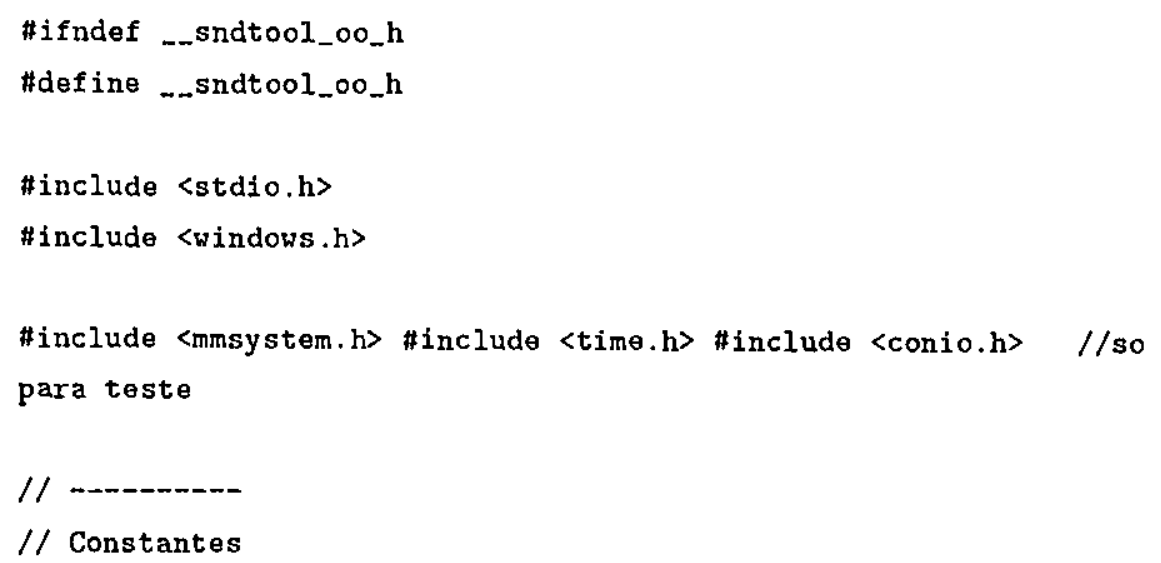




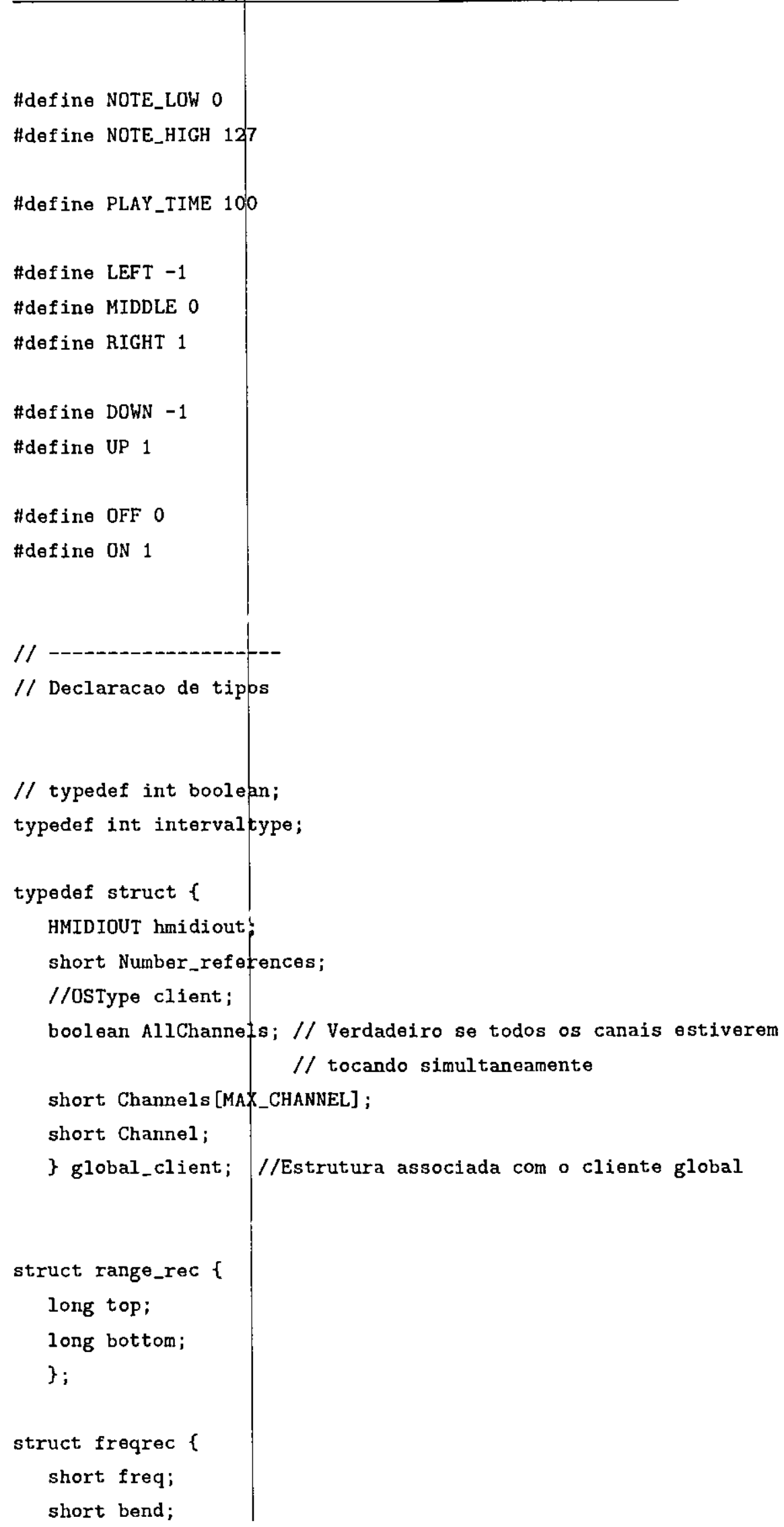


;

enum MIDImestype \{

keyoff, key_on_off, mod_wheel, foot_control, data_entry_MSB, volume, pan_AtoB, pan_select, fx_cont, data_entry_LSB,

sustain_switch, reg_par_LSB, reg_par_MSB, user_control, prog_change, bank_select, chan_press, poly_press, pitch_bend, all_off, reset, t_clock, ctv_sens, s_ex, dump\};

enum pantype $\{A B, A, B, C D, A L L\}$;

typedef struct $\{/ /$ tipo de mensagem

MIDImestype Name;

Int Value [5];

\} Message;

typedef struct $\{/ /$ tipo de mensagem

int Channel;

int Value [3] ;

\} Message 2;

/*class TabSom

\{

public:

TabSom(void);

void Preset(void);

void User(int *);

private:

int tab [10];

\}

*/

// Classe basica de mensagens em programas MIDI

class MIDIPacket

\{

public:

MIDIPacket (void);

DWORD GetProxMens (void);

boolean AddMens (int, int,int);

boolean RemoveMens (void); 
private:

unsigned char flags;

unsigned char num_mes; // numero de mensagens

long tStamp;

DWORD mensagem [MAX_MENS] ; // mensagens

\};

class KERNEL

\{

public:

KERNEL (void);

MIDIPacket *MIDIcomandSingle(Message);

boolean MIDI commandInclude(MIDIPacket *, Message);

boolean MIDI commandRemove(MIDIPacket *);

MIDIPacket *KERNEL : : GetPacket (void);

global_client *KERNEL: :GetClient(void);

boolean Initialize_MIDI(void);

boolean StartUP_MIDI (globaI_client *);

boolean Shut_MIDI();

boolean ShutDown_MIDI(global_client *);

boolean Get_Next_Chanhel(UINT cd);

boolean Get_Previous_Channel(UINT cd);

boolean Get_Specific. Channel(UINT cn);

boolean Initialize_Channel (void);

void TabSom_Preset(void);

vold TabSom_User(int *); 
//private:

global_client *clienteMIDI;//cliente global

int tab_som [15] ;

MIDIPacket *pacote;

\};

class MAPPING

t

public:

freqrec Value_to_MIDIfrequency(int value, int range);

freqrec Major_Third(int base_frequency,

int pitch_bend, intervaltype sense);

freqrec Major_Fifth(int base_frequency,

int pitch_bend, intervaltype sense);

short $P$ an (range_rec range, int value, int direction);

short MIDI_map(float value_to_be_mapped,

int min_interval, int max_interval);

short MIDI_inverse_map(int value_to_be_mapped,

int min.interval, int max_interval);

\};

class SINGLE_STREAM: public KERNEL

\{

public:

void NextTable();

SINGLE_STREAM();

boolean Set_Channel(UINT Channel=0); // Rene

boolean Pitch_Bend_64(int channel,

int value, global_client *);

void Play_Single_off(MIDIPacket *,global_client *

Message $2 *$, long int time_to_wait); 


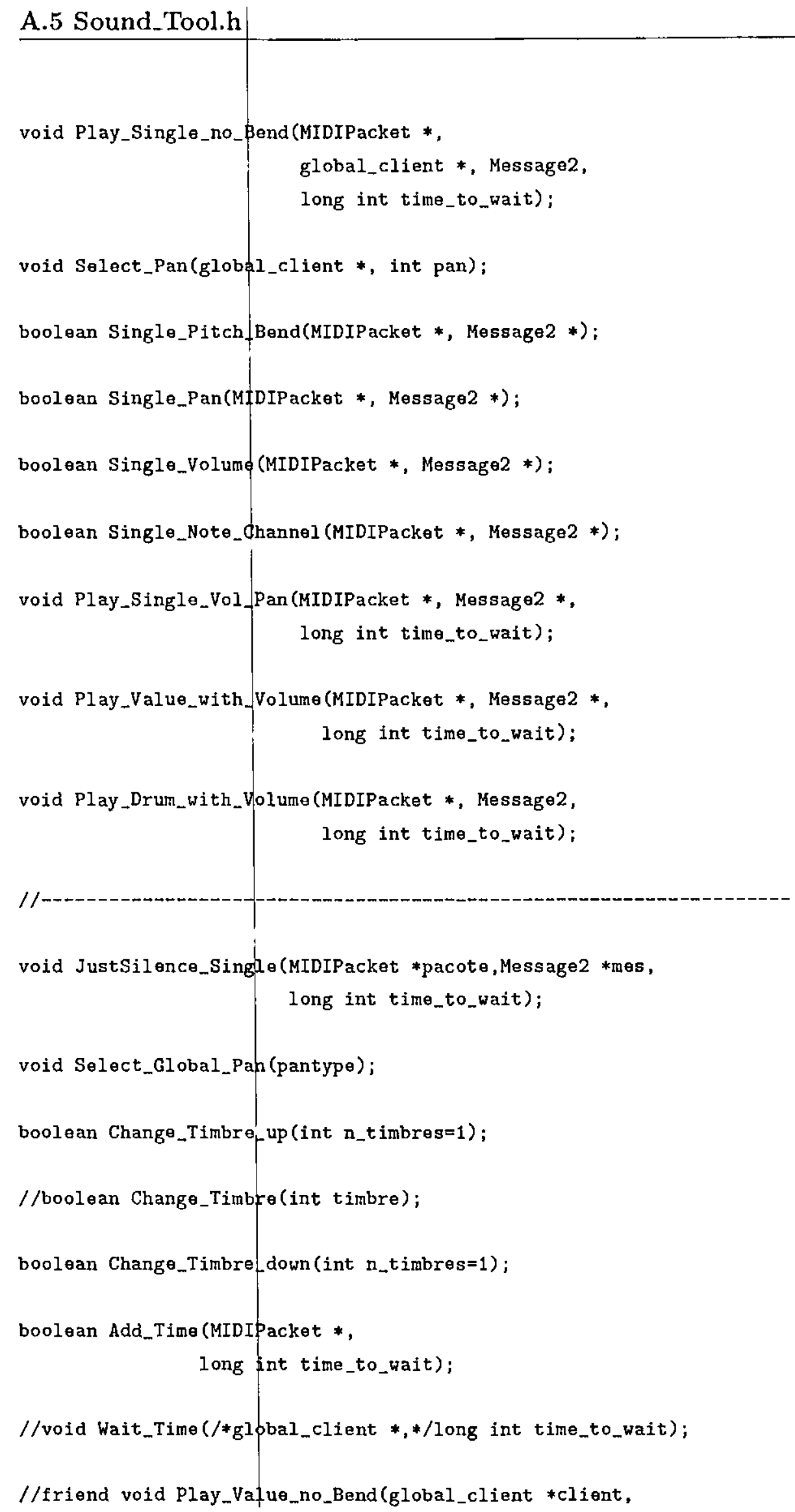

void JustSilence_Single(MIDIPacket *pacote, Message 2 *mes, long int time_to_wait);

void Select_Global_Pah (pantype);

boolean Change_Timbre,up (int n_timbres=1);

//boolean Change_Timbre(int timbre);

boolean Change_Timbre_down (int n_timbres=1);

boolean Add_Time(MIDIPacket *,

long int time_to_wait);

//void Wait_Time(/*global_client *,*/long int time_to_wait);

//friend void Play_Value_no_Bend(global_client *client, 
// Message2 *mes, float time_to_wait);

MIDIPacket *output1;

/*

ponteiros para os canais MIDI (Rene)

*/

short CHANNEL_X;

short CHANNEL_Y;

short CHANNEL_Z;

short CHANNEL_CD;

UINT ACTUAL_CHANNEL;

private:

void RefreshChannels();

void ConfereCanais (short ant_canal);

protected:

UINT ACTUAL_TABLE;

int $\mathrm{tab}[10]$ [MAX_CHANNEL];

\} ;

class MULTIPLE_STREAM: public SINGLE_STREAM

\{

public:

// -

void JustPlayIt_Single(MIDIPacket *, Message2 *,

Iong int time_to_wait);

void Play_Value_on(MIDIPacket *, global_client *,

Message2, Message2, Message 2 mes3,1

long int time_to_wait);

void Play_Value_off(global_client *,

Message $2 *$, long int time_to_wait);

void Play_Value_no_Bend(MIDIPacket *, global_client *,

Message2*, long int time_to_wait);

void All_Notes_off(global_client *,

long int time_to_wait); 


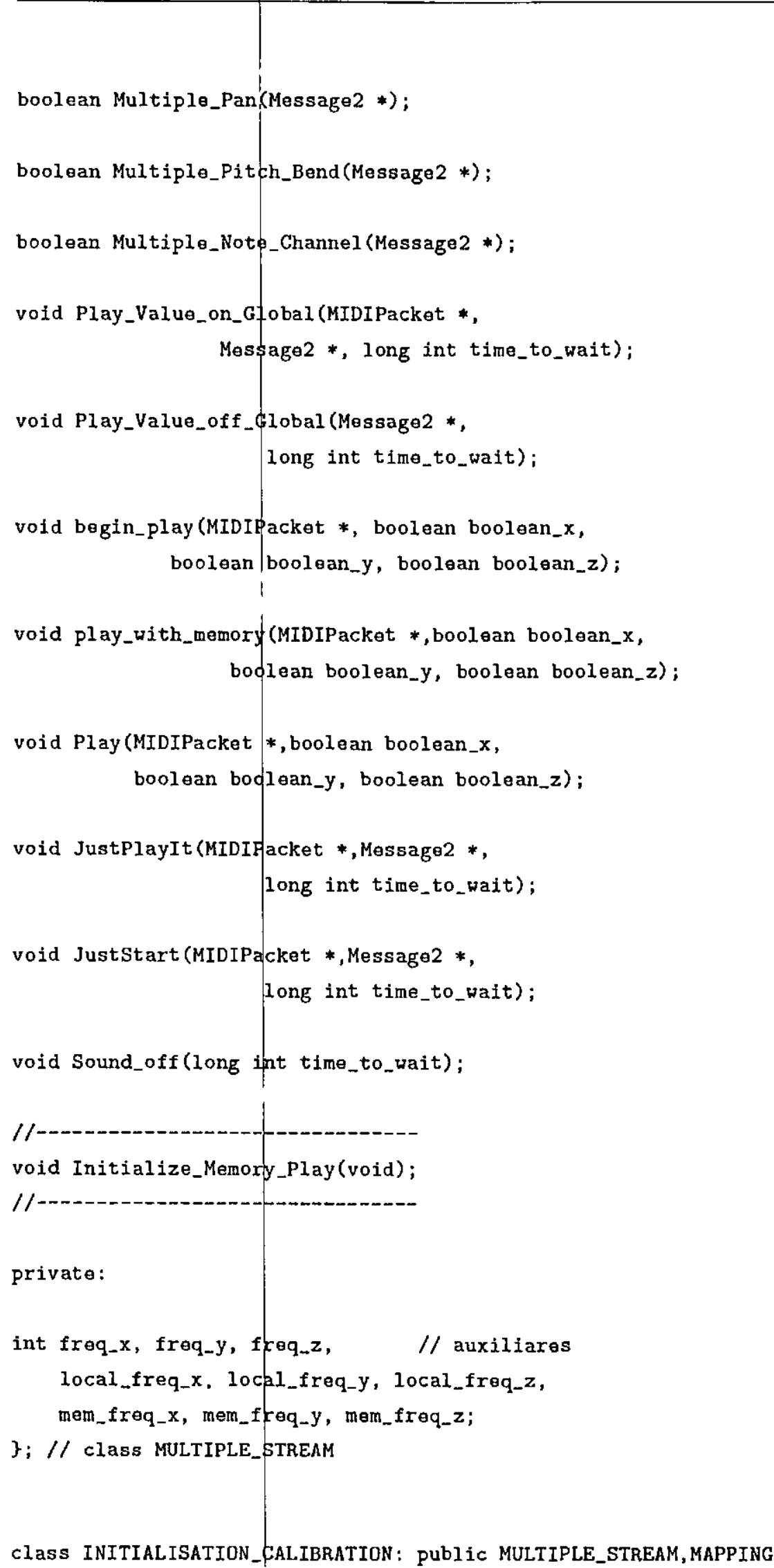


\{

public:

boolean Initialize_Sound(void);

void Shut_Sound(void);

boolean Set_Initial_Timbre();

//void Initialize_Memory_Play(void);

// substituida por MUTIPLE_STREAM: : Initialize_Memory_Play()

void Wait_Time(long int time_to_wait);

void just_wait(long int time_to_wait);

boolean SendMessage(global_client *, long int time_to_wait);

boolean MIDIWritePacket (global_client *, MIDIPacket *);

void Calibrate(global_client *, long int time_to_wait);

void Calibrate_Current_Timbre (MIDIPacket *);

\}; // class INITIALISATION_CALIBRATION

\#endif//_. sndtool_oo_h

Fim do Codigo

\section{A.6 SV_Sound_Kernel.h}

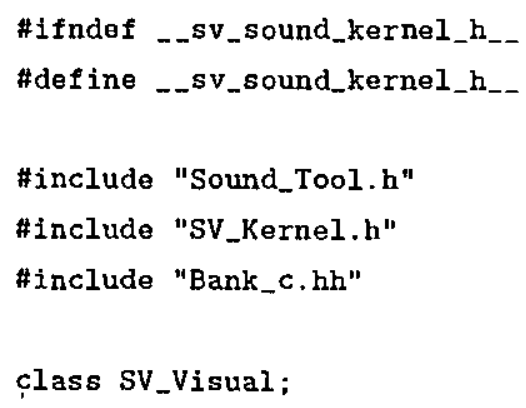




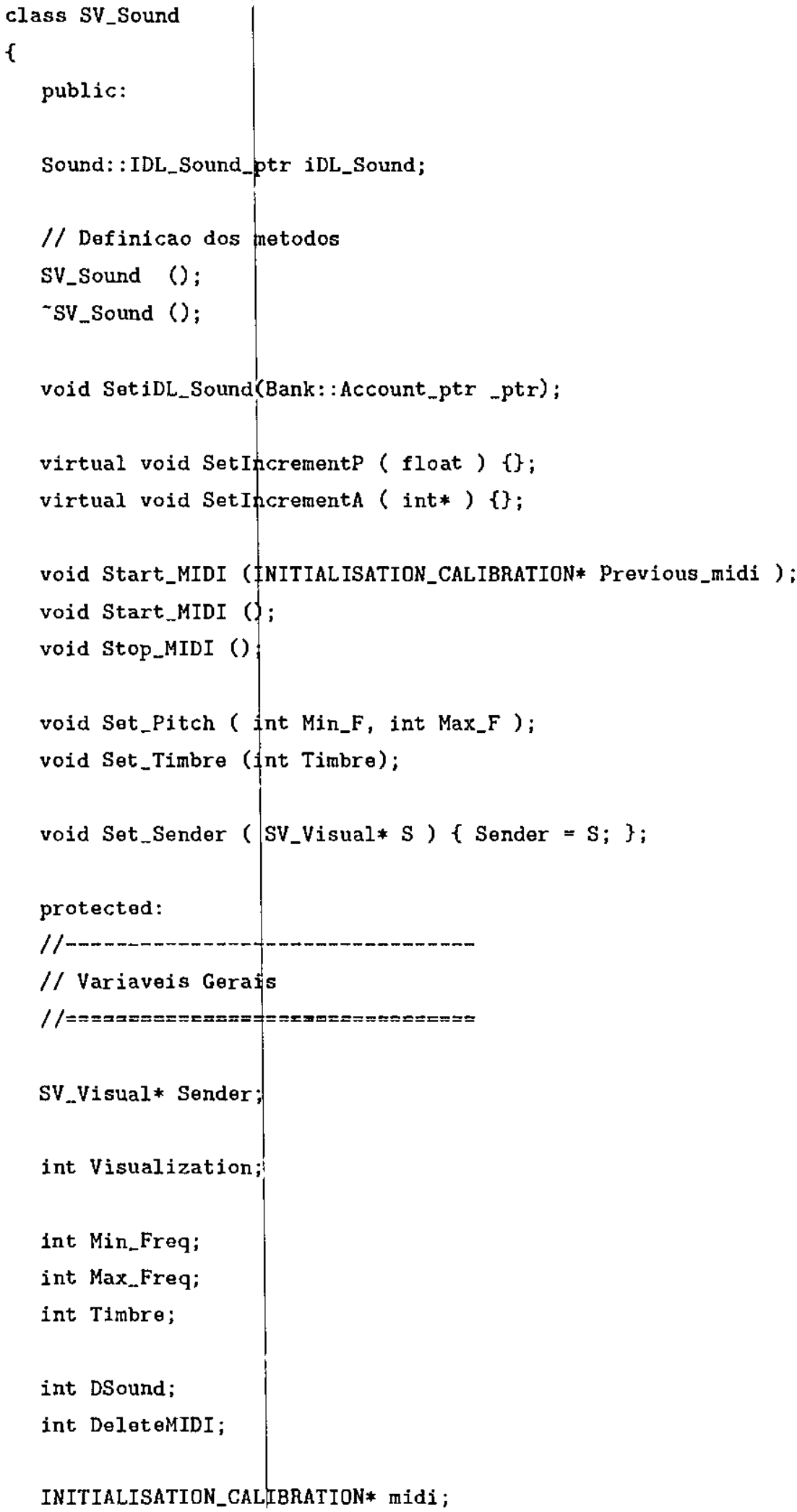


;

\#endif

Fim do Codigo

\section{A.7 SV_Sound_Coord.h}

Começo do Codigo

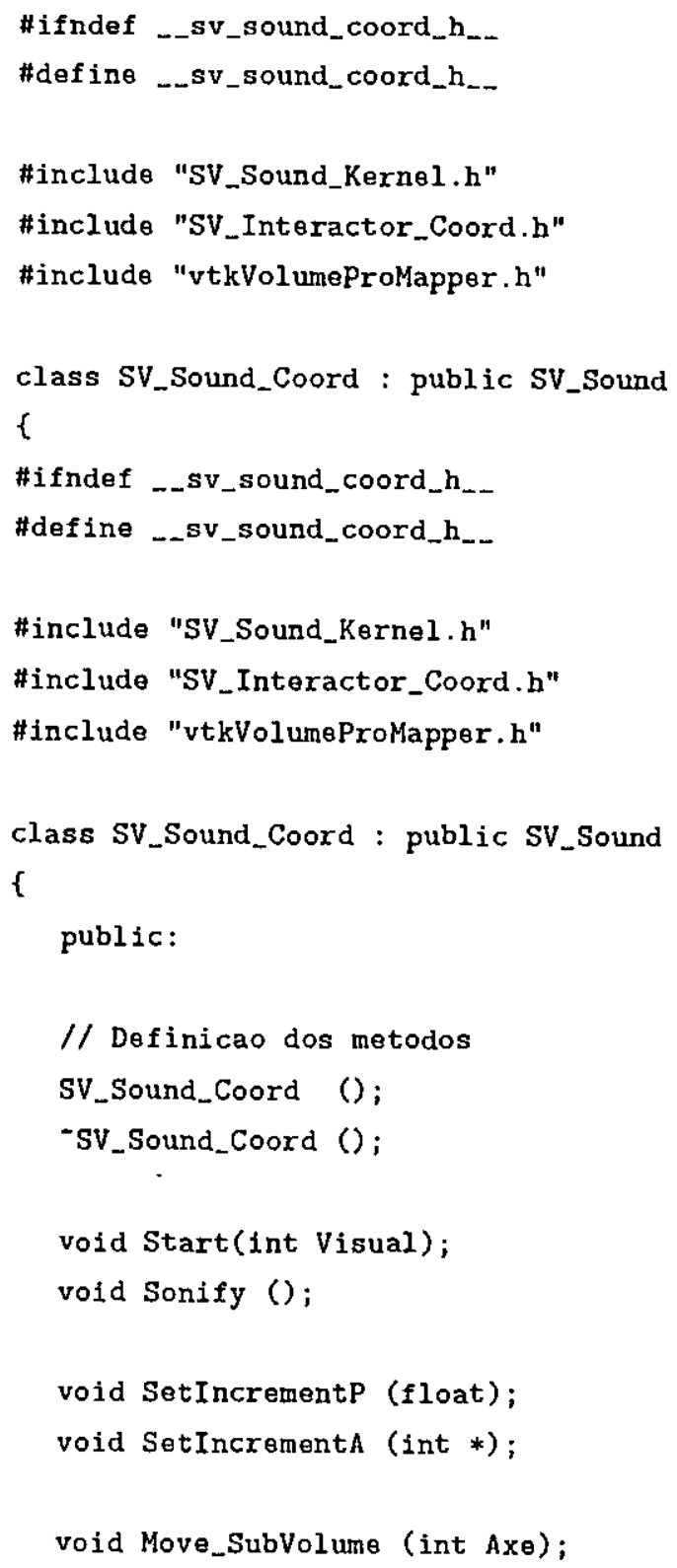




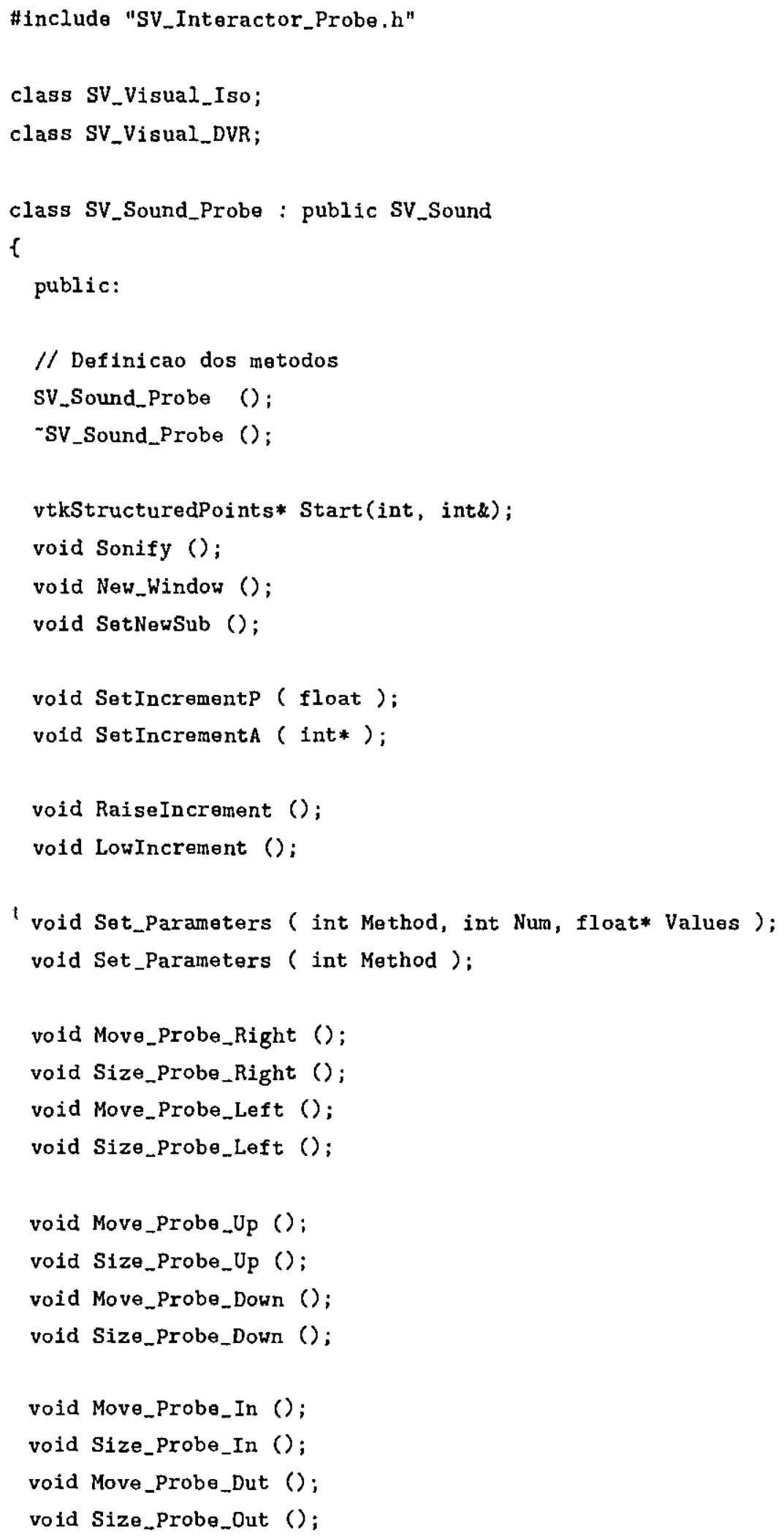




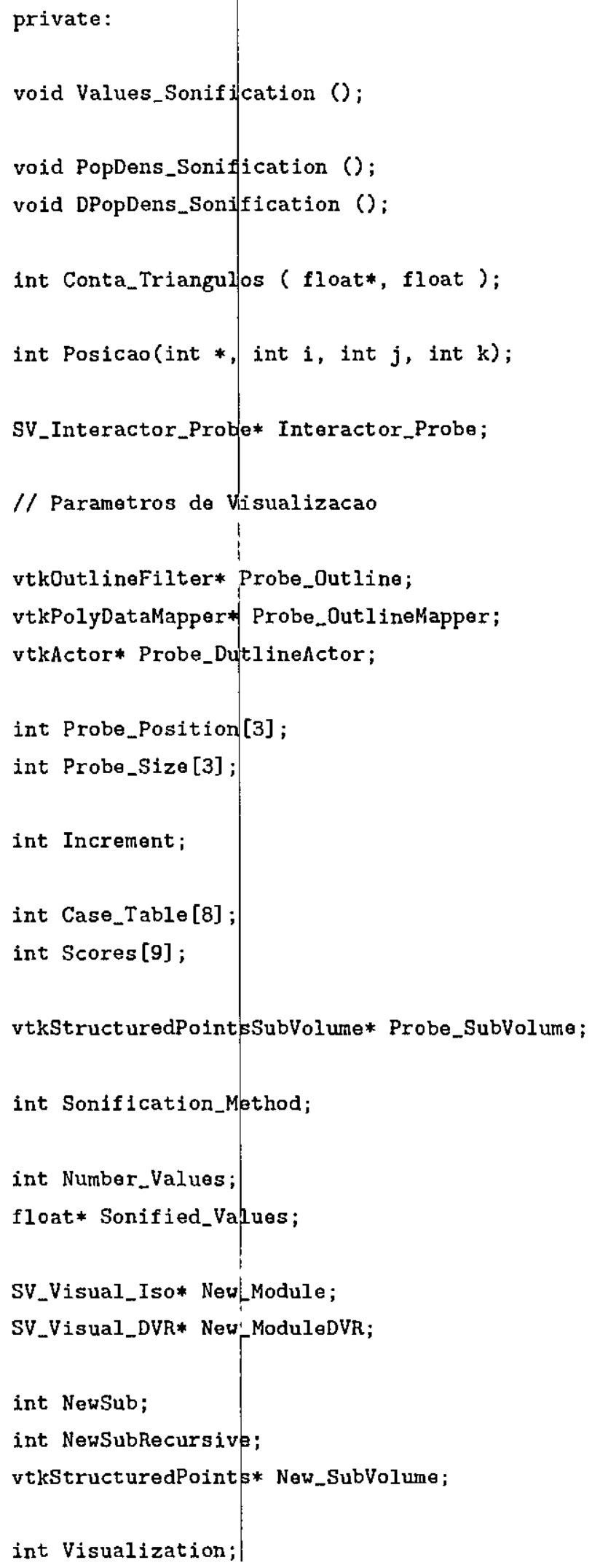


\};

\#endif

\section{A.9 SV_Sound_Grid.h}

Começo do Codigo

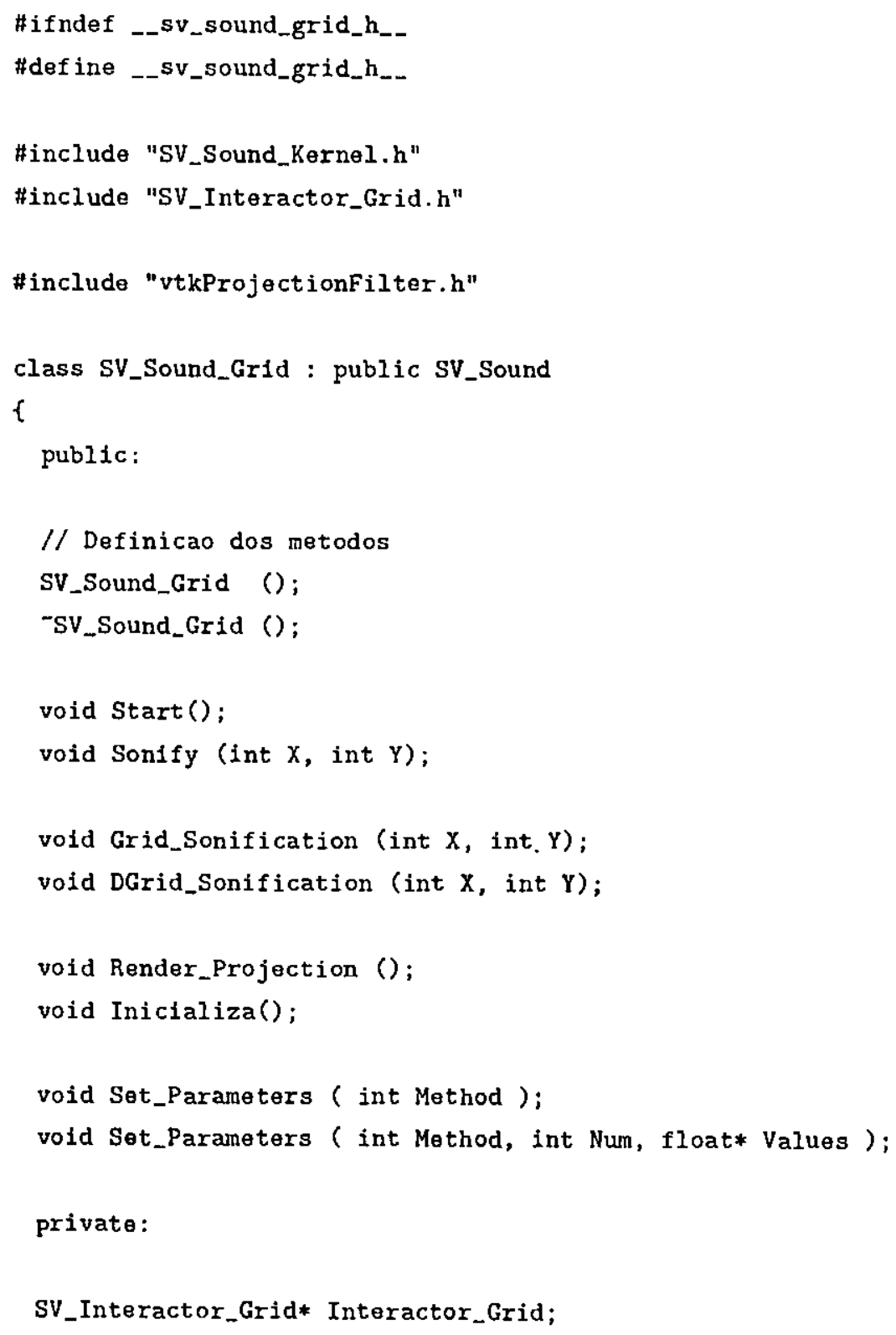




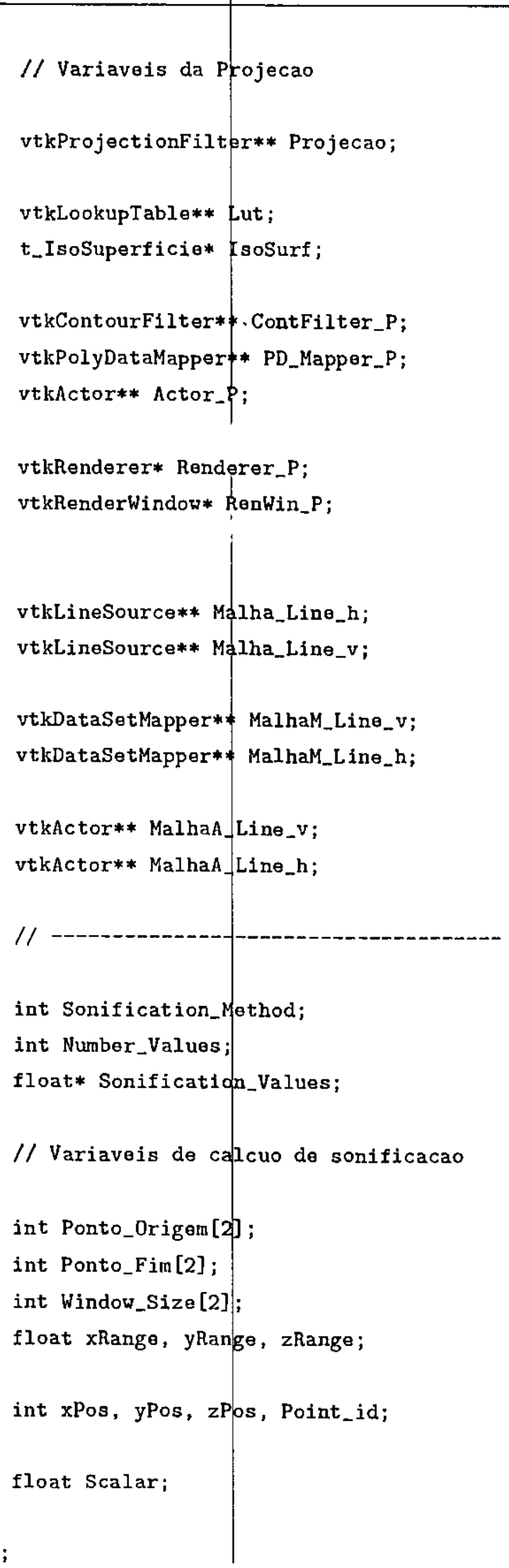




\section{A.10 SV_Interactor_Kernel.h}

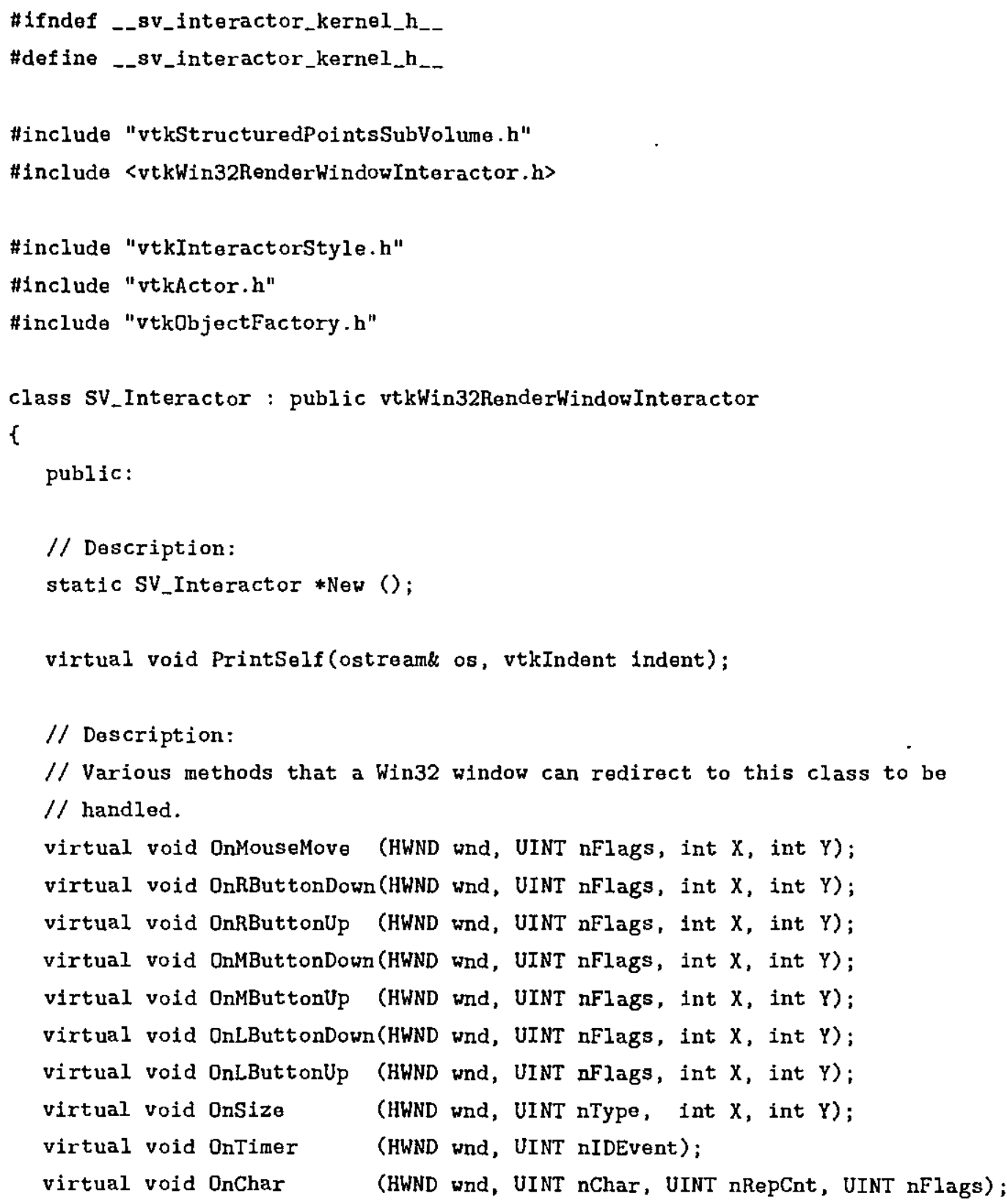




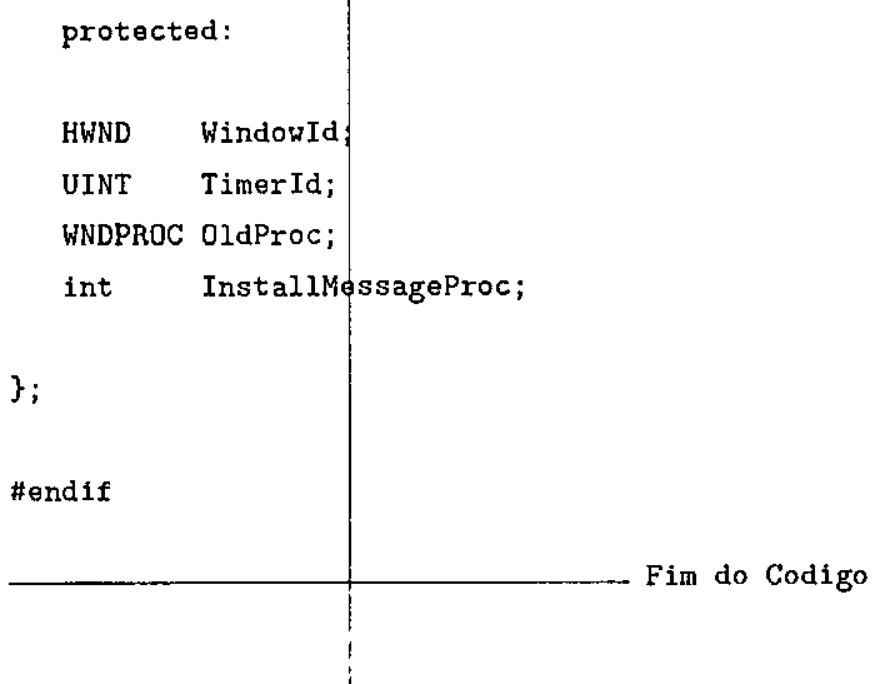

\section{A.11 SV_Interactor_Coord.h}

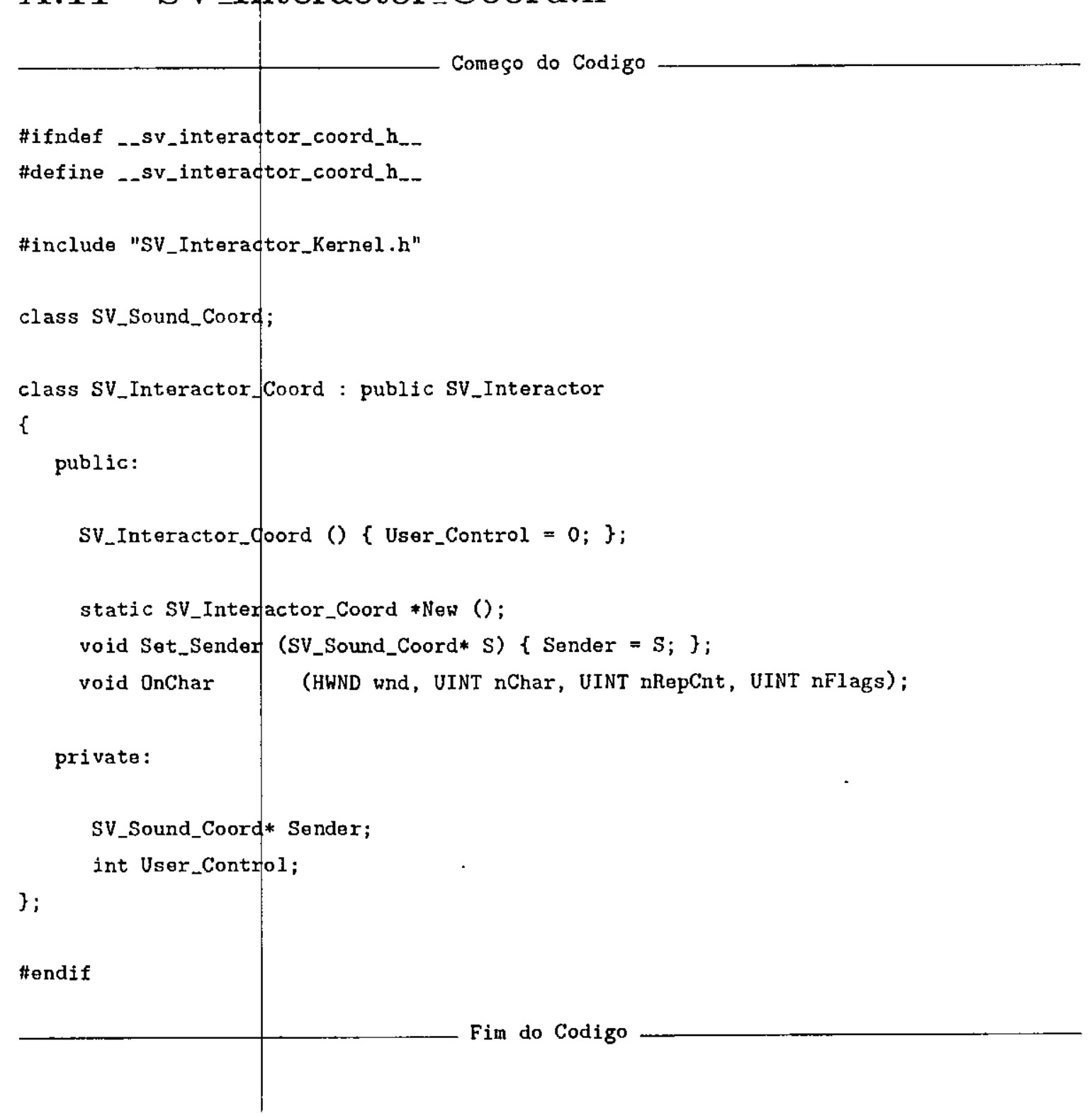




\section{A.12 SV_Interactor_Probe.h}

Começo do Codígo

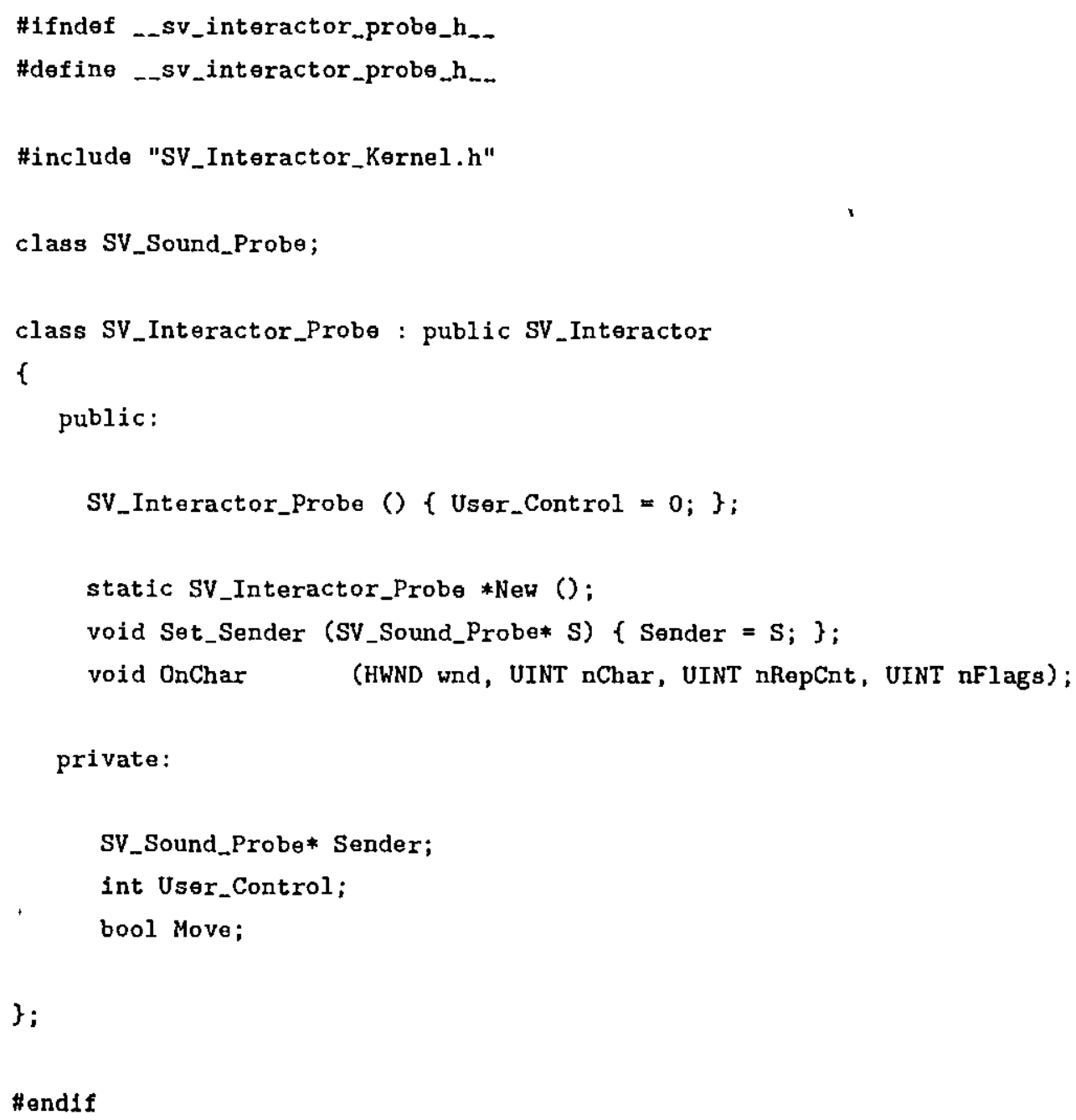

\section{A.13 SV_Interactor_Grid.h}

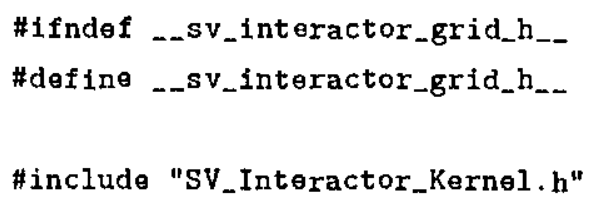




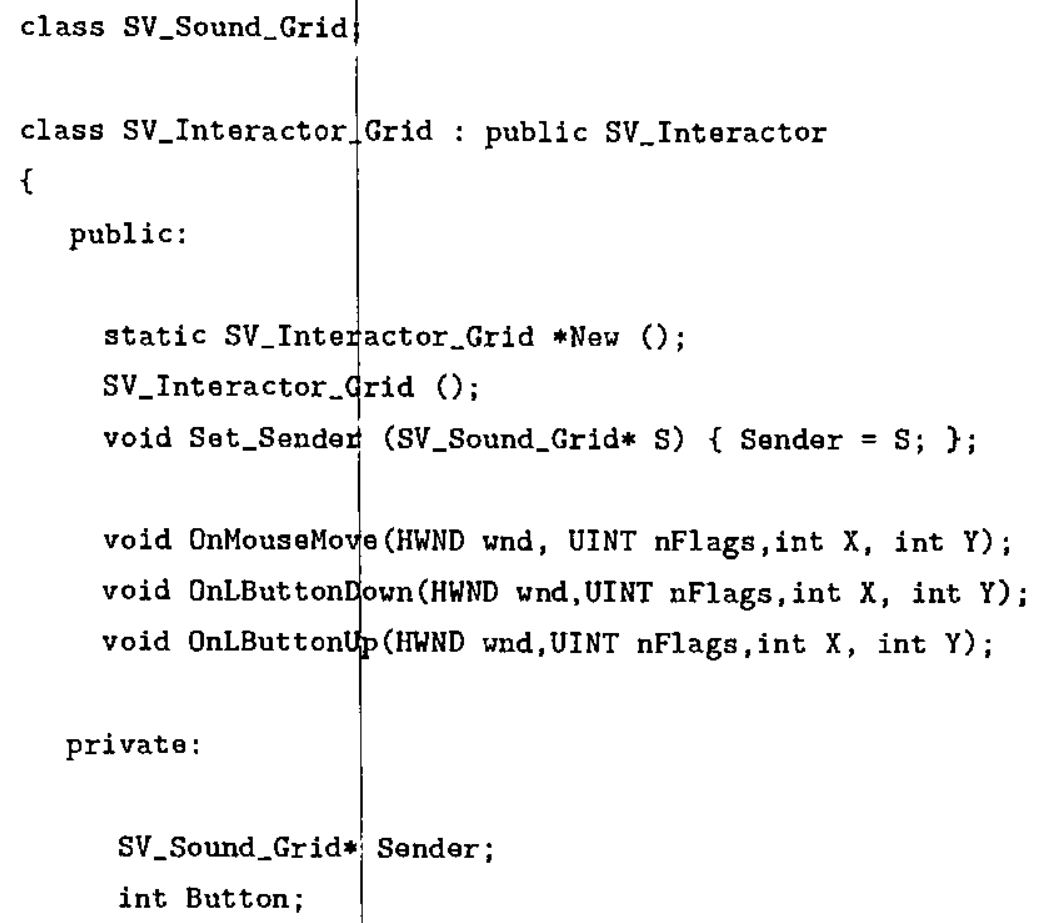

\section{A.14 VKThread.h}

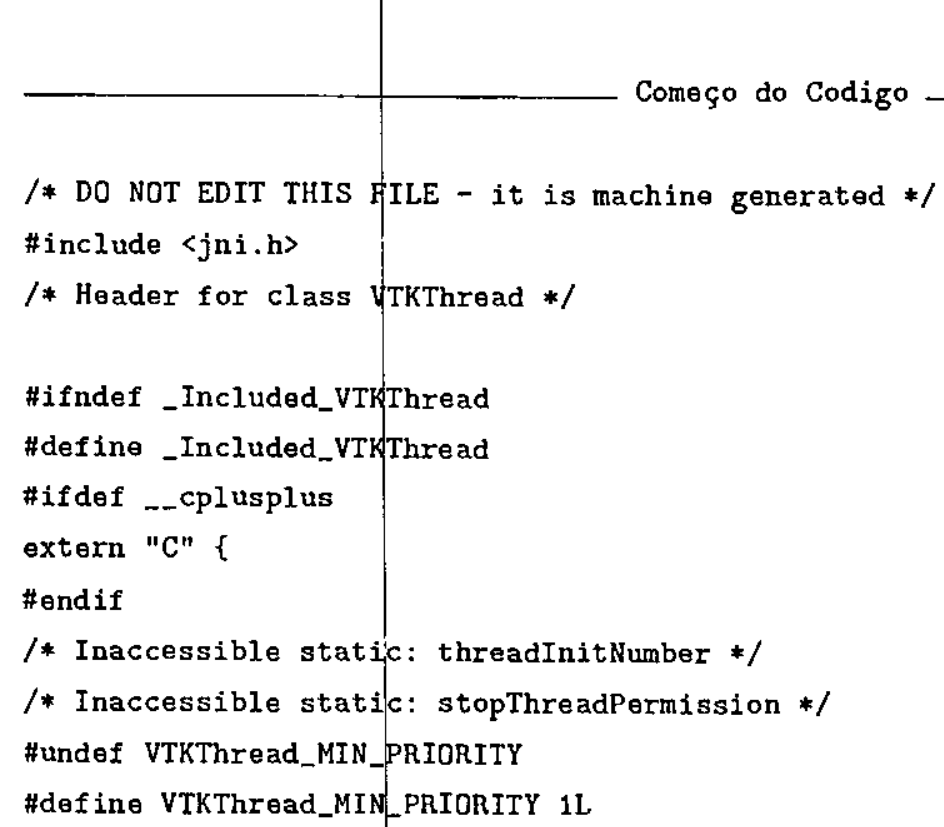


\#undef VTKThread_NORM_PRIORITY

\#define VTKThread_NORM_PRIORITY $5 \mathrm{~L}$

\#undef VTKThread_MAX_PRIORITY

\#define VTKThread_MAX_PRIORITY 10L

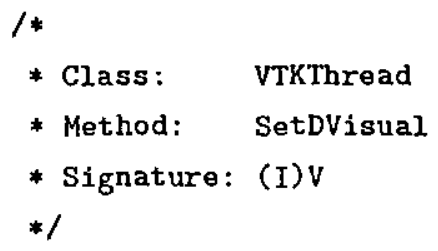


JNIEXPORT void JNICALL Java_VTKThread_SetIsoParameters

(JNIEnv *, jobject, jint, jfloatArray);

/*

* Class: VTKThread

* Method: SetDVRParameters

* Signature: (I [FI) V

$* /$

JNIEXPORT void JNICALL Java_VTKThread_SetDVRParameters

(JNIEnv *, jobject, jint, jfloatArray, jfloat,

jfloat, jfloat, jfloat, jfloat, jint, jint );

$1 *$

* Class: vTkThfead

* Method: RendefIso

* Signature: ()V

*/

JNIEXPORT void JNICALL Java_VTKThread_RenderIso

(JNIEnv *, jobject);

/*

* Class: VTKThread

* Method: RenderDVR

* Signature: () v

$* /$

JNIEXPORT void JNICALL Java_VTKThread_RenderDVR

(JNIEnv *, jobject);

$/ *$

* Class: VTKThread

* Method: RenderIsoSound

* Signature: ()V

*/

JNIEXPORT void JNICALL Java_VTKThread_RenderIsoSound

(JNIEnv *, jobject) ;

$1 *$

* Class: VTKThread

* Method: RenderpvrSound

* Signature: () V

*/

JNIEXPORT void JNICALL Java_VTKThread_RenderDVRSound

(JNIEnv *, jobject) ; 
$1 *$

* Class: VTKThread

* Method: SetSoundParameters

* Signature: (IIIII) $v$

*1

JNIEXPORT void JNICALL Java_VTKThread_SetSoundParameters

(JNIEnv *, jobject, jint, jint, jint);

$/ *$

* Class: VTKThread

* Method: SetSoundCoordParameters

* Signature: (I) V

$* 1$

JNIEXPORT void JNICALL Java_VTKThread_SetSoundCoordParameters

(JNIEnv *, jobject, jint, jint);

/*

* Class: VTKThread

* Method: SetSoundProbeParameters

* Signature: (I [F) V

$* /$

JNIEXPORT void JNICALL Java_VTKThread_SetSoundProbeParaneters

(JNIEnv *, jobject, jint, jint, jfloatArray);

$/ *$

* Class: VTKThread

* Method: SetSoundGridParameters

* Signature: (I $[F) V$

$* 1$

JNIEXPORT void JNICALL Java_VTKThread_SetSoundGridParameters

(JNIEnv *, jobject, jint, jint, jfloatArray);

/*

* Class: VTKThread

* Method: SetSoundProbe

* Signature: ()V

$* 1$

JNIEXPORT void JNICALL Java_VTKThread_SetSoundProbe

(JNIEnv *, jobject, jint);

/*

* Class: VTKThread 
* Method: SetSoundGrid

* Signature: () V

*/

JNIEXPORT void JNICALL Java_VTKThread_SetSoundGrid

(JNIEnv *, jobject, jint);

/*

* Class: VTKThread

* Method: RestoreData

* Signature: ()V

*/

JNIEXPORT void JNICALL Java_VTKThread_RestoreData

(JNIEnv *, jobject);

/*

* Class: VTKThread

* Method: SetCoordincrementP

* Signature: (F) V

*I

JNIEXPORT void JNICALL Java_VTKThread_SetCoordIncrementP

(JNIEnv *, jobject, jfloat);

/*

* Class: VTKThread

* Method: SetCoordincrementA

* Signature: ( [I) V

*1

JNIEXPORT void JNICALL Java_VTKThread_SetCoordIncrementA

(JNIEnv *, jobject, jintArray);

/*

* Class: VTKThread

* Method: SetProbeincrementP

* Signature: (F) V

$* 1$

JNIEXPORT void JNICAL. Java_VTKThread_SetProbeIncrementP

(JNIEnv *, jobject, jfloat);

/*

* Class: VTKThread

* Method: SetProbelincrementa

* Signature: ([I)V

*/ 


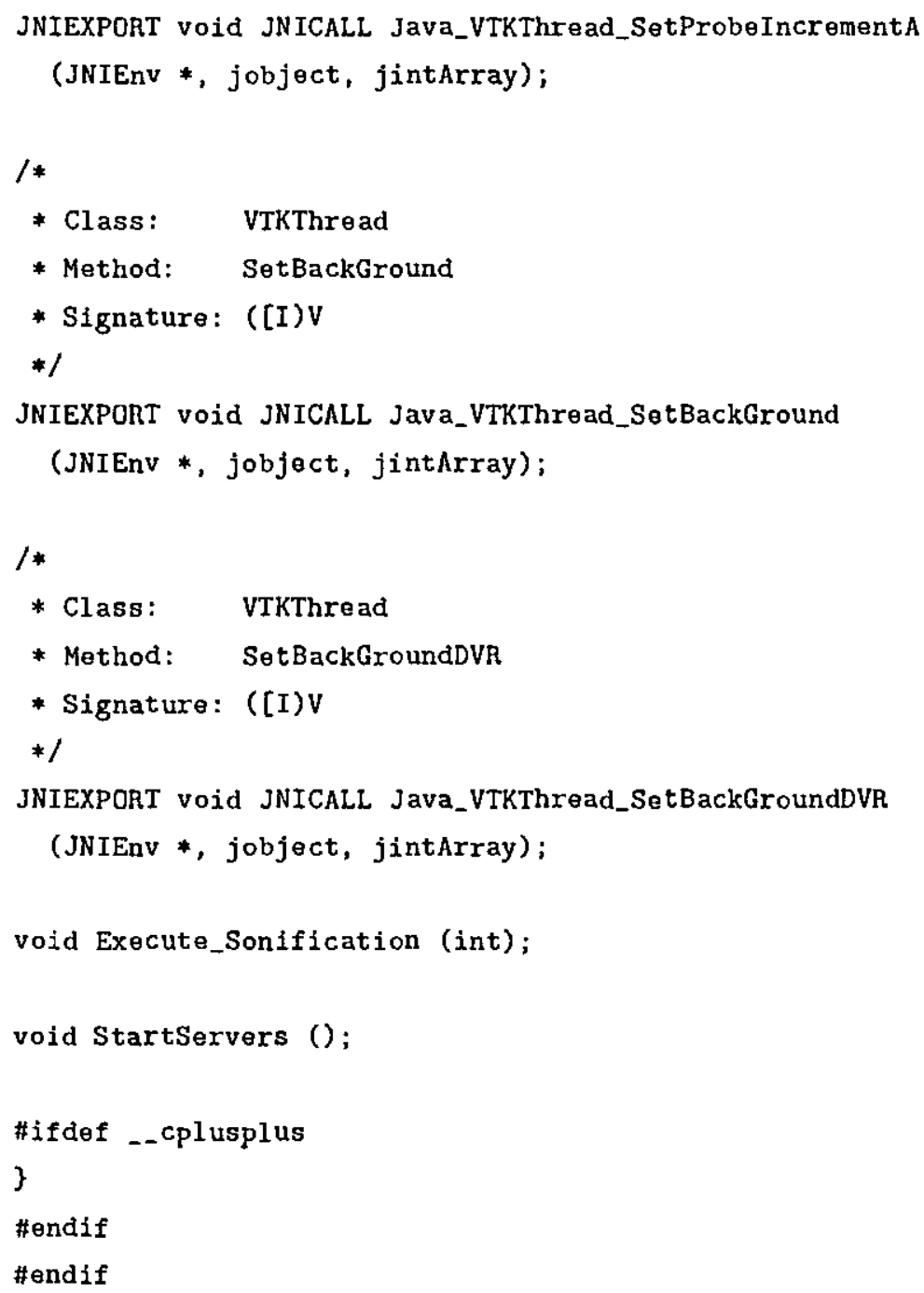

\section{A.15 Vizualization.idl}

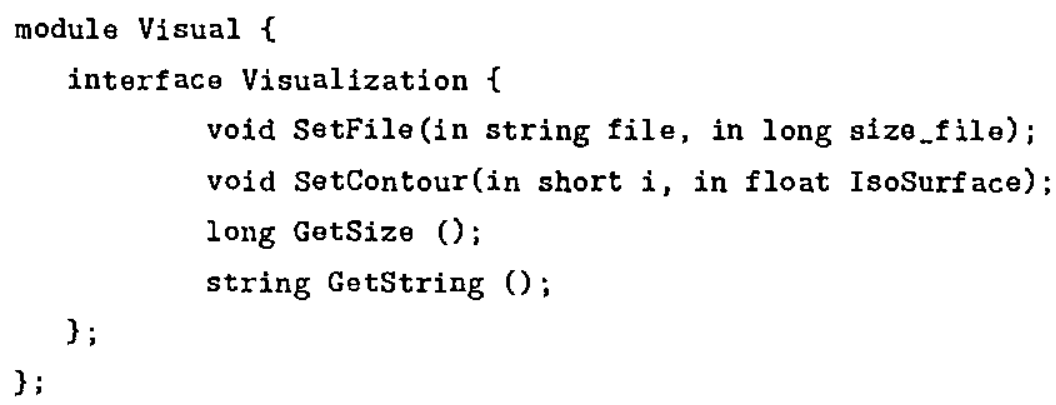


Fim do Codigo

\section{A.16 Sound.idl}

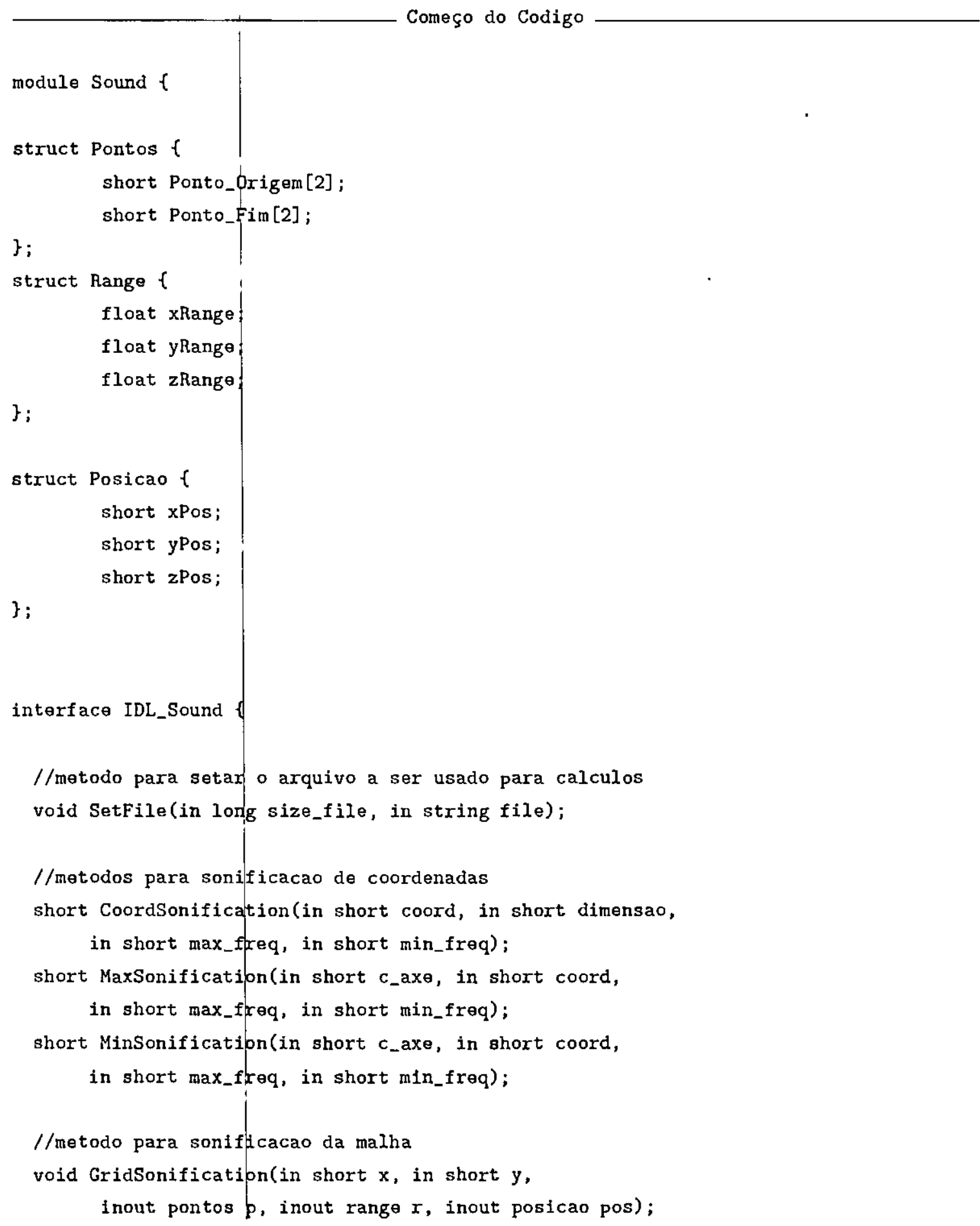


float PointID(in posicao pos);

//calcula a frequencia

short ScalarValue(in float scalar, in float max_scalar,

in float min_scalar, in short max_freq, in short min_freq);

//metodo para sonificacao da sonda

void SetNumValues(in short $n$ );

void Setvalues (in float value, in short ind);

short PopDensSonification(in short probe_positionx,

in short probe_positiony, in short probe_positionz,

in short probe_sizex, in short probe_sizey,

in short probe_sizez, in short sonification_method,

in short max_freq, in short min_freq);

short ValuesSonification(in short probe_positionx,

in short probe_positiony, in short probe_positionz,

in short probe_sizex, in short probe_sizey,

in short probe_sizez, in short max_freq, in short min_freq);

\};

\};

Fim do Codigo

\section{A.17 VizualizationImpl.h}

Começo do Codigo

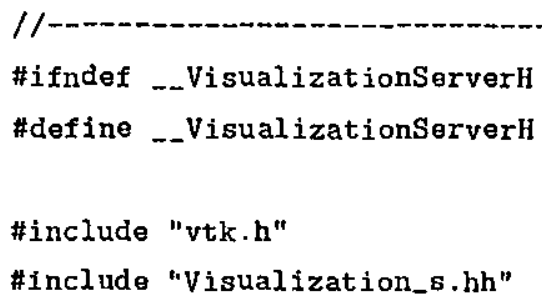




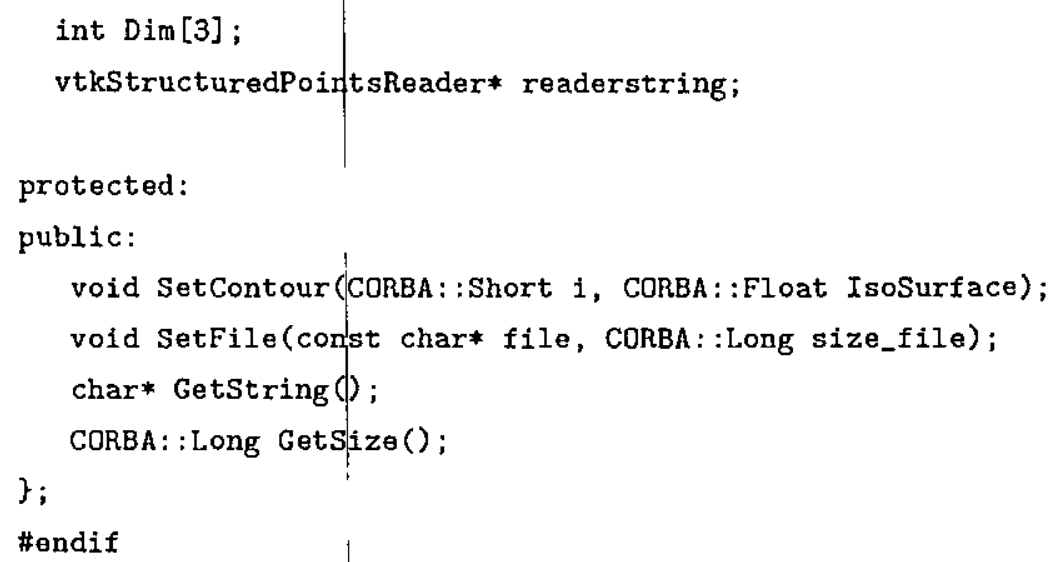

\section{A.18 SoundImpl.h} Fim do Codigo 


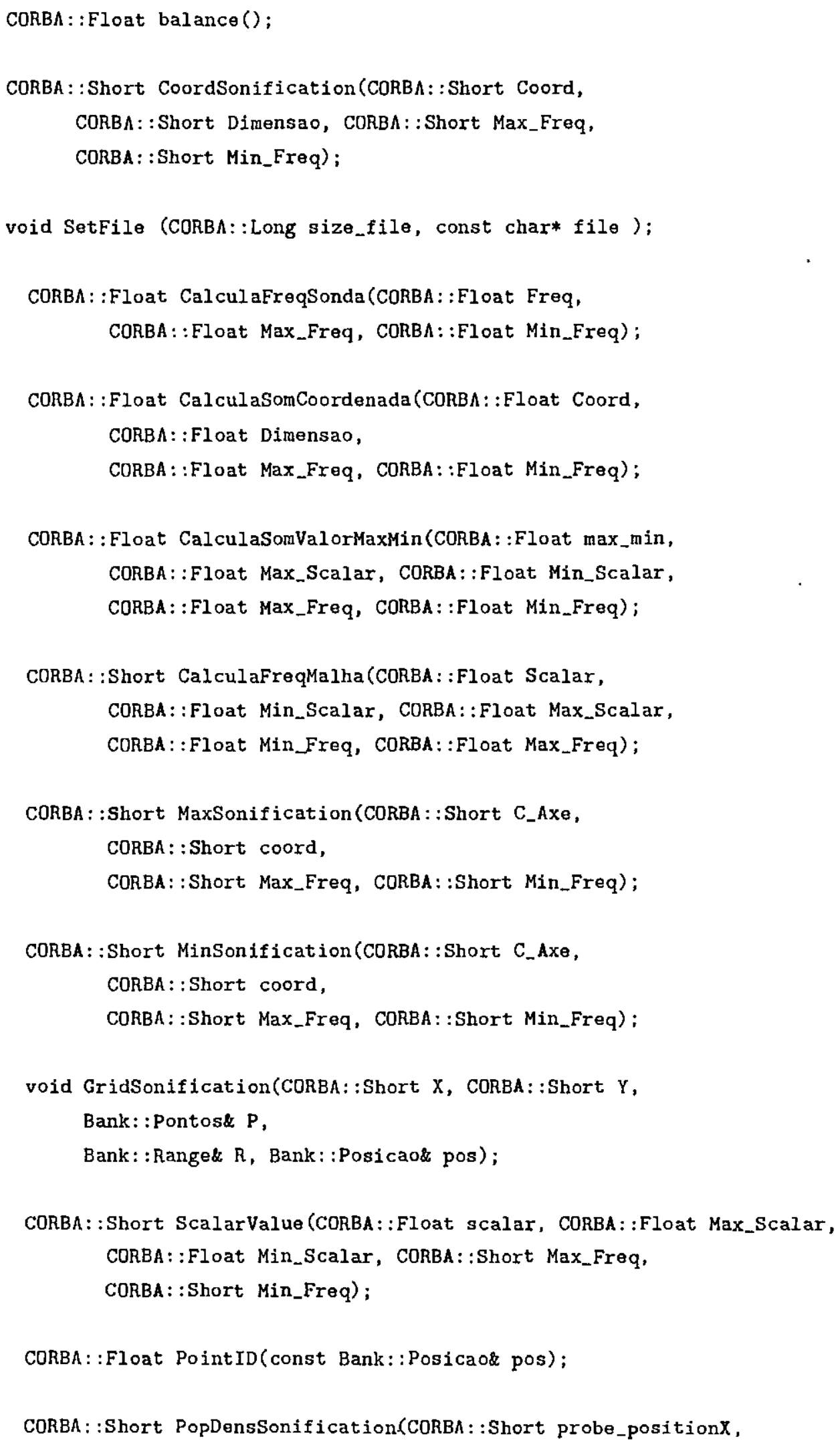




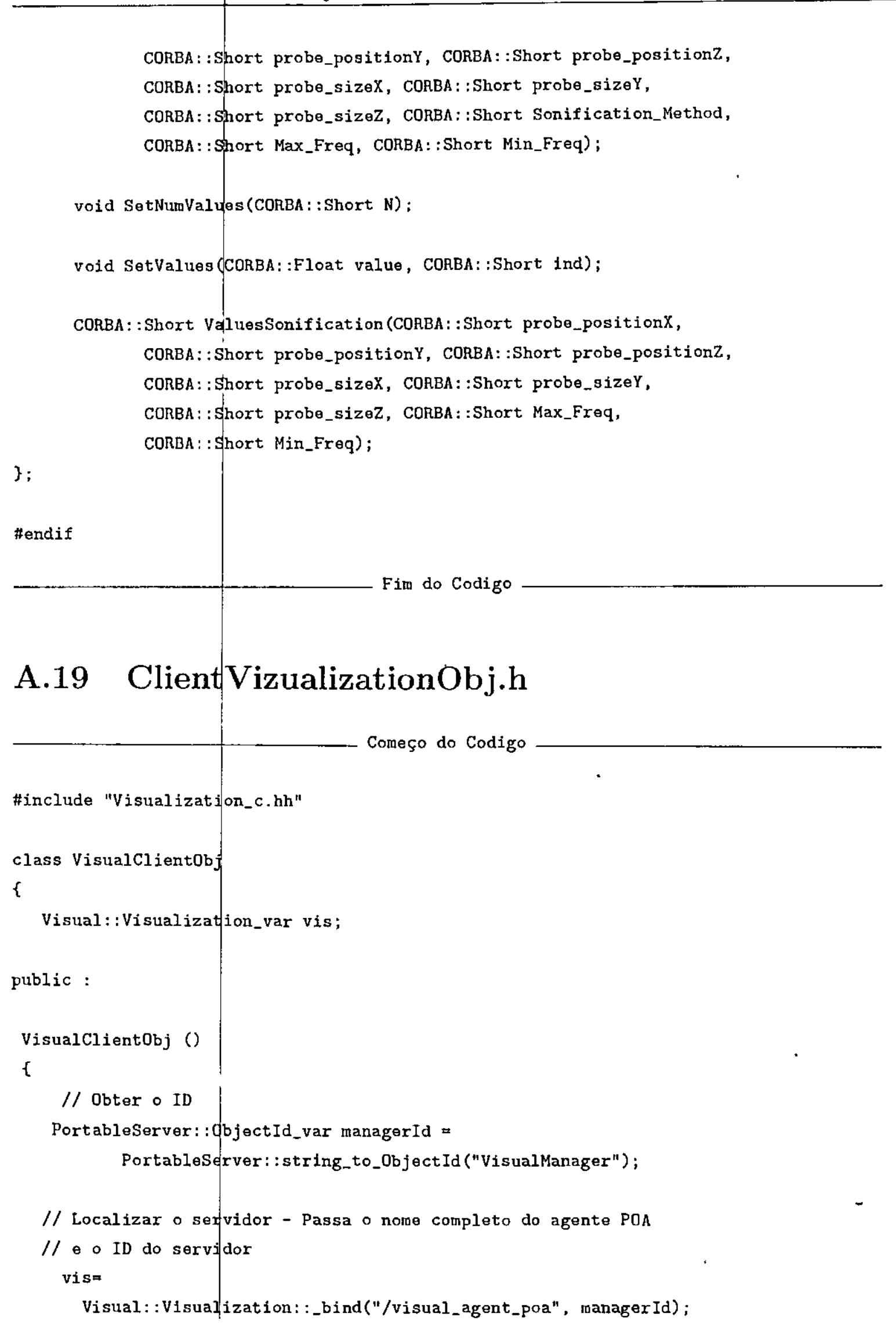


\}

Visual: Visualization_var GetID () \{ return vis; \}; \} ;

Fim do Codigo

\section{A.20 ClientSoundObj.h}

Começo do Codigo

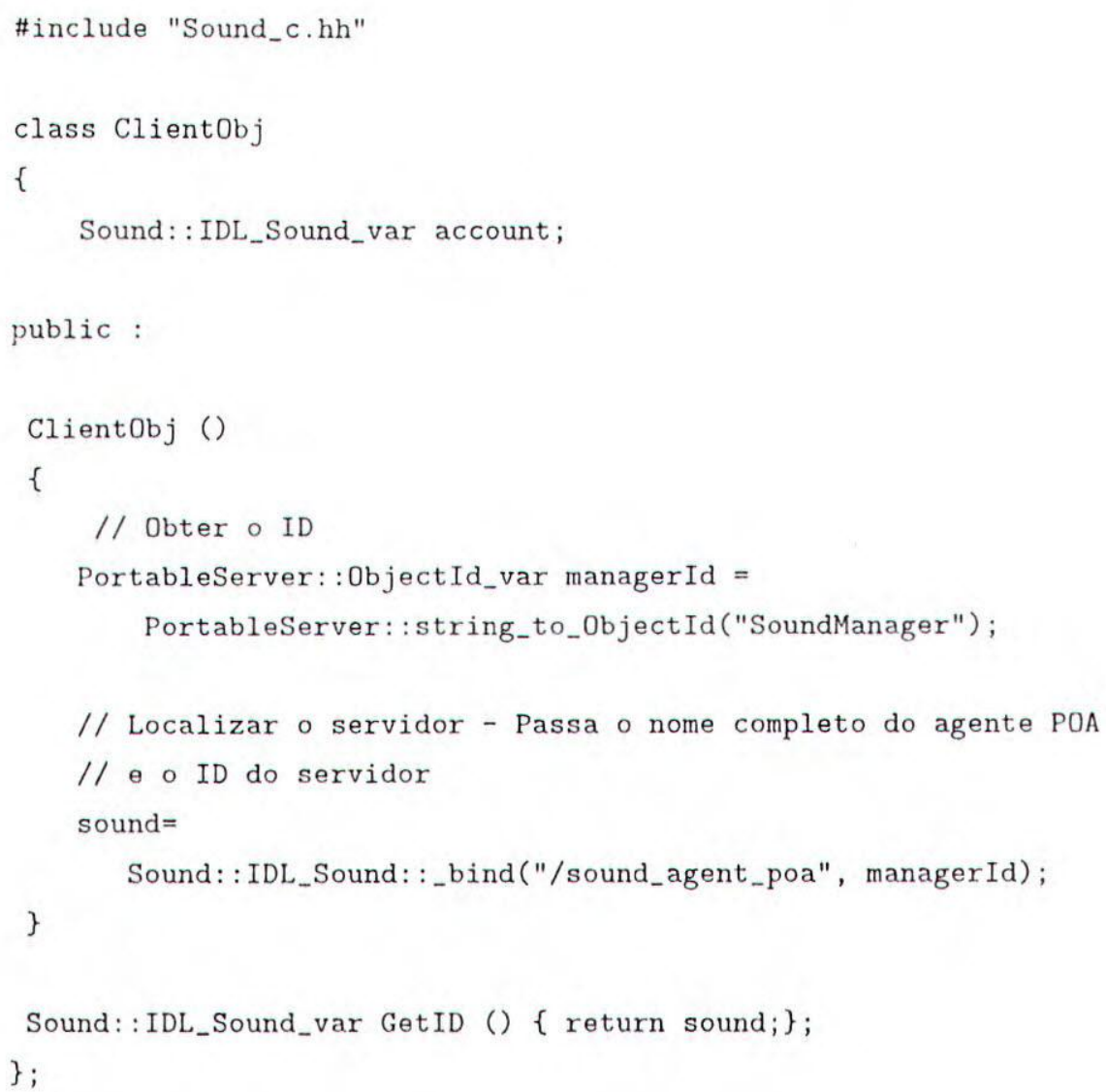

